Portland State University

PDXScholar

Fall 1-1-2013

\title{
Development of Dynamic Thermal Performance Metrics for Eco-roof Systems
}

Seth Sinclair Moody

Portland State University

Follow this and additional works at: https://pdxscholar.library.pdx.edu/open_access_etds

Part of the Environmental Design Commons, Natural Resources and Conservation Commons, and the Other Mechanical Engineering Commons

Let us know how access to this document benefits you.

\section{Recommended Citation}

Moody, Seth Sinclair, "Development of Dynamic Thermal Performance Metrics for Eco-roof Systems" (2013). Dissertations and Theses. Paper 666.

https://doi.org/10.15760/etd.666

This Thesis is brought to you for free and open access. It has been accepted for inclusion in Dissertations and Theses by an authorized administrator of PDXScholar. Please contact us if we can make this document more accessible: pdxscholar@pdx.edu. 
Development of Dynamic Thermal Performance Metrics

\title{
For Eco-roof Systems
}

\section{by}

Seth S. Moody

A thesis submitted in partial fulfillment of the

requirements for the degree of

\author{
Master of Science \\ in \\ Mechanical Engineering
}

Thesis Committee:

David Sailor, Chair

Graig Spolek

Sergio Palleroni

Portland State University

2012 


\begin{abstract}
In order to obtain credit for an eco-roof in building energy load calculations the steady state and time-varying thermal properties (thermal mass with evapotranspiration) must be fully understood. The following study presents results of experimentation and modeling in an effort to develop dynamic thermal mass performance metrics for eco-roof systems. The work is focused on understanding the thermal parameters (foliage \& soil) of an eco-roof, further validation of the EnergyPlus Green Roof Module and development of a standardized metric for assessing the time-varying thermal benefits of eco-roof systems that can be applied across building types and climate zones.

Eco-roof foliage, soil and weather parameters were continuously collected at the Green Roof Integrated PhotoVoltaic (GRIPV) project from 01/20/2011 to 08/28/2011. The parameters were used to develop an EnergyPlus eco-roof validation model. The validated eco-roof model was then used to estimate the Dynamic Benefit for Massive System (DBMS) in 4 climate-locations: Portland Oregon, Chicago Illinois, Atlanta Georgia and Houston Texas.

GRIPV30 (GRIPV soil with 30\% soil organic matter) was compared to 12 previously tested eco-roof soils. GRIPV30 reduced dry soil conductivity by $50 \%$, increased field capacity by $21 \%$ and reduced dry soil mass per unit volume by $60 \%$. GRIPV30 soil had low conductivity at all moisture contents and high heat capacity at moderate and high moisture content. The characteristics of the GRIPV30 soil make it a good choice for moisture retention and reduction of heat flux, improved thermal mass (heat storage) when integrating an eco-roof with a building.
\end{abstract}


Eco-roof model validation was performed with constant seasonal moisture driven soil properties and resulted in acceptable measured - modeled eco-roof temperature validation. LAI has a large impact on how the Green Roof Module calculates the ecoroof energy balance with a higher impact on daytime (measured - modeled) soil temperature differential and most significant during summer.

DBMS modeling found the mild climates of Atlanta Georgia and Houston Texas with eco-roof annual DBMS of 1.03, 3\% performance improvement above the standard building, based on cooling, heating and fan energy consumption. The Chicago Illinois climate with severe winter and mild spring/summer/fall has an annual DBMS of 1.01. The moderate Portland Oregon climate has a below standard DBMS of 0.97. 


\section{Acknowledgments}

I would like to thank David J. Sailor for his mentoring, continued financial and intellectual support of this work and my building sciences research in general. Without Dr. Sailor's previous work developing the EnergyPlus Green Roof Module and establishment of the Green Building Research Laboratory (GBRL) this work would not have been possible.

I would also like to thank Adam Scherba, Hazel Owens, Bailey Johnson, Laura Holloway and Pamela Wallace for their assistance in establishing and maintaining the PSU GRIPV instrumentation and data collection systems as well as the GBRL instrumentation and data collection systems.

This research was supported by the National Science Foundation, grant 0853933. Any opinions, findings, and conclusions or recommendations expressed herein are those of the authors and do not necessarily reflect the views of the national science Foundation. We would also like to acknowledge the financial and in-kind support from Portland General Electric, Solarworld, Oregon BEST, and the City of Portland. 


\section{Table of Contents}

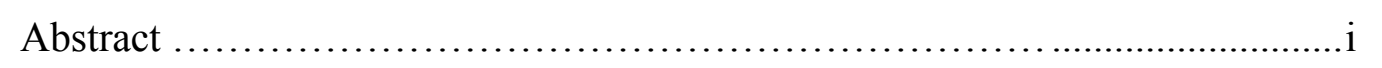

Acknowledgements .........................................................ii

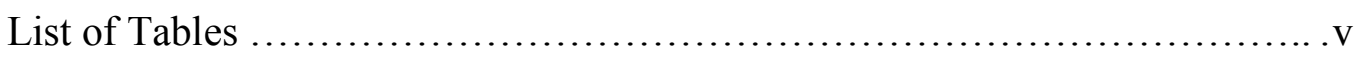

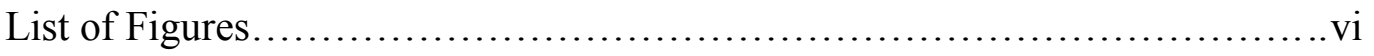

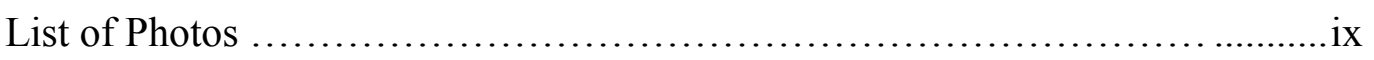

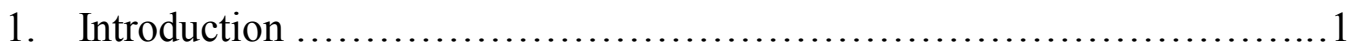

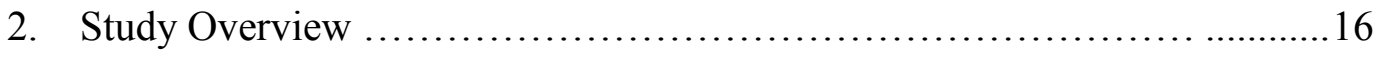

3. Eco-roof Performance Modeling ................................... 17

4. EnergyPlus Model Validation ...................................... 28

5. Dynamic Benefit of Massive System (DBMS) .......................43

6. Results \& Discussion ............................................47

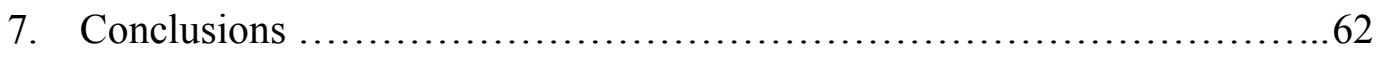

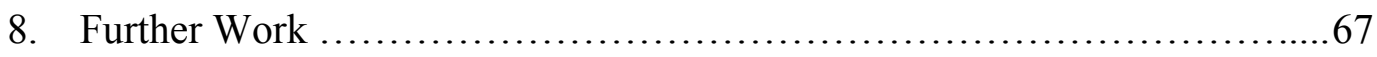

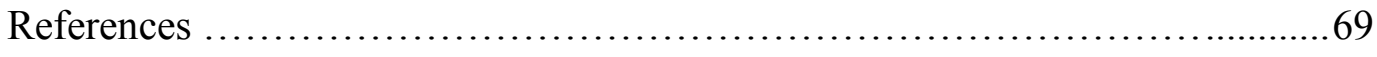

Appendix

Tables, Figures \& Graphs.............................................. 74 


\section{List of Tables}

Table 1: GBRL studied eco-roof soils \& compositions.................................

Table 2: GBRL studied eco roof soils \& dry properties ..................................13

Table 3: Fractional vegetative cover Green RooF

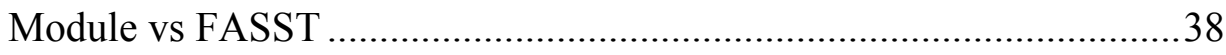

Table 4: Temperature validation statistics (LAI 8.72) ...................................40

Table 5: Cities and climates chosen for DBMS study ....................................44

Table 6: Portland winter roof surface temperatures.......................................54

Table 7: Portland spring roof surface temperatures ........................................55

Table 8: Portland summer roof surface temperatures ........................................56 


\section{List of Figures}

Figure 1: United States energy consumption by sector ............................... 1

Figure 2: Heating \& cooling load components .......................................... 4

Figure 3: Eco-roof material layers ........................................................ 6

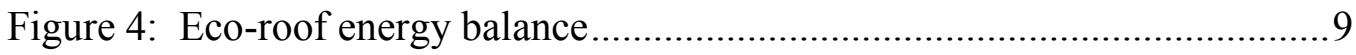

Figure 5: EnergyPlus simulation process overview ...................................... 18

Figure 6: EnergyPlus module integration with

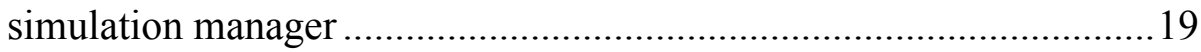

Figure 7: ASHRAE climate zones \& chosen city locations ............................20

Figure 8: EnergyPlus Green Roof Module energy balance ...............................23

Figure 9: Tray and sensor arrangement, plan view ......................................29

Figure 10: Tray and sensor arrangement, front cross section ........................... 30

Figure 11: GRIPV30 soil bulk density.................................................... 31

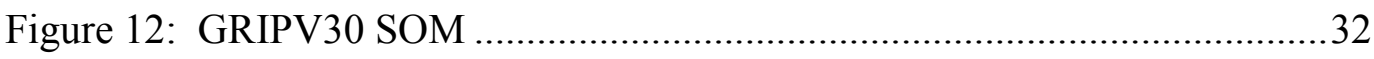

Figure 13: GRIPV 30 moisture dependent conductivity................................. 34

Figure 14: GRIPV 30 moisture dependent heat capacity................................34

Figure 15: Winter snapshot of measured and modeled validation temperature data ............................................... 40

Figure 16: Spring snapshot of measured and modeled validation temperature data

Figure 17: Summer snapshot of measured and modeled validation temperature data 
Figure 18: Bulk density vs soil field capacity.............................................47

Figure 19: Eco-roof soil conductivity vs volumetric

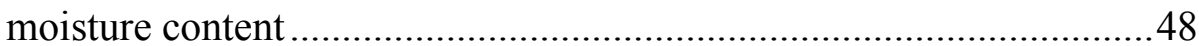

Figure 20: Eco-roof soil heat capacity vs volumetric moisture content

Figure 21: Asymptotic behavior of evaporative cooling on steady state R-value vs energy consumption .50

Figure 22: Seasonal energy consumption comparison and DBMS Portland Oregon 51

Figure 23: Seasonal energy consumption by type, Portland Oregon 52

Figure 24: Outside surface temperature comparison, Winter Portland Oregon .53

Figure 25: Inside surface temperature comparison, Winter

Portland Oregon .53

Figure 26: Inside surface temperature comparison, Spring

Portland Oregon .55

Figure 27: Inside surface temperature comparison, Summer

Portland Oregon .56

Figure 28: Seasonal energy consumption comparison and DBMS

Chicago Illinois .57 
Figure 29: Seasonal energy consumption by type

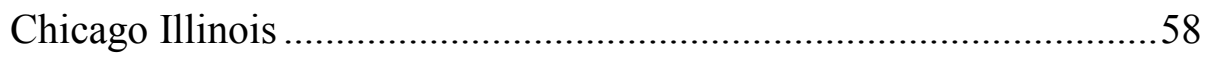

Figure 30: Seasonal energy consumption comparison and DBMS

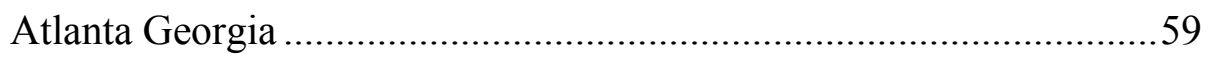

Figure 31: Seasonal energy consumption by type

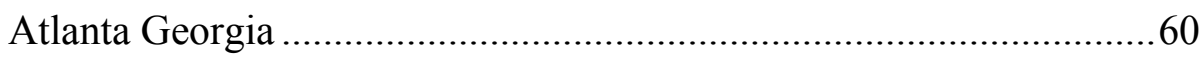

Figure 32: Seasonal energy consumption comparison and DBMS

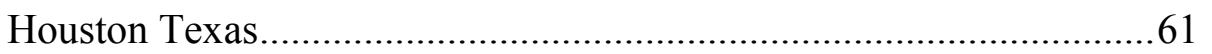

Figure 33: Seasonal energy consumption by type

Houston Texas.............................................................................6 61 


\section{List of Photos}

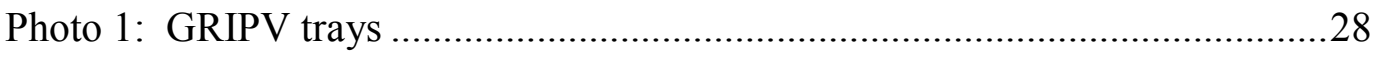

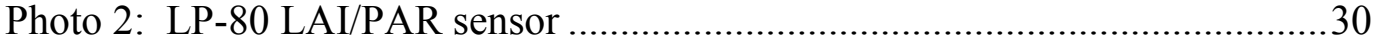

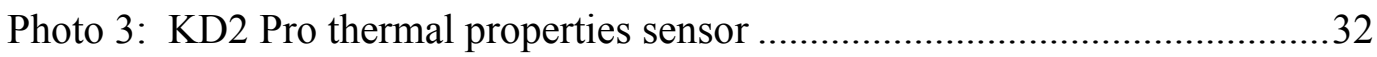

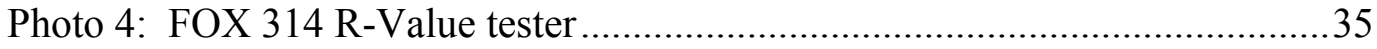

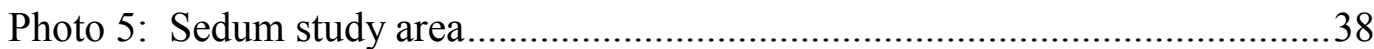

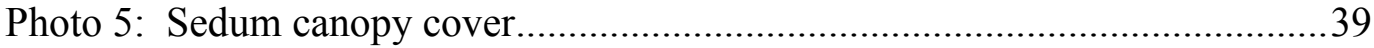




\section{Introduction}

In $201141 \%$ of all energy used in the United States was consumed by a combination of residential and commercial buildings, figure 1. Urban development, building operations and building construction practices are more and more the focus of global efficiency and sustainability efforts. In certain regions of the United States and internationally there has been a rise in interest,

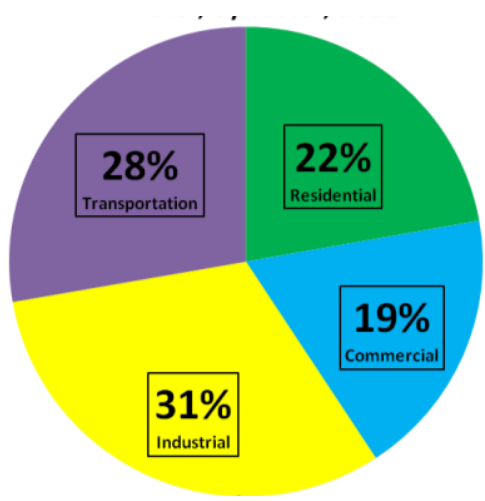

Figure 1: United States energy consumption by sector, 2011 practice and regulation of sustainable building. With this has come a rise in popularity and construction of green roofs (eco-roofs) (1). Eco-roof systems can play multiple roles in helping a building achieve sustainability goals. When properly designed, integrated and constructed an eco-roof system has the potential to extend roof longevity an estimated 20 to 30 years (2), provide storm water mitigation of between 25 and $75 \%$ (3; 1) increase building revenues through greater occupancy rates, reduce the urban heat island (UHI) by an average $1.5^{\circ} \mathrm{C}(4 ; 5)$, improve urban bio-diversity and potential to lower building energy consumption through surface temperature and heat flux reduction $(4 ; 6 ; 7 ; 8 ; 9 ; 10)$.

Thermal performance benefits of eco-roof systems have been documented in many studies primarily using temperature, heat flux and energy $(8 ; 6 ; 7 ; 11 ; 10)$. A standardized design method for incorporating eco-roof thermal performance into building energy load calculations has not been developed and poses a great challenge when considering the many criteria and parameters that define a building, an eco-roof and the 
surrounding climate. In recent years consideration for improved building thermal performance (energy efficiency) has shifted code envelope $\mathrm{U}$ requirements downward ( $\mathrm{R}$ value upward). The recent shift in energy code for building envelope construction places the eco-roof over a R-3.5 $\left(\frac{m^{2} *^{\circ} K}{W}, \mathrm{SI}\right)^{1}$ roof insulation that has the effect of near complete thermal isolation of the eco-roof from the building interior $(12 ; 13)$. With regard to thermal performance, the eco-roof has now been treated as an additional, moderate to high albedo, spongy layer draped over the building roof $(4 ; 14)$

In order to allow flexibility in materials and promote innovation in building design and construction the U.S. Federal Government is promoting, and a few states have implemented performance based code compliance as an alternative to prescriptive path code compliance (13).

Current practice in design of an eco-roof primarily considers storm water and aesthetics but does not consider the plant and soil layer contribution to the greater thermal performance of the building. The big question for eco-roof systems becomes: When considering the complicated nature of diurnal and seasonal (time varying) effects on plants, and eco-roof soil moisture and thermal properties, how does a designer-engineer parameterize the time varying plant and soil impacts so that an eco-roof can be effectively utilized as part of a building load calculation/credit when following a performance based path for code compliance?

There are many questions about eco-roof technology that have not been answered. In 2009 Portland State University (PSU) was awarded a National Science Foundation grant 1SI units of $\mathrm{R}$ are $\left(\frac{\mathbf{m}^{2} *^{*} \mathbf{K}}{\mathbf{w}}\right)$ and IP unit of $\mathrm{R}$ are $\left(\frac{\mathrm{ft}^{\mathbf{2}} *^{\circ} \mathbf{F} * \mathbf{h r}}{\mathbf{B t u}}\right)$. Conversion to $\mathrm{R}(\mathrm{IP})=5.6783 * \mathrm{R}(\mathrm{SI})$. 
to study the combination of green roof and photovoltaic technologies. Funding provided by the NSF grant was used to construct the Green Roof Integrated Photovoltaic (GRIPV) research facility. "The goal of GRIPV is to study the combination of green roof and photovoltaic systems in the urban rooftop environment of Portland, Oregon". The study is formulated around 3 fundamental questions:

1. What are the relationships between green roof evapotranspiration, PV energy production, and green roof carbon gain?

2. How do PV arrays and green roofs impact building energy consumption?

3. What is the impact of roof-mounted PV arrays and green roofs on the development of the urban heat island?

Work described in this report is focused on the second GRIPV research question. The following is a quantitative analysis of the dynamic thermal parameters and methodology for the integration of an eco-roof into a building heating and cooling load calculation. 


\title{
1.1 Building Heating and Cooling Load (energy) Calculations
}

\author{
Heating and cooling load \\ calculations are the primary \\ design basis for most heating \\ and air conditioning systems. \\ Calculation of heating and \\ cooling loads significantly \\ affects the capital cost and \\ sizing for every component of
}

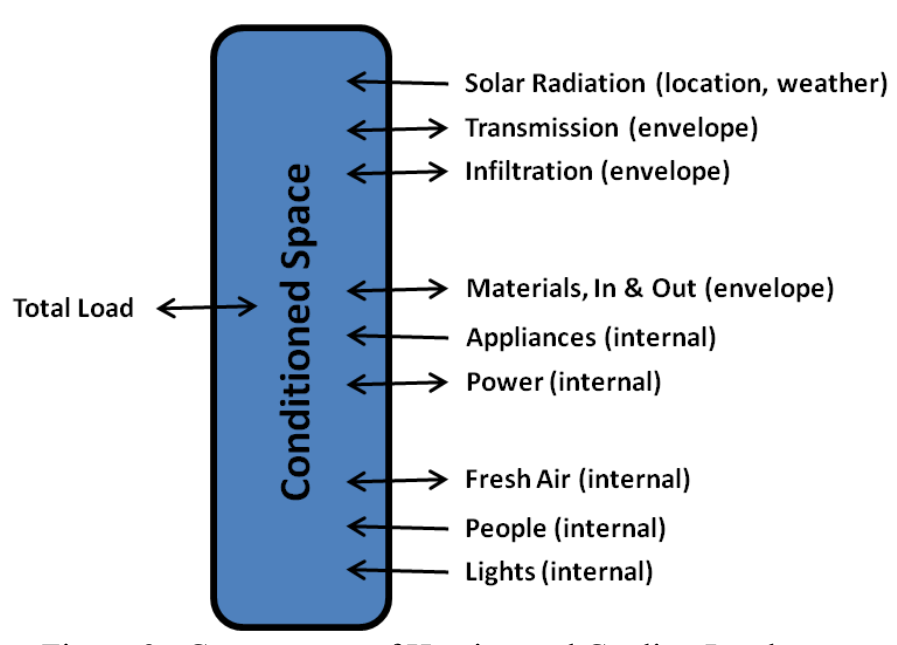

Figure 2: Components of Heating and Cooling Loads, Courtesy ASHRAE 2009 Handbook

systems that condition the building indoor environment. Calculation of heating and cooling loads also impacts human comfort, productivity, building operating cost and energy consumption (15). Envelope temperature and heat flux due to heating and cooling loads must be mitigated in order to maintain a building at internal thermal and air quality design criteria. Minimizing building heating and cooling loads is the first step in design of a sustainable building thermal comfort and air handling system. The parameters that affect heating and cooling loads are building location, weather, envelope and internal loads. For purposes of design load calculation the parameters are broken down into specific components, figure 2 . The parameters of location and weather are typically not controllable by the building designer but can be accounted for and therefore utilized for minimizing heating and cooling loads. The heating and cooling parameters that a designer can reliably control and account for are the envelope (roof, walls, and floor) and internal loads. Modeling has shown that winter heating conditions, on an eco-roof 
thermally connected to the building, can increase heating loads when sunny and decrease heating loads when outside temperatures are cold (8). Numerous eco-roof models and experiments in many global locations have shown that building rooftop temperature and heat flux are significantly reduced during summer cooling conditions, as compared to conventional roof technologies $(6 ; 7 ; 8 ; 11 ; 16 ; 17)$. Dr. David J. Sailor has developed the "Green Roof Module" (16) for the DOE whole building energy calculation software, "Energy Plus". Determination of eco-roof impact on heating and cooling energy consumption, on an annual basis in multiple North American locations, has been performed (18). There are many methods and metrics used to evaluate the performance of an eco-roof. To this date a methodology for parameterzing, optimizing and integrating an eco-roof into building energy calculations has not been developed.

\subsection{The Eco-Roof System}

By combining plants, moist soil, the proper amount of insulation and necessary roof support a dynamic thermal system is created, which is unique to a vegetated façade (eco-roof or green wall). There are two primary types of eco-roof: extensive and intensive. An extensive eco-roof typically has a soil thickness of $5-15 \mathrm{~cm}$ and an intensive eco-roof has a soil layer typically greater than $20 \mathrm{~cm}(19)$. An eco-roof is constructed of 6 material layers. Eco-roof layers from top to bottom are: plants, growing media (soil), drainage layer/root barrier, roof membrane, insulation and roof

support structure, figure 3. Plants chosen for eco-roofs vary with context, level of acceptable maintenance and desired aesthetic. Because of their low maintenance, drought tolerance and ability to limit transpiration (conserve soil moisture) native 
plants, clumping grasses or sedges and succulents, primarily sedums, are the plants typically chosen for an eco-roof. The soil layer is a combination of light weight mineral aggregates (sand, expanded clay, vermiculite, perlite and or gravel) and soil organic matter (SOM). SOM, similar to the mineral aggregate, is a composition material usually made of compost, manure and or recycled paper. The exact makeup of the mineral components and SOM is dependent on the soil provider and what is locally available.

The volumetric ratio of mineral and organic soil components vary widely. The ratio is dependent on the soil provider and eco-roof plant

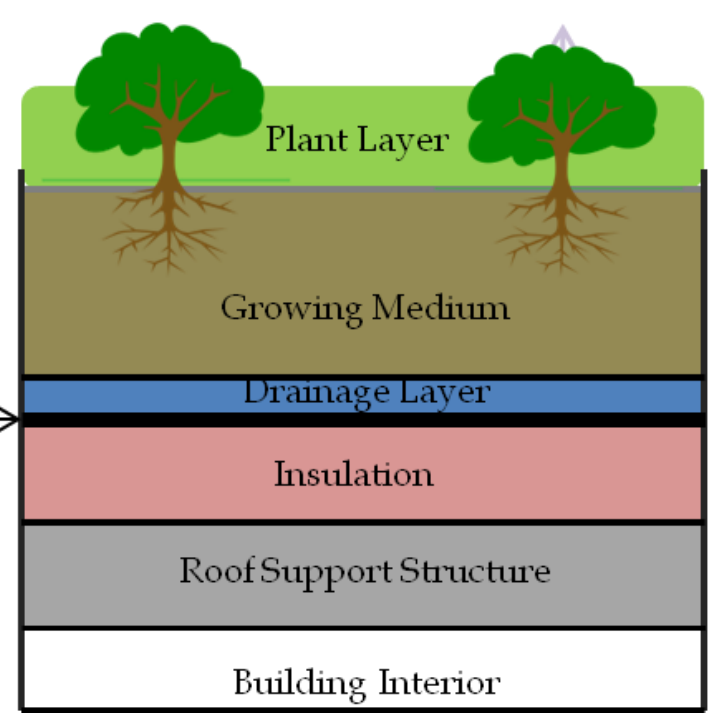

Figure 3: Typical eco-roof material layer configuration

selection. The growing media's ability to retain moisture is directly related to the types and ratios of mineral and SOM. The mineral component of eco-roof soil is usually greater than $50 \%$ by volume, more often in the $75 \%$ range. The type of aggregate material is normally chosen based on local availability and price. Soil organic matter (SOM) is usually between 0 and $20 \%$. Historically SOM in eco-roof soil has been kept low, around $10 \%$, in order to reduce soil decomposition and coincident storm event induced nutrient run off, table 
1. Recently higher values of SOM for eco-roof soil have been introduced in an effort to reduce soil compaction, improve plant health, soil moisture retention and field capacity.

Table 1: Composition and field capacity, \% by volume, of 13 eco-roof soils tested by Green Building Research Laboratory (6): GRIPV30 = soil used at Green Roof Integrated PV test facility, PS = porous silicate, $\mathrm{EC}=$ expanded clay, $\mathrm{ES}=$ expanded slate.

\begin{tabular}{|cccc|}
\hline $\begin{array}{c}\text { Soil } \\
\text { Type }\end{array}$ & $\begin{array}{c}\text { Mineral } \\
(\boldsymbol{\%})\end{array}$ & Soil Organic Matter $(\boldsymbol{\%})$ & $\begin{array}{c}\text { Field Capacity } \\
\left(\mathbf{m}^{\mathbf{3}} / \mathbf{m}^{-3}\right)\end{array}$ \\
\hline GRIPV30 & 60 & 30 & 0.51 \\
PS50C10 & 90 & 10 & 0.48 \\
PS50C00 & 100 & 0 & 0.44 \\
PS75C00 & 100 & 0 & 0.44 \\
PS75C10 & 90 & 10 & 0.49 \\
ES50C10 & 90 & 10 & 0.27 \\
ES50C00 & 100 & 0 & 0.25 \\
ES75C00 & 100 & 0 & 0.15 \\
ES75C10 & 90 & 10 & 0.22 \\
EC50C10 & 90 & 10 & 0.29 \\
EC50C00 & 100 & 0 & 0.30 \\
EC75C00 & 100 & 0 & 0.23 \\
EC75C10 & 90 & 10 & 0.26 \\
\hline
\end{tabular}

The drainage layer/root barrier facilitates water transport off the roof when soil reaches its maximum moisture capacity (field capacity). The drainage layer/root barrier protects the roots from pooling moisture, allows necessary aeration of the roots and prevents roots from penetrating and damaging the water proof roof membrane below the drainage layer. The roof membrane is a layer of water proof material that protects the roof insulation and support structure from moisture. Roof insulation is usually a layer of closed cell high density foam of between $5-10 \mathrm{~cm}$ (dependent upon local and regional building energy code). The materials used for construction of the roof structure are based upon the building purpose and design but must be capable of supporting the eco-roof and any additional soil moisture loads (rain or snow). 


\subsection{Eco-Roof Energy Balance}

Similar to standard roof construction an eco-roof energy balance is dominated by the sky temperature (global radiation or lack thereof). Plant, soil, insulation and support layers are the four primary elements in the thermal performance of an ecoroof. If the plant and soil layers are in thermal contact with the support layer the 4 primary layers combine to create a unique composite material that acts as a thermal mass with evaporative cooling. The seasonal and diurnal moisture dynamics in the plants and soil combine to provide sensible and latent energy exchange with the atmosphere, energy storage (thermal mass) and sensible energy exchange with the insulation and building support layers. Insulation and roof support materials provide resistance and depending on material type there can be energy storage in the roof support material, figure 4 . 


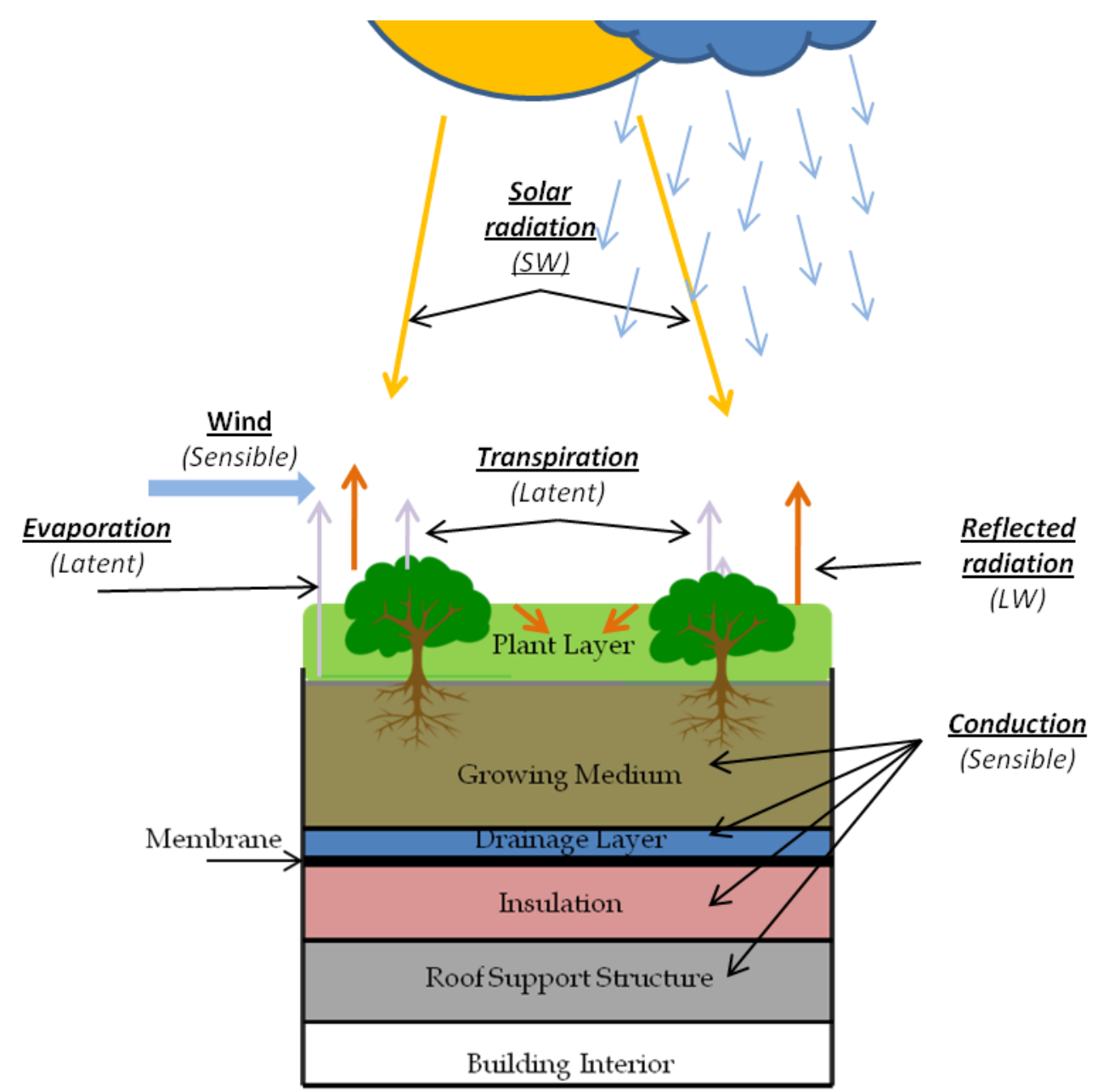

Figure 4: Eco-roof energy balance with primary material layers.

A final note about the unique nature of an eco-roof: Compared to an eco-roof or green wall, a typical building roof or facade is a large surface area that doesn't typically have much evaporative cooling capability; thermal mass systems are generally not capable of evaporative cooling. An eco-roof is unique in that the plant and soil layer combine to create a thermal mass with evaporative cooling (evapotranspiration). 


\subsubsection{Plant layer}

The relevant parameters for thermal performance of the eco-roof plant layer are to this date best described by plant transpiration, radiation absorbtivity and leaf area index (LAI). Plant transpiration is the pumping method with which a plant moves $\mathrm{H}_{2} \mathrm{O}$ and minerals from its roots to its leaves, for photosynthesis. Transpiration, similar to but opposite to human breathing, exchanges $O_{2}$ created during photosynthesis, with $\mathrm{CO}_{2}$ needed by the plant for photosynthesis. Plant transpiration occurs through stomata which are adjustable pores in the leaf surface that allow exchange of the gases and water vapor that are necessary for plant photosynthesis. More pertinent to plant thermal performance, stomata regulate the amount of water that changes phase from liquid to vapor (latent heat exchange with the atmosphere) and is released to the surrounding micro climate which cools the plant canopy. A cool canopy and canopy shading cools the soil which increases heat flux from the building interior. Solar radiation is used by plants to perform photosynthesis. Absorbtivity of solar radiation describes the proportion of long and short wave energy that is taken in by a plant leaf in order to fuel the photosynthesis process in that leaf. Plants can directly absorb nearly $40 \%$ of solar energy incident upon their leaves (20). The high level of radiation absorbtivity by eco-roof plants contributes greatly to the overall thermal performance of an eco-roof. LAI, in its most simple definition, is the one sided projected area of a leaf occupying the horizontal projected area of the vegetation (21). LAI is the primary factor in determining the fraction of energy intercepted 
by the plant canopy and used by the plant for photosynthesis, before being absorbed by the growing media or reflected back to the atmosphere. The LAI of a canopy varies from plant species to plant species. In forestry the maximum LAI varies from 6 (deciduous trees) to 8 (coniferous forest plantations). In agriculture LAI varies from 2 to 4 for annual crops with a mean LAI for grassland of 2.5 (22). Values for eco-roof system LAI values could not be found in the general literature for comparison to GRIPV values. The LAI for the mixed sedum GRIPV trays was on average 3.67 , see section 4.1.3.

\subsubsection{Soil Layer}

Similar to today's standard building materials soils have primary thermal properties: conductivity $\left(\frac{W}{m *{ }^{\circ} K}, k\right)$, specific heat $\left(\frac{J}{k g *{ }^{\circ} K}, C_{p}\right)$ along with long and short wave radiative properties of reflectivity and emissivity. Within the building industry R value is used to describe a material's ability to resist the flow of energy (heat flux). The measure of R-value is based on material thickness and conductivity at a steady state temperature differential. Like conventional building materials an eco-roof soil can be evaluated for its $k, C_{p}$ and steady state $\mathrm{R}$ value. Unlike a typical building material, eco-roof soil also retains moisture which helps to mitigate storm events and maintain the health of plants. Volumetric moisture content $\left(\frac{m^{3}}{m^{3}}, V M\right)$ is a measure of soil moisture based on a relative soil volume. VM has been shown to be a critical influence on the thermal properties $\left(k, C_{p}\right.$ and steady state $\mathrm{R}$ value) of all soil types $(14 ; 23 ; 24)$. VM can range from $0 \%$ (oven 
dry) to greater than $50 \%$ (moisture saturated). Soil moisture field capacity, or simply field capacity, is the maximum fraction of moisture a soil will retain after being saturated and when gravimetric drainage has ceased. The ratio of mineral, SOM, soil VM and soil voids of eco-roof soil affect the total soil layer heat capacity and conductivity. Conductivity and specific heat of eco-roof soil change over time based on the change of constituent parts of the soil: mineral aggregate, SOM, soil VM and soil compaction. The time scales which the constituent parts degrade or change vary greatly. Mineral weathering occurs very slowly, over multiple or hundreds of years; therefore the mineral content of the soil will remain relatively constant over time. Soil VM can change on a seasonally, weekly, and for soils with low moisture or low field capacity, daily time scale. Over long (multiple year) time scales soil will compact and will decrease heat capacity, increase conductivity and decrease field capacity due to reduction of soil voids (8; 9). Finally it is worth noting that volumetric ratio's of mineral and SOM components may increase or decrease depending on the type and health of plants and their capability of adding organic carbon to the soil. A time scale for addition or reduction of soil organic carbon has not yet been quantified for an eco-roof plant/soil system.

One part of keeping eco-roof capital cost competitive with standard construction is the weight of the soil at field capacity. It is therefore important that eco-roof soils are engineered to be light in weight in order to reduce the capital cost associated with additional support structure but be capable of 
retaining or storing a large soil proportion of precipitation moisture. Bulk density is the dry soil mass per unit volume $\left(\frac{\mathrm{kg}}{\mathrm{m}^{3}}\right)$ but also gives an indication of the amount of voids (air pockets) in soil. Bulk density of eco-roof soils ranges from between $345 \frac{\mathrm{kg}}{\mathrm{m}^{3}}$ to $1,490 \frac{\mathrm{kg}}{\mathrm{m}^{3}}(14)$, table 2. Eco-roof soil can be much less or greater in density than an average loose soil which has a bulk density of $1200 \frac{\mathrm{kg}}{\mathrm{m}^{3}}$.

The least dense soil, GRIPV30, has a bulk density of $345 \frac{\mathrm{kg}}{\mathrm{m}^{3}}$, similar to that of dry shredded coconut $\left(324-352 \frac{\mathrm{kg}}{\mathrm{m}^{3}}\right)(25)$,

Table 2: Soil moisture field capacity, bulk density and thermal properties for 13 GBRL tested soils: GRIPV30 = soil used at Green Roof Integrated $\mathrm{PV}$ test facility, $\mathrm{PS}=$ porous silicate, $\mathrm{EC}=$ expanded clay, $\mathrm{ES}=$ expanded slate.

\begin{tabular}{|c|c|c|c|c|}
\hline & \multicolumn{3}{|c|}{ Dry Eco-Roof Soil Properties } \\
\hline Soil Type & $\begin{array}{c}\text { Soil Field } \\
\text { Capacity, } \\
\text { VM } \\
\left(\mathbf{m}^{3} / \mathbf{m}^{3}\right)\end{array}$ & $\begin{array}{c}\text { Bulk } \\
\text { Density, } \\
\rho \\
\left(\mathrm{kg} / \mathrm{m}^{\wedge} 3\right)\end{array}$ & $\begin{array}{l}\text { Conductivity, } \\
\mathbf{K}\left(\mathbf{W} / \mathbf{m}^{*} \mathbf{K}\right)\end{array}$ & $\begin{array}{c}\text { Heat } \\
\text { Capacity, C } \\
\left(\mathbf{M J} / \mathbf{m}^{\wedge} \mathbf{3}^{*} \mathbf{K}\right)\end{array}$ \\
\hline GRIPV30 & 0.51 & 345 & 0.1 & 0.755 \\
\hline PS75C10 & 0.49 & 678 & 0.122 & 0.861 \\
\hline PS75C00 & 0.44 & 727 & 0.117 & 0.852 \\
\hline PS50C00 & 0.44 & 1021 & 0.226 & 1.094 \\
\hline PS50C10 & 0.48 & 1054 & 0.151 & 1.047 \\
\hline EC75C10 & 0.26 & 1150 & 0.17 & 1.012 \\
\hline ES75C00 & 0.15 & 1239 & 0.222 & 1.287 \\
\hline ES75C10 & 0.22 & 1248 & 0.205 & 1.284 \\
\hline EC75C00 & 0.23 & 1279 & 0.19 & 1.124 \\
\hline EC50C10 & 0.29 & 1293 & 0.188 & 1.232 \\
\hline EC50C00 & 0.3 & 1412 & 0.202 & 1.3 \\
\hline ES50C10 & 0.27 & 1432 & 0.225 & 1.25 \\
\hline ES50C00 & 0.25 & 1486 & 0.219 & 1.27 \\
\hline
\end{tabular}

Bulk density is dependent upon compaction, mineral aggregate type and proportion of mineral aggregate to SOM. Soil with high compaction and or greater portion of mineral aggregate typically has a greater bulk density, fewer voids and lower field capacity. Alternatively as the soil proportion of SOM is 
increased bulk density, dry soil conductivity and dry soil heat capacity go down while field capacity increases.

\subsection{Dynamic Benefit for Massive System (DBMS)}

In 2001 Oak Ridge National Laboratories has proposed a measure of thermal effectiveness for envelopes utilizing thermal mass systems. Dynamic benefit for massive system (DBMS) is defined as a material or assembly's ability to thermally perform above its steady state R-value due to material configuration and climate interactions. "DBMS has no physical meaning; it is a modeled relative measure of thermal performance as compared to a modeled standard construction" (26). The DBMS of a material is the dimensionless ratio between the modeled thermal mass steady state $\mathrm{R}$-value equivalent $\left(\mathrm{R}_{\mathrm{T} \text {,mass,equiv }}\right)$ and the steady state $\mathrm{R}$-value $\left(\mathrm{R}_{\mathrm{ss}}\right)$ of the thermal mass. Heating and cooling energy consumption of the thermal mass modeled as a standard steady state assembly $\left(\mathrm{E}_{\mathrm{HC}, \mathrm{SS}}\right)$ must equal the heating and cooling energy consumption of the modeled thermal mass assembly ( $\left.\mathrm{E}_{\mathrm{HC}, \mathrm{Tmass}}\right)$. $\mathrm{R}_{\mathrm{T} \text {,mass,equiv }}$ is a standard material/assembly steady state $\mathrm{R}$ value iterated until the modeled building has equal heating and cooling energy consumption to that of the modeled building with the thermal mass material/assembly ( $\left.\mathrm{E}_{\mathrm{HC}, \mathrm{Tmass}}\right)$, equation (1). A DBMS value greater than 1 indicates a thermal mass assembly has better relative R-value performance than a standard assembly of equal energy consumption. A DBMS value less than 1 indicates a thermal mass assembly with less relative R-value performance to that of a standard assembly with equal energy consumption.

DBMS is then calculated as: 
DBMS $=\frac{\mathrm{R}_{\mathrm{T}, \text { mass,equiv }}}{\mathrm{R}_{\mathrm{Ss}}}$, when $\mathrm{E}_{\mathrm{HC}, \mathrm{SS}}=\mathrm{E}_{\mathrm{HC}, \mathrm{Tmass}}$

Where:

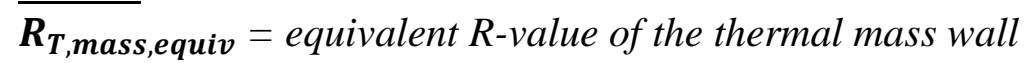

assembly.

$\mathbf{R}_{\mathrm{ss}}=$ steady state $R$-value.

$\mathbf{E}_{\mathbf{H C}, \text { Tmass }}=$ modeled energy consumption of the building using

thermal mass wall assembly.

$\mathbf{E}_{\mathbf{H C}, \mathbf{s s}}=$ modeled energy consumption of the building using steady state $R$ -

value.

It is a large task for a laboratory or building materials association to implement a new set of standards, ratings and labeling for new building materials or systems especially when the performance of the materials or systems change from climate to climate. Additionally there has yet to be industry consensus on thermal mass effect testing and modeling. The work that has been done at ORNL on thermal mass systems and DBMS is to this date the most in depth. It is suggested by ORNL researchers that the next step is ASTM standards for thermal mass modeling procedures. 


\section{Study Overview}

The goal of this study is three fold:

1. Further validate and identify areas needing refinement in the EnergyPlus Green Roof Module.

2. Develop a standardized metric (DBMS) for evaluating the time varying thermal benefits of an eco-roof system.

3. Evaluate the DBMS for an eco-roof, subject to moisture dependent properties, in 4 separate cities and ASHRAE climate zones: Portland Oregon (4C), Chicago Illinois (5A), Atlanta Georgia (3A) and Houston Texas (2A).

In this study, the whole building energy simulation software EnergyPlus (v.6) is used to calculate soil surface temperatures as well as heating, cooling and associated fan loads necessary in order to meet the above 3 goals. 


\section{Eco-Roof Performance Modeling}

Modeling the thermal performance of an eco-roof is a challenge due to the complex nature of heat transfer through the eco-roof, and mass transfer through the soil and plant layers.

\subsection{Energy Plus}

EnergyPlus is a Department of Energy whole building energy analysis software package that evolved from the BLAST and DOE-2 programs. BLAST (Building Loads Analysis and System Thermodynamics) and DOE-2 were developed in the late 1970's and early 1980's as energy and load simulation tools. EnergyPlus is designed to assist design engineers and architects in sizing HVAC equipment, evaluate building retrofit options, perform life cycle cost analysis and optimize building energy performance.

\section{EnergyPlus provides:}

1. An effective way to combine the modeling of an eco-roof with whole building (annual) energy analysis.

2. A pathway to evaluating the DBMS of an eco-roof, as compared to a roof with the same steady state $\mathrm{R}$ value.

3. Opportunity to design the eco-roof and insulation layers for best thermal performance.

Two input files are required to run an EnergyPlus simulation. First the EnergyPlus user develops a building input file (IDF) based upon the building physical make-up and HVAC/energy systems. Second a weather file - site location (EPW) is chosen. EnergyPlus then calculates the heating and cooling loads necessary to maintain user 
specified internal building thermal control including secondary HVAC and primary plant energy consumption, figure 5. EnergyPlus is not capable of handling every simulation possibility but it is capable of handling design options that are linked through other programs or modules created by outside developers. For proposed new modules a peer review is performed before the new module is integrated into the next release of EnergyPlus (27), figure 6. In the 2007 release of EnergyPlus a Green Roof Module (16), that simulates the detailed mass and energy balance

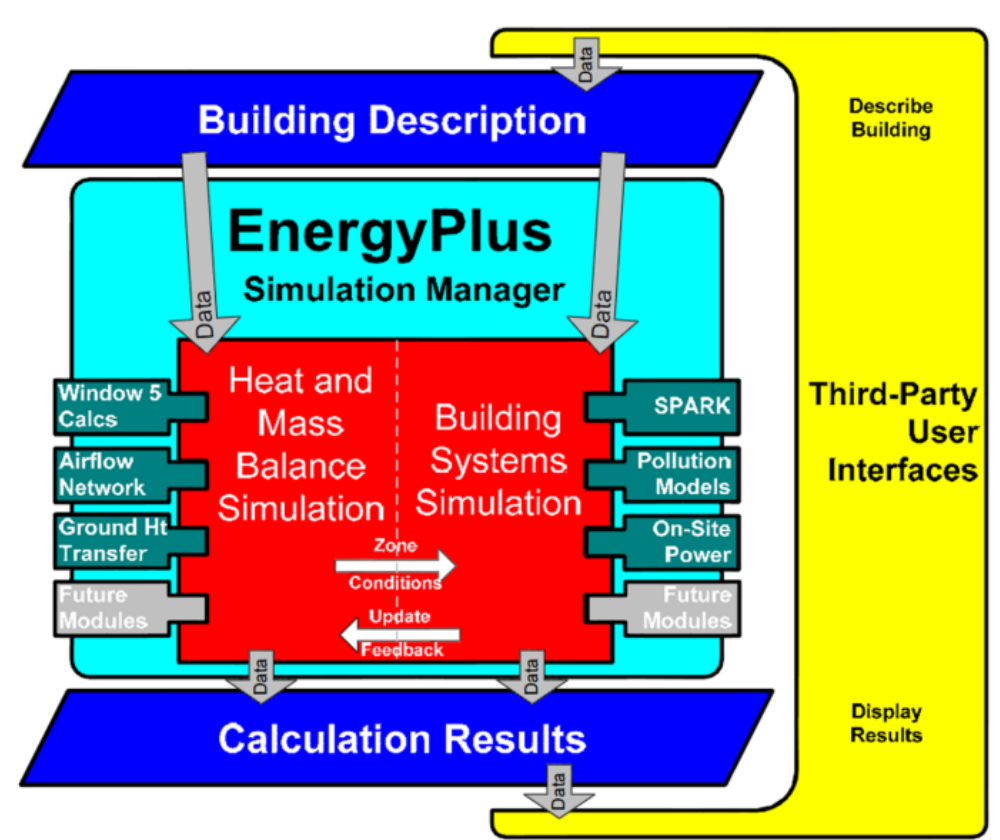

Figure 5: EnergyPlus simulation process overview of an eco-roof, was approved and implemented (28). EnergyPlus V6 with Green Roof Module and weather files formatted as TMY2 were used for this study. 


\subsubsection{EnergyPlus Building Input Data File (IDF)}

Detailed building information including: building geometry, materials and their properties, internal loads, electrical and mechanical equipment, and schedules are

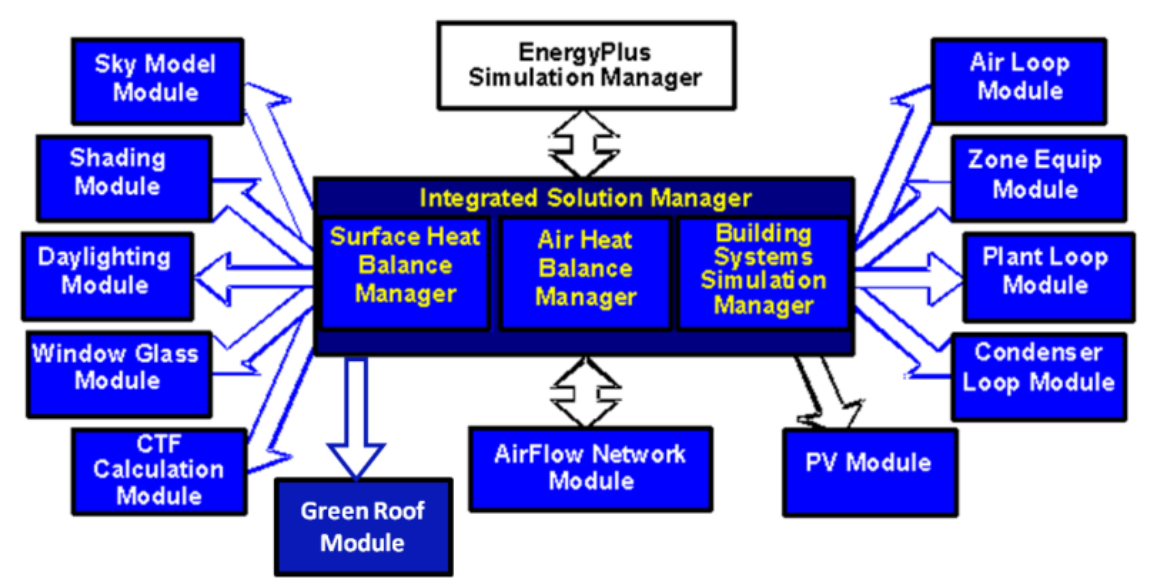

Figure 6: EnergyPlus module integration with simulation manager.

introduced into the EnergyPlus simulation manager through an input data file

(IDF). In order to simplify the process of IDF development the U.S. Department

of Energy (DOE) has created a database of benchmark buildings called the

"Commercial Building Energy Consumption Survey" (CBECS). CBECS

benchmark buildings are a national sample survey of information on the stock of

U.S. commercial buildings which includes: geometry, energy related chara

cteristics, energy consumption and expenditures. The DOE provides EnergyPlus

building IDF files that are representative of CBECS benchmark buildings for

many major cities in every ASHRAE North American climate zone, see figure 6.

Based on location, benchmark DOE CBECS new 2004 medium office buildings

(29) were selected and or modified to be used in this study, figure 7, table 5 and

section 5.1. Portland, Chicago, Atlanta and Houston were chosen based on: 
climate likely to support a densely vegetated eco-roof, diurnal temperature difference which changes heat flux direction (thermal mass charge and discharge) or a diurnal temperature difference to provide a thermal lag which delays building peak heating or cooling loads.

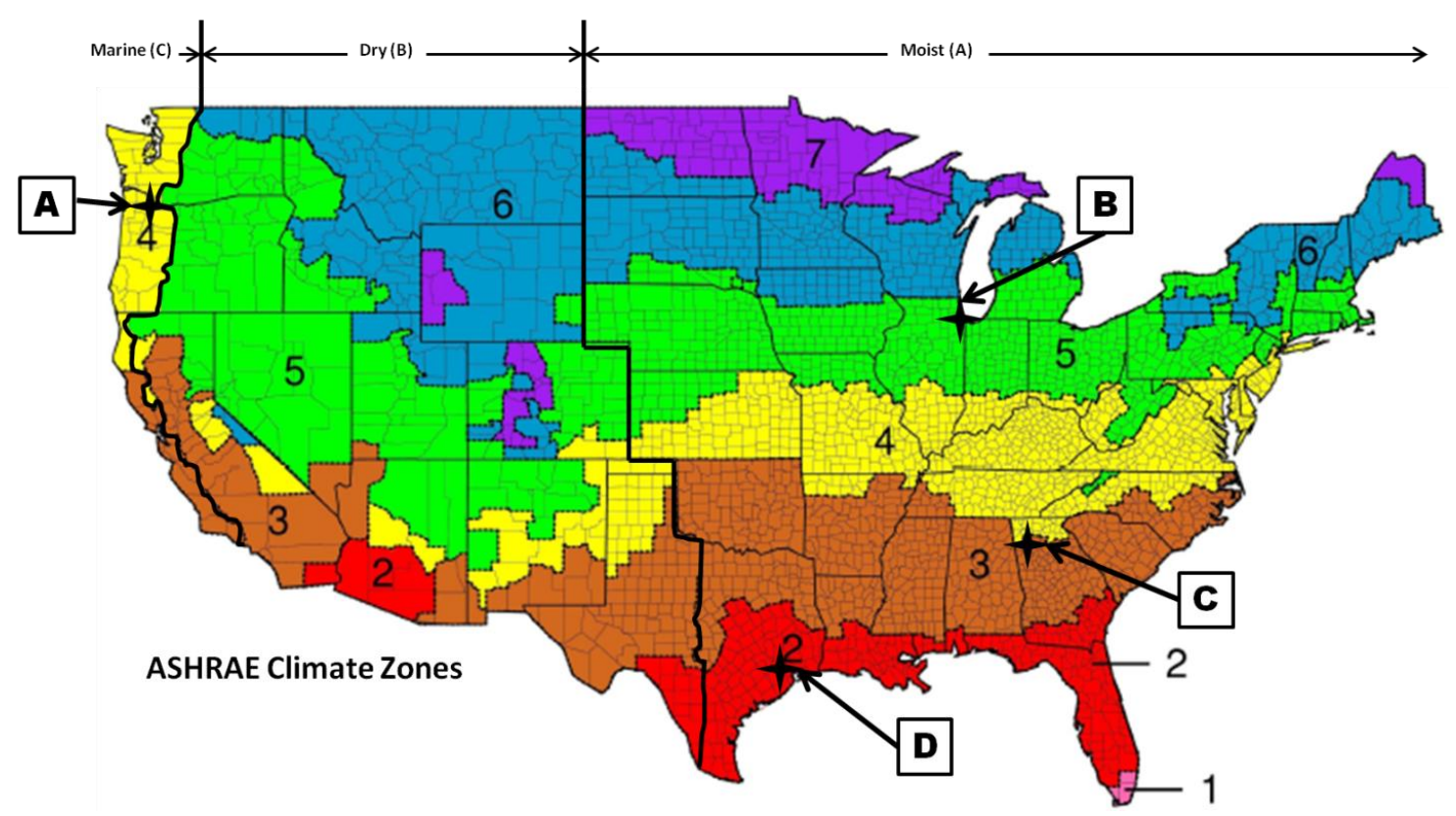

Figure 7: ASHRAE climate zones and 4 selected cities evaluated for DBMS in the U.S. Portland Oregon 4C(A), Chicago Illinois - 5A(B), Atlanta Georgia - 3C(C) and Houston Texas - 2D(D).

\subsubsection{EnergyPlus Weather Input File (EPW)}

Location and climate is fundamental to understanding building energy consumption, heating loads, cooling loads and many other calculations used for modeling a building. A TMY dataset includes dry-bulb temperature, dew-point temperature, relative humidity, barometric pressure, direct normal radiation, diffuse horizontal radiation, total \& opaque sky cover, wind direction, wind speed and certain additional data (30). TMY data sets are available for locations corresponding to most major airports and represent typical weather, taken from 30 
years of historical hourly weather data. TMY data is based on general location and corrected for building specific elevation, but not corrected for microclimate and mesoscale variations from the airport weather station to the building site.

\subsubsection{EnergyPlus Surface Heat Balance Manager}

EnergyPlus uses the "Surface Heat Balance Manager" component to calculate indoor and outdoor building surface heat fluxes, figures $5 \& 6$. The surface heat balance is given by:

$q_{\text {sol_sW }}+q_{L W}+q_{\text {conv }}-q_{c o n}=0$

Where:

$q_{\text {sol_sw }}=$ absorbed short wave solar radiation heat flux.

$q_{L W}=$ long wave radiation heat flux.

$q_{c o n v}=$ convection heat flux.

$q_{c o n}=$ conduction heat flux into or from the building surface.

Within the surface heat balance manager the "Conduction Transfer Function" module (figures $5 \& 6$ ) creates functions that are used to calculate conduction heat fluxes through walls and roof as a function of material properties, historic fluxes and environmental temperatures. The CTF method has a limitation for thermal mass systems, such as an eco-roof, in that it requires a greater number of time steps to converge. In this study, the default 6 time steps per hour was increased to 20. 


\subsubsection{EnergyPlus Green Roof Module}

A standard roof and eco-roof are generally dominated by solar radiation. In an eco-roof sensible (convection) and latent (evapotranspiration) heat flux from the plant and soil layers combine with conduction into the soil to balance solar radiation (and long wave exchange), figure 8 .

The green roof module takes into account:

- Long wave (LW) and short wave (SW) radiation exchange within the plant canopy.

- Plant canopy effects on convective heat transfer.

- Evapo-transpiration (latent heat) from the soil and plants.

- Heat conduction (sensible heat) and storage in the soil layer. 
A key factor for consideration in this study is that time varying moisture dependent thermal properties are not yet implemented in the Green Roof Module due to CTF instability.

The Green Roof module is based on the Fast All Season Soil Strength (FASST) model developed for the U.S. Army Corps of Engineers.. FASST tracks energy and moisture transport (including ice and snow) within a vegetated soil (21). The FASST model is divided into two moisture and energy budgets: Foliage and soil.

\subsubsection{Green Roof Module Foliage layer Parameters}

The combined foliage layer radiative, convective and conductive energy balance in FASST is calculated with equation 3.

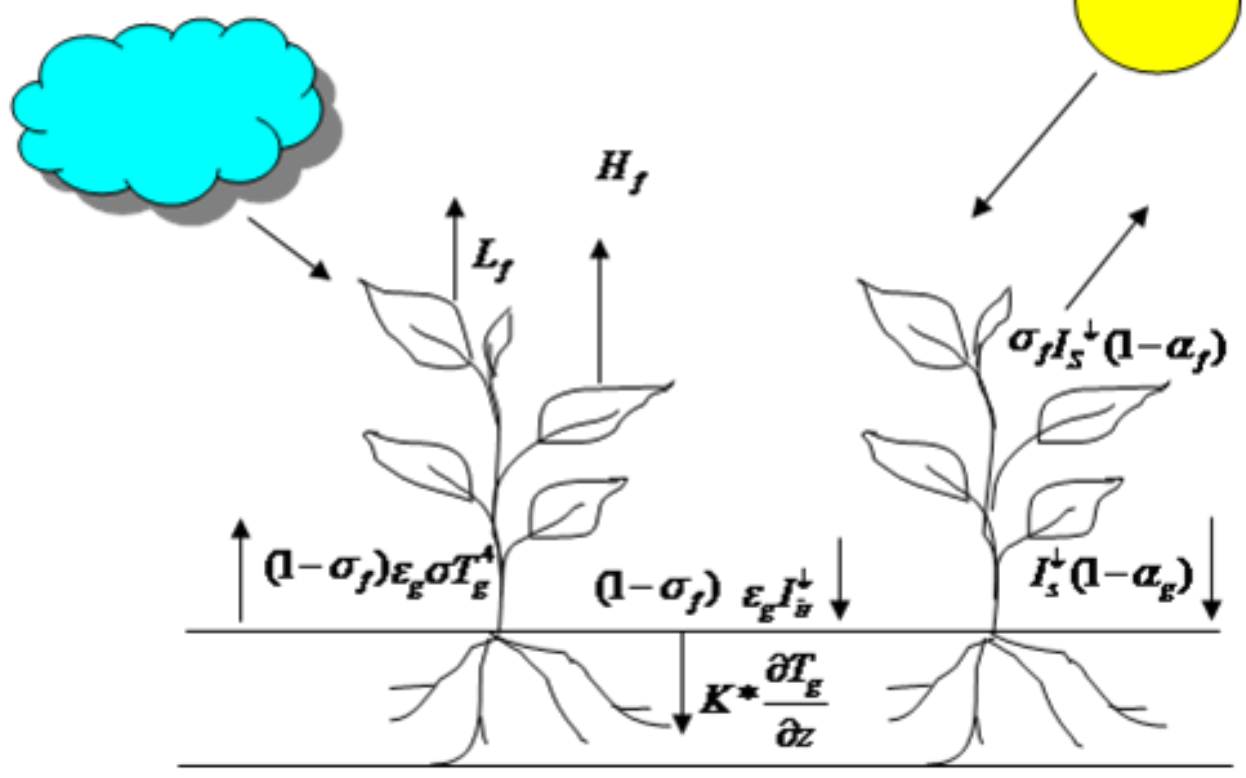

Figure 8: EnergyPlus Green Roof Module energy balance. 
Foliage Layer Energy Balance:

$\boldsymbol{F}_{\boldsymbol{f}}=\sigma_{f}\left[I_{S W}\left(1-\alpha_{f}\right)+\varepsilon_{f} I_{L W}-\varepsilon_{f} \sigma T_{f}^{4}\right]+\frac{\sigma_{f} \varepsilon_{g} \varepsilon_{f} \sigma}{\varepsilon_{1}}\left(T_{g}^{4}-T_{f}^{4}\right)+H_{f}+L_{f}$

The foliage layer energy balance accounts for vegetation absorption of long and short wave radiation and the multiple reflections of energy within the canopy due to the vegetation fractional coverage, sensible heat and latent heat fluxes expressed in the variables $\boldsymbol{\sigma}_{\boldsymbol{f}}, \boldsymbol{H}_{\boldsymbol{f}} \& \boldsymbol{L}_{\boldsymbol{f}}$, equations $4,5 \& 6$.

Fractional Vegetation Coverage

$\boldsymbol{\sigma}_{\boldsymbol{f}}=0.9-0.7 * \exp (-0.75 * L A I)$

$I_{S W}=$ short wave radiation

$I_{L W}=$ long wave radiation

$\alpha_{f}=$ foliage absorbtivity

$\varepsilon_{f}=$ foliage emissivity

$\underline{\text { Sensible Heat Flux }}$

$$
\begin{aligned}
& \boldsymbol{H}_{\boldsymbol{f}}=\left(1.1 L A I \rho_{a f} C_{p, a} C_{f} W_{a f}\right)\left(T_{a f}-T_{f}\right) \\
& \boldsymbol{L A I}=\text { Leaf Area Index } \\
& \boldsymbol{\rho}_{\boldsymbol{a f}}=\text { Density of air within the canopy at leaf temperature }\left(\frac{\mathrm{kg}}{\mathrm{m}^{3}}\right) . \\
& \boldsymbol{C}_{\boldsymbol{p}, \boldsymbol{a}}=\text { Specific heat of air at constant pressure }\left(\frac{1005.6 \mathrm{~J}}{\mathrm{~kg} *^{\circ} \mathrm{K}}\right) . \\
& \boldsymbol{C}_{\boldsymbol{f}}=\text { Bulk heat transfer coefficient } \\
& \boldsymbol{W}_{\boldsymbol{a f}}=\text { Wind speed within the canopy }\left(\frac{\mathrm{m}}{\mathrm{s}}\right) .
\end{aligned}
$$


$\boldsymbol{T}_{a f}-\boldsymbol{T}_{\boldsymbol{f}}=$ Difference between internal foliage canopy temperature and leaf temperature $\left({ }^{\circ} \mathrm{K}\right)$

\section{Foliage Latent Heat Flux}

$$
\begin{aligned}
\boldsymbol{L}_{\boldsymbol{f}}=\left(l_{f} L A I \rho_{a f} C_{f} W_{a f} r^{\prime \prime}\right)\left(q_{a f}-q_{f, \text { sat }}\right) \\
\boldsymbol{l}_{\boldsymbol{f}}=\text { Latent heat of vaporization at foliage temperature }\left(\frac{\mathrm{J}}{{ }^{\circ} \mathrm{K}}\right) . \\
\boldsymbol{C}_{\boldsymbol{f}}=\text { Bulk heat transfer coefficient } \\
\boldsymbol{q}_{\boldsymbol{a f}}-\boldsymbol{q}_{\boldsymbol{f}, \text { sat }}=\text { Difference between internal foliage canopy temperature } \\
\text { and leaf temperature }\left({ }^{\circ} \mathrm{K}\right) \\
\boldsymbol{r}^{\prime \prime}=\text { leaf surface wetness factor }=\left(\frac{r_{a}}{r_{a}+r_{s}}\right) .
\end{aligned}
$$

Where:

$$
\begin{aligned}
& \boldsymbol{r}_{\boldsymbol{a}}=\frac{1}{C_{f_{*} * W_{a f}}}=\text { leaf boundary layer moisture exchange resistance }\left(\frac{\mathrm{s}}{\mathrm{m}}\right) . \\
& \boldsymbol{r}_{\boldsymbol{s}}=\frac{r_{s, \min }}{L A I} * f_{1} * f_{2} * f_{3}=\text { stomatal resistance }\left(\frac{\mathrm{s}}{\mathrm{m}}\right) .
\end{aligned}
$$

Stomatal resistance is a function of minimum resistance, LAI and fractional multiplying factors of solar radiation and atmospheric moisture defined in the FASST model developed by Frankenstein and Koenig (21)

\subsubsection{Green Roof Module Soil layer Parameters}

Similar to the foliage energy balance, the soil energy balance is primarily a function of radiation absorption (dominated by fractional vegetation coverage), sensible heat flux, and latent heat flux but has the additional term soil conductivity, equation 7. 
Soil Layer Energy Balance:

$$
\begin{aligned}
& \boldsymbol{F}_{\boldsymbol{g}}=\left(1-\sigma_{f}\right)\left[I_{S W}\left(1-\alpha_{g}\right)+\varepsilon_{g} I_{L W}-\varepsilon_{g} \sigma T_{g}^{4}\right]-\frac{\sigma_{f} \varepsilon_{g} \varepsilon_{f} \sigma}{\varepsilon_{1}}\left(T_{g}^{4}-T_{f}^{4}\right)+H_{g}+ \\
& L_{g}+K \frac{\partial T_{g}}{\partial Z}
\end{aligned}
$$

Sensible heat flux exchange between the air in the plant canopy and the soil layer is mainly a function of convection and $\Delta \mathrm{T}$ between the canopy air and the ground which is given by:

$\underline{\text { Sensible Heat Flux }}$

$$
\begin{gathered}
\boldsymbol{H}_{\boldsymbol{g}}=\left(\rho_{a g} C_{p, a} C_{h}^{g} W_{a f}\right)\left(T_{a f}-T_{g}\right) \\
\rho_{a g}=\text { Density of air at soil temperature } \\
C_{h}^{g}=\text { Sensible flux bulk transfer coefficient at ground layer } \\
T_{a f}-T_{g}=\text { Difference between air and ground temperature }
\end{gathered}
$$

Latent heat flux in the soil layer is dependent upon the mixing ratio of the soil surface and wind speed within the canopy:

\section{$\underline{\text { Latent Heat Flux }}$}

$\boldsymbol{L}_{\boldsymbol{g}}=\left(C_{e}^{g} l_{g} W_{a f} \rho_{a g}\right)\left(q_{a f}-q_{g}\right)$

$\boldsymbol{C}_{\boldsymbol{e}}^{\boldsymbol{g}}=$ Bulk transer coefficient

\section{Conductivity Heat Flux}

$K \frac{\partial T_{g}}{\partial Z}=$ soil conductivity 


\subsubsection{Green Roof Module Parameters of interest:}

LAI becomes a dominant parameter with both foliage and soil energy balance equations for the absorption of radiation as well as plant transpiration through leaf wetness and stomatal resistance.

Fractional vegetation cover

$\sigma_{f}(L A I)$

Foliage Sensible Heat Flux

$\boldsymbol{H}_{\boldsymbol{f}}\left(\boldsymbol{L A I}, \rho_{a f}, C_{p, a}, C_{f}, W_{a f}, \Delta T\right)$

Foliage Latent Heat Flux

$\boldsymbol{L}_{\boldsymbol{f}}=\left(l_{f} \boldsymbol{L} \boldsymbol{A} \boldsymbol{I} \rho_{a f} C_{f} W_{a f} \boldsymbol{r}^{\prime \prime}\right)\left(q_{a f}-q_{f, s a t}\right)$

\section{Stomatal Resistance, $\boldsymbol{r}_{\boldsymbol{s}}$}

$\boldsymbol{r}^{\prime \prime}=\frac{r_{a}}{r_{a}+r_{s}}$

Where:

$\boldsymbol{r}_{\boldsymbol{s}}=\frac{r_{s, \min }}{\boldsymbol{L A I}} * f_{1} * f_{2} * f_{3}$

Soil volumetric moisture along with corresponding soil thermal conductivity and heat capacity are parameters of interest within the soil layer.

$\boldsymbol{\Theta}=V M=$ volumetric soil moisture content $=$ proportion of moisture within the soil.

$\boldsymbol{K}=$ soil conductivity $=$ weighted conductivity of soil mineral, organic and moisture components.

$\boldsymbol{C}_{\boldsymbol{p}}=$ soil volumetric heat capacity $=$ weighted heat capacity of soil mineral, organic and moisture components. 


\section{EnergyPlus Model Validation}

Measured data collected from laboratory and field experiments were used to determine foliage parameters, seasonal and discrete soil thermal properties and identify and tune EnergyPlus Green Roof Module parameters. An EnergyPlus ecoroof (GRIPV) validation model with custom weather file was developed. The GRIPV model was compared and tuned to measured GRIPV soil surface temperatures. The validated and tuned eco-roof model parameters are used in section 5 for the multi climate eco-roof DBMS model inputs.

\subsection{Green Roof Integrated Photo-Voltaic (GRIPV) Project}

The GRIPV project is located on the 3rd floor patio of Science Research and Teaching Center (SRTC) at the Portland State University campus. GRIPV weather station, foliage LAI and soil properties data were used for three purposes: create custom EnergyPlus weather (TMY2) and building (IDF) files, validation for custom TMY2 and IDF files and to tune key model parameters in order to use the validated model for eco-roof DBMS evaluations in other climates. The GRIPV project is composed of 4 eco-roof trays and a comprehensive weather station, photo 1. Each

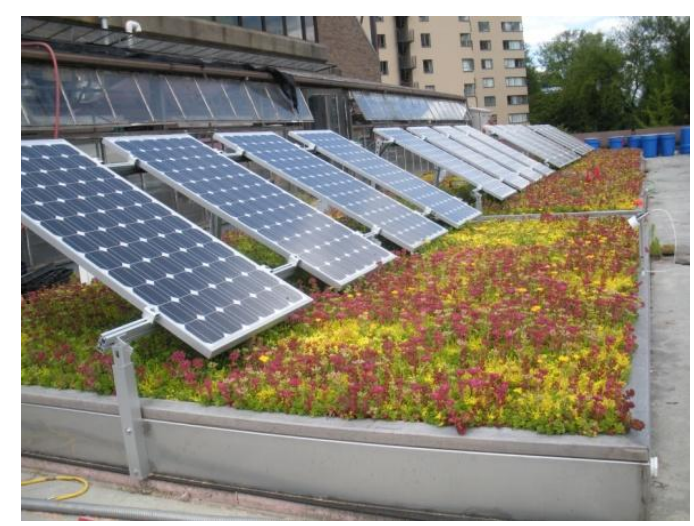

Photo 1: GRIPV tray's 1 (foreground) 1 thru 4. 
tray is $4.57 \mathrm{~m} \times 3.66 \mathrm{~m}$ and has a semi-intensive soil depth of $0.191 \mathrm{~m}$. Each tray has 4 -175 w photovoltaic panels shading approximately half of the tray, figure 9 . Trays 1 and 3 were planted with a variety of sedum plants (sedum only) while trays 2 and 4 were planted with a mix of herbaceous and sedum plants (mixed tray). For purposes of this study data was collected from trays 1 and 3 (sedum only) south facing foliage (un-shaded by PV array), soil and associated temperature (TC) and moisture sensors (MS), figures $9 \& 10$. The following GRIPV weather station data set was collected: dry bulb, relative humidity, wind speed, wind direction, global horizontal radiation,

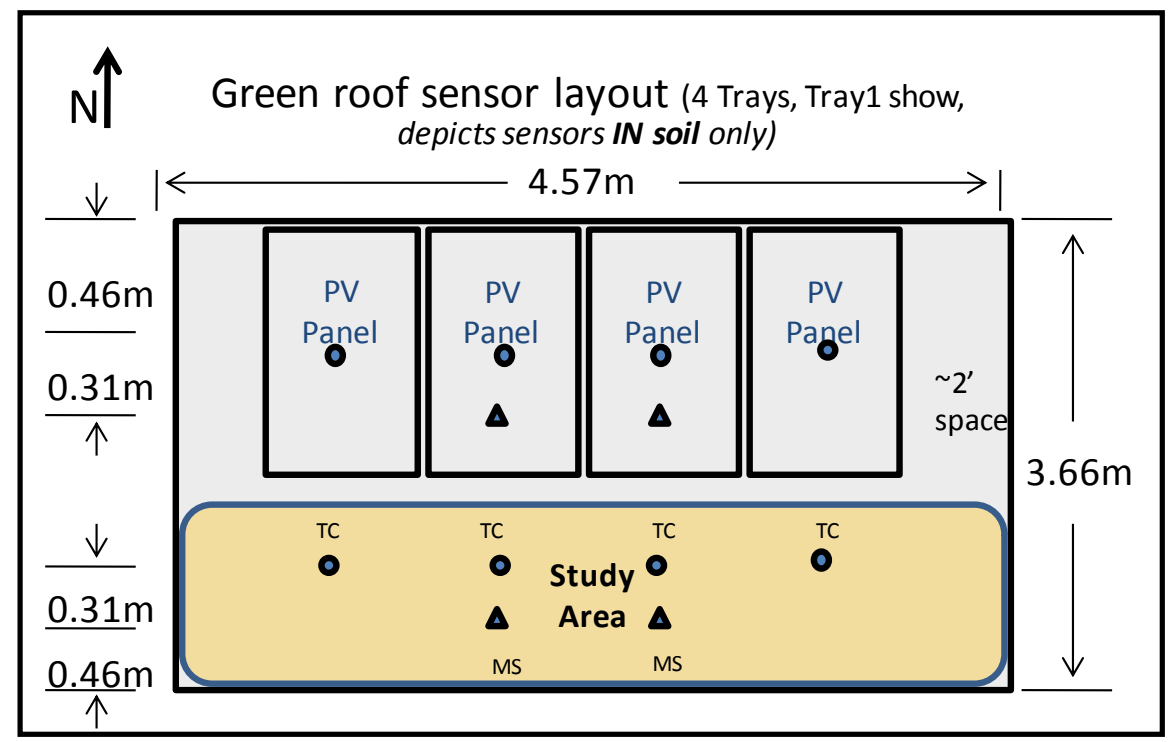

Figure 9: Tray and sensor arrangement, plan view. $\mathrm{TC}=$ thermocouple, $\mathrm{MS}=$ moisture sensor.

direct normal radiation and diffuse horizontal radiation. All data was collected on 1 minute intervals and post processed for hourly averages. 


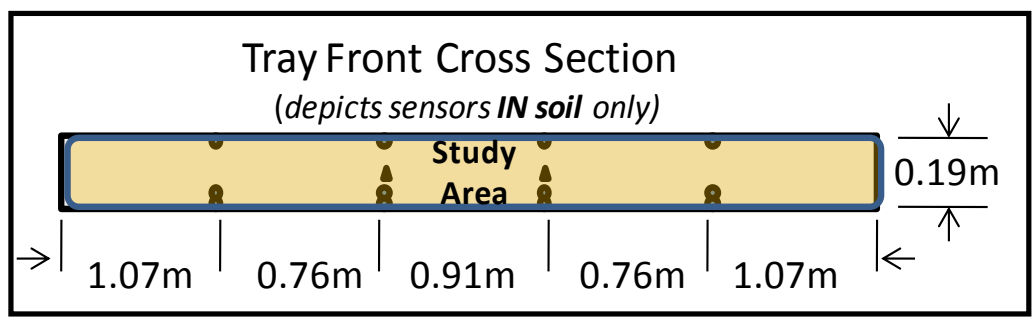

Figure 10: Individual tray and sensor arrangement, front cross section.

\subsubsection{GRIPV Validation Model Foliage Parameters}

Leaf area index was experimentally

evaluated using a Decagon Accupar LP-80, leaf area index \& photosynthetically active radiation sensor (PAR, 400 to $700 \mathrm{~nm}$ ). The LP-80 simultaneously measures PAR beneath the foliage canopy via 80 individual wand mounted sensors and above the canopy with a remote sensor in order to calculate the canopy LAI, photo 2. LAI measurements were taken on a single spring day in seven different

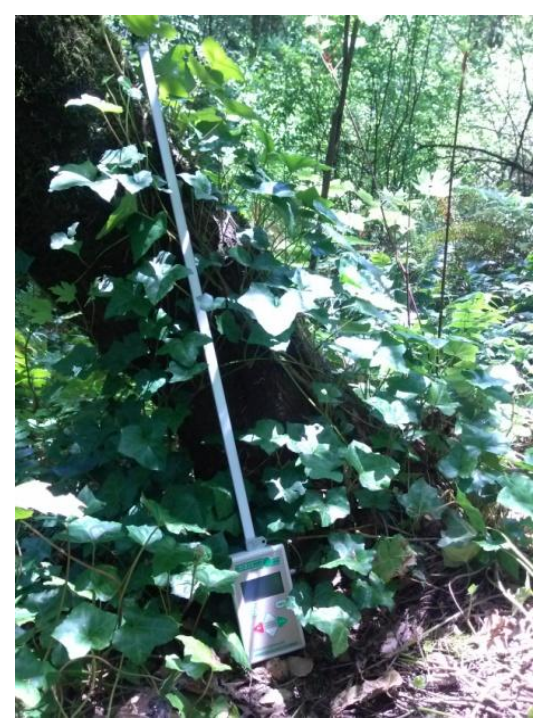

Photo 2: LP-80 LAI \& PAR sensor. Photo courtesy of Laura Holloway. locations with an average LAI of 3.67 and standard deviation of 0.4

\subsubsection{GRIPV Validation Model Soil Parameters}

Nine GRIPV soil parameters, including 3 with seasonal moisture variations, were evaluated in order to validate the Portland CBECS eco-roof model to the GRIPV project data: soil thickness, bulk density, soil organic matter, dry conductivity, dry heat capacity, conductivity and heat capacity as a function of 
moisture content, field capacity and seasonal moisture content. Bulk density was evaluated by taking 24 volumetric soil core samples, oven drying them and measuring their mass, figure 11.

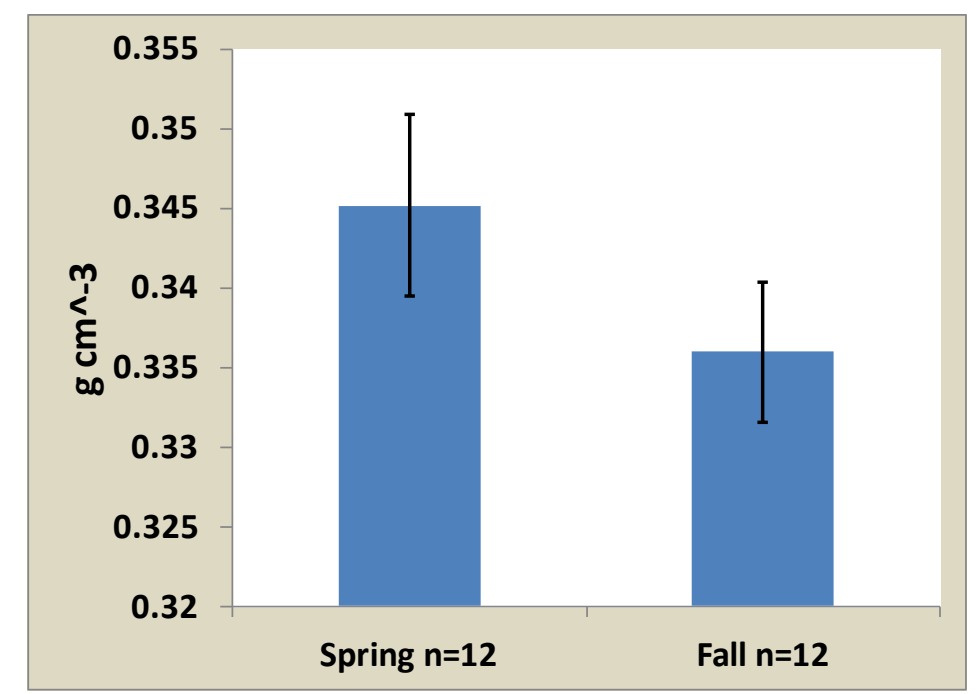

Figure 11: GRIPV30 soil bulk density, spring and fall.

Soil organic matter was determined from 54 in-situ GRIPV samples and 6 dry GRIPV30 stored soil samples. Each sample was weighed, sifted to remove aggregate, weighed again and the remaining material fired at $550^{\circ} \mathrm{C}$ for 3 hours after which the remains were re-weighed in order to determine the ratio of volatized organic matter. The average SOM for GRIVP30 soil was 30\% figure 12. 


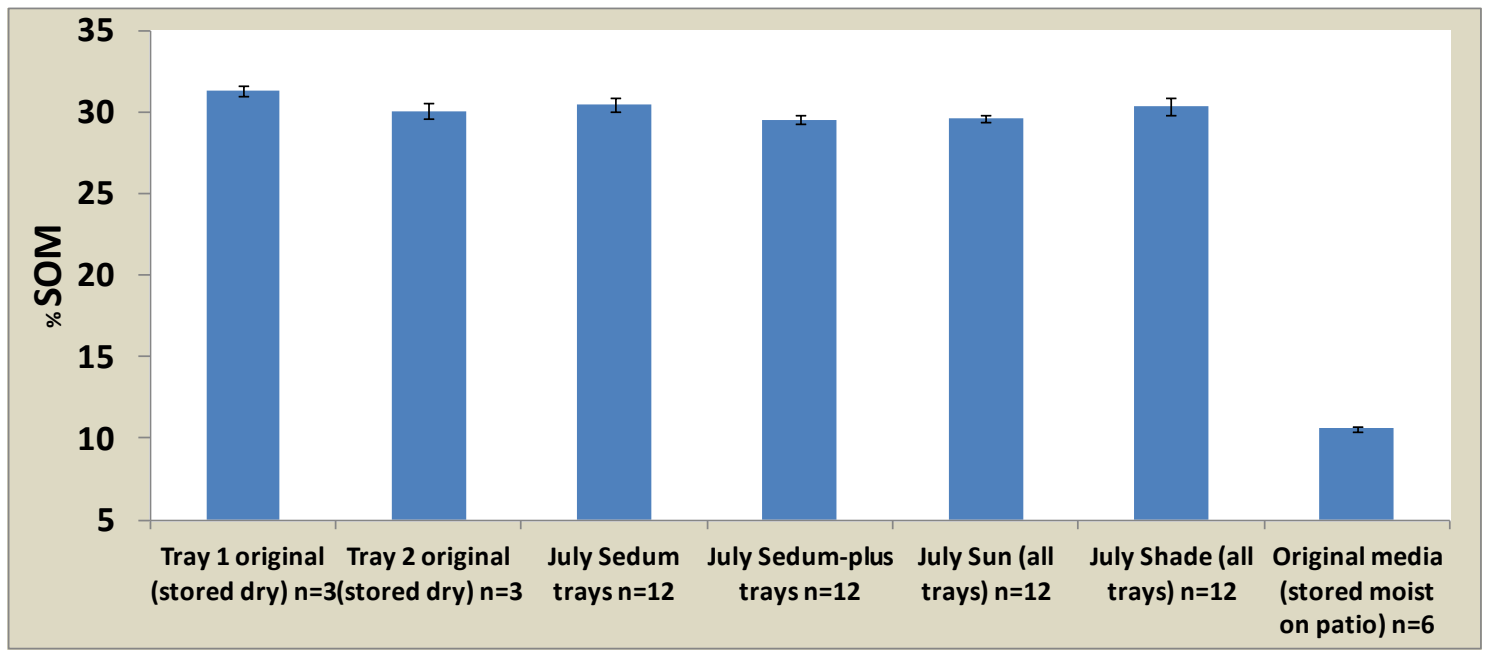

Figure 12: Soil Organic Matter comparison of as delivered original GRIVP30 soil, 1 year (summer) post planting and 1 year unplanted GRIPV30.

Dry soil conductivity, dry soil heat capacity and moisture dependent conductivity and heat capacity were determined using the KD2 Pro: Thermal properties analyzer. The KD2 Pro employs a dual probe which is capable of measuring conductivity and heat capacity. The KD2 Pro uses transient heating in the probes to approximate the solution to the differential equation for an infinite heat source. Further details of KD2 Pro operation and theory are found in the KD2 Pro Operators Manual (31), photo 3.

To determine dry thermal properties first soil samples were oven dried for 24 hours at $250^{\circ} \mathrm{C}$.

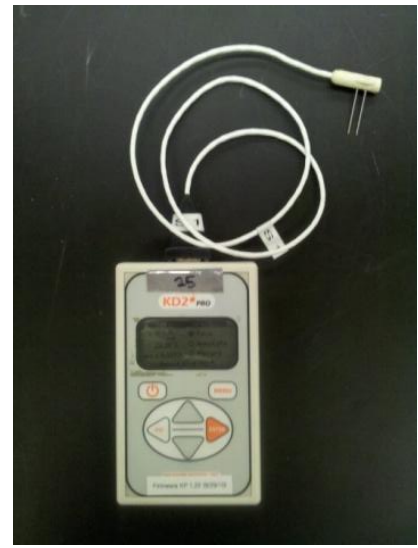

Photo 3: KD2 Pro thermal properties analyzer.

Two liters of oven dried soil was layered in an 8.5 liter pail, the dual probe was placed on top of the layer and an additional 2 liters of oven dried soil was layered over the probe. The soil and probe were then compacted together by dropping the 
pail 30 times from a height of $4 \mathrm{~cm}$. Dry thermal properties where then recorded at $15-20$ minute intervals. The average GRIPV30 dry conductivity was 0.100 $\frac{W}{m^{2} *^{\circ} K}$ and heat capacity $0.755 \frac{M J}{m^{3} *^{\circ} K}$.

Moisture dependent conductivity and heat capacity were determined using the KD2 Pr0, EC-5 soil moisture probe and a precision scale. Each previously oven dried 2 liter soil sample was weighed then thoroughly mixed with 0.8 liters $(40 \%$ by volume) water covered and moisture allowed to normalize throughout the soil overnight. Soil was again thoroughly mixed, weighed, covered and allowed to normalize overnight. 2 liters of $40 \% \mathrm{VM}$ soil was placed in an 8.5 liter pail, KD2 dual probe and an EC-5 soil moisture probe were placed on top of the soil layer and the second 2 liters of $40 \% \mathrm{VM}$ soil placed over top of probes. The $40 \% \mathrm{VM}$ soil and probes were then compacted by dropping 30 times from $4 \mathrm{~cm}$. The 8.5 liter pail was placed upon a precision scale and soil allowed to air dry over the course of 2 weeks while moisture dependent conductivity, heat capacity and VM were recorded, figures $13 \& 14$ 


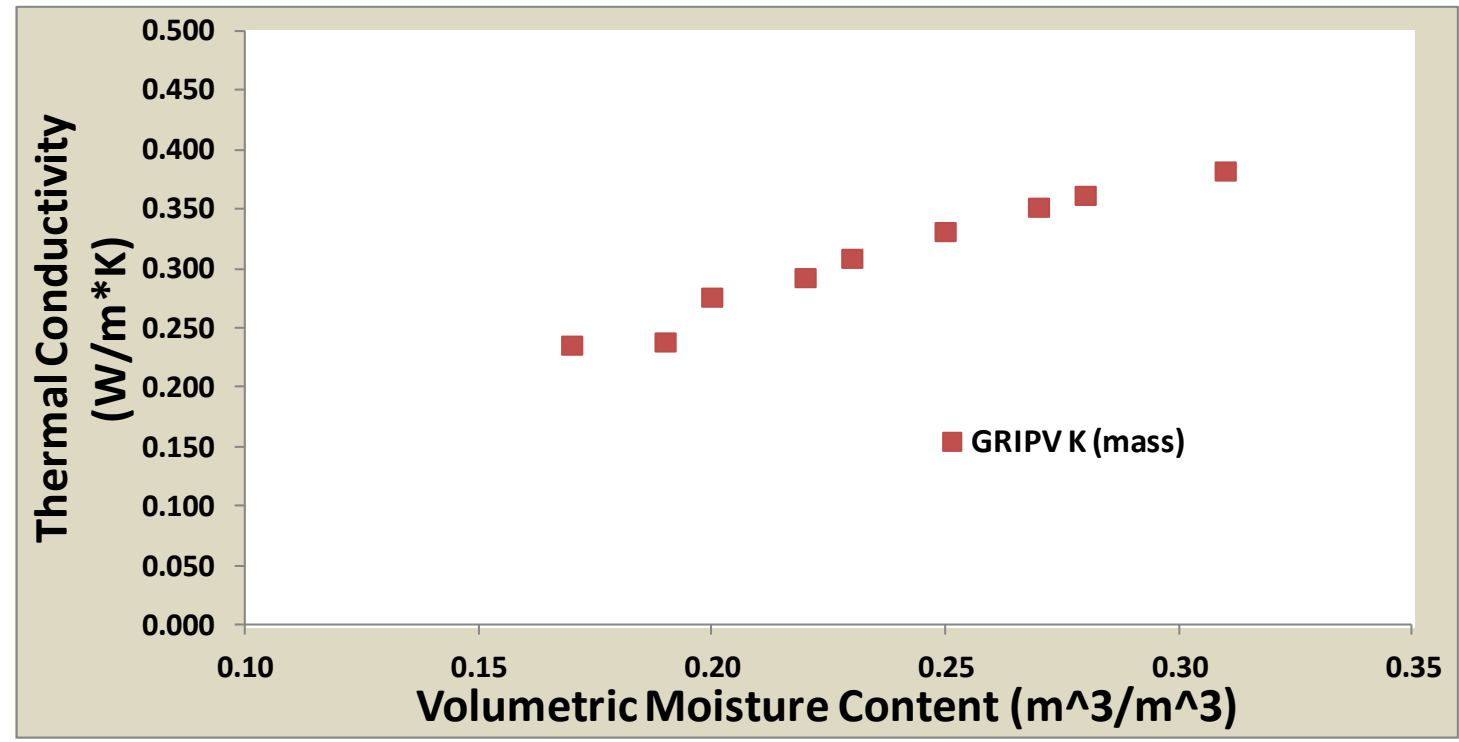

Figure 13: GRIPV 30 moisture dependent soil conductivity.

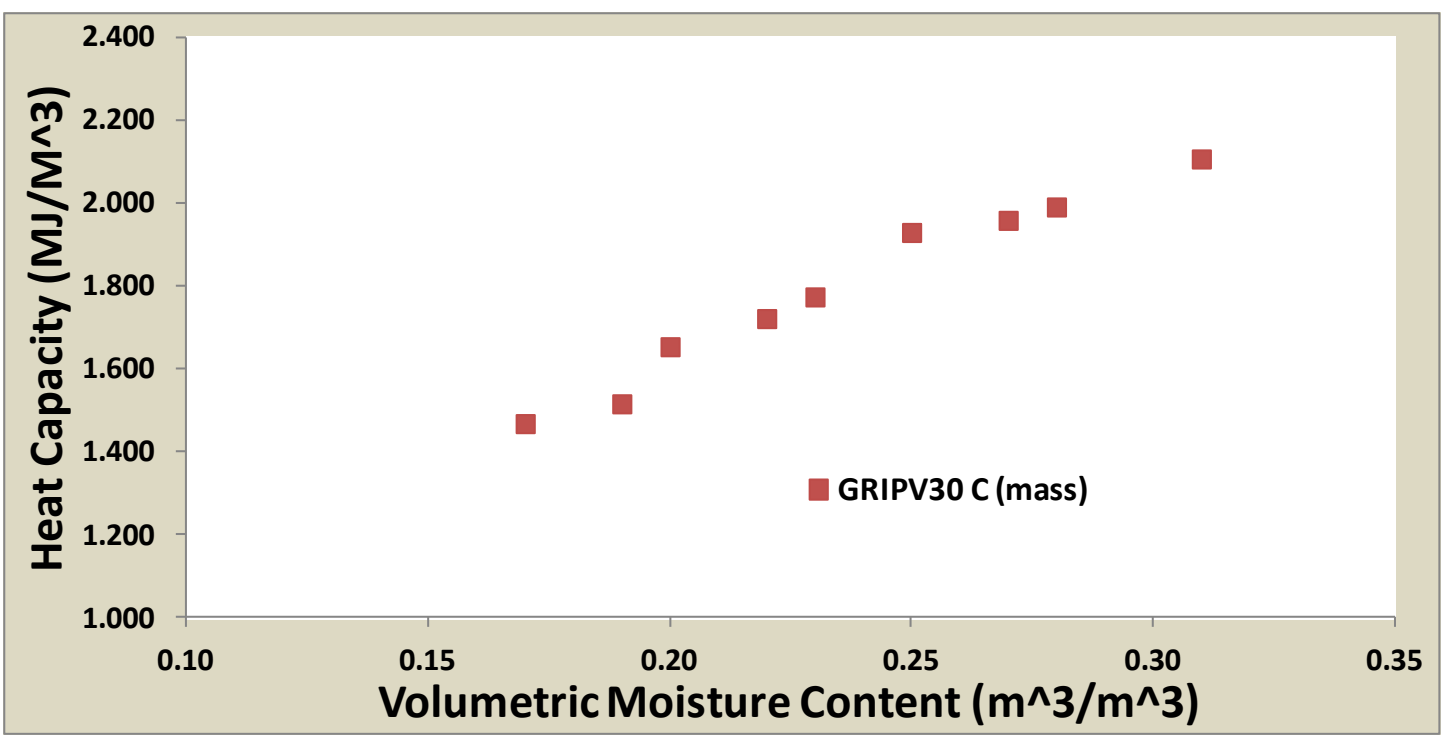

Figure 14: GRIPV30 moisture dependent soil heat capacity. 
The LaserComp Fox 314 heat flow meter was used to verify dry soil conductivity values taken by the KD2 Pro. The Fox 314 performs conductivity tests based on solution of the 1D

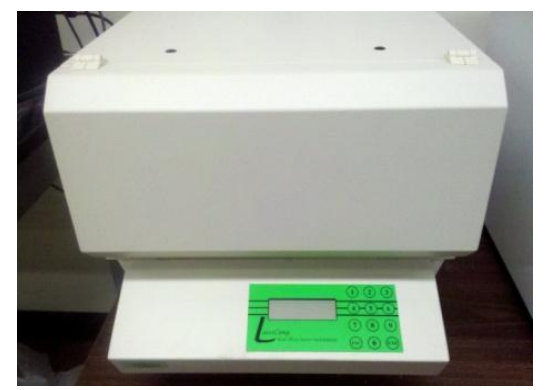

Photo 4: Fox314 Heat Flow Meter

heat conduction equation (32) and in accordance with ASTM C518, ISO 8301 and ASTM C1045-01. The Fox 314 uses a cold upper plate and hot lower plates, each with hundreds of thermocouples, that sandwich and test materials up to $10 \mathrm{~cm}$ thick, photo 4 . Conductivity testing was performed at 3 separate temperature differentials $\left(0-25^{\circ} \mathrm{C}, 10-35^{\circ} \mathrm{C} \& 20-45^{\circ} \mathrm{C}\right)$. The average conductivity for the three temperature differentials was $0.101 \frac{w}{m^{2} *^{\circ} K}$. Fox314 and KD2 Pro dry soil conductivity measures were within $1 \%$ agreement with each other.

Moisture-influenced thermal properties of GRIPV30 soil were derived from the linear relationship of conductivity and volumetric heat capacity to volumetric moisture content, figures $13 \& 14$. Equations $9 \& 10$ were used to generate table 9, “GRIPV30 soil thermal properties", for soil VM values of $0-51 \%$ (field capacity), see Appendix “Tables, Figures \& Graphs”.

$$
\begin{aligned}
& \boldsymbol{K}_{\boldsymbol{s}, \boldsymbol{v m}}=1.13 * V M+0.1 \\
& \boldsymbol{C}_{\boldsymbol{s}, v \boldsymbol{m}}=4.75 * V M+0.755
\end{aligned}
$$

\subsection{Eco-roof (GRIPV) Validation Model}

A Portland building model with GRIPV eco-roof was created by modifying a Seattle Washington benchmark CBECS building model, the same region and climate 
zone, with SRTC (Portland Oregon) latitude, longitude and elevation. The following default model class inputs were modified: conduction transfer function was chosen as the heat balance algorithm, time step was set to 20, precipitation and irrigation schedules were turned off, within material class the IEAD NonResRoof insulation thickness was set to $0.78 \mathrm{~m}$ (thermally isolating the eco-roof from the building similar to SRTC roof underlying GRIPV trays) and eco-roof output variables activated (soil temperature, moisture and flux). As mentioned in section 3.1.4, though capable of modeling the mass and energy balance portion of evapotranspiration, due to CTF instability the Green Roof Module is not capable of updating soil thermal properties based on time varying soil moisture. The work around for this issue was to divide the validation model run period into 3 seasons, winter, spring and summer. For each season a corresponding eco-roof with seasonal moisture driven soil thermal properties was implemented. All other model inputs were default values.

\subsection{GRIPV Validation Weather File}

A custom Energy Plus TMY2 weather file was modified from a standard Portland international airport TMY2 weather file using SRTC location, elevation and data collected from the GRIPV weather station, located on $3^{\text {rd }}$ floor patio of SRTC. Custom weather data was collected from 20 January 2011 to 28 August 2011. The GRIPV weather parameters used for the custom TMY2 SRTC weather file were: dry bulb, calculated dew point, relative humidity, wind speed, wind direction, global horizontal radiation, direct normal radiation and diffuse horizontal radiation. The remaining Portland international airport weather parameters were left unchanged. 


\subsection{Eco-roof Model Validation}

\subsubsection{Eco-roof Model Tuning}

Two adjustments, one to the output data and one to the model, were made in order to reduce RMSE of the differential surface temperature (measured modeled).

1. Model output temperature for the soil surface was adjusted for depth. The GRIPV soil surface thermocouples are $1.3 \mathrm{~cm}$ below the actual surface. In order to adjust for the model depth discrepancy the predicited flux, boundary temperatures and soil thermal properties were used to compute temperatures $1.3 \mathrm{~cm}$ below the modeled soil surface.

2. LAI is used in every Green Roof Module energy component, other than soil conduction, of the foliage and soil energy balance equations, sections 3.1.4.1 \& 3.1.4.2. The parameter that couples the foliage and soil energy balances is $\boldsymbol{\sigma}_{\boldsymbol{f}}$, fractional vegetative cover. Further research of the FASST model (21) found variations on the method for calculating fractional vegetation coverage using LAI.

\section{Grasses:}

$\boldsymbol{\sigma}_{\mathbf{f}, \text { grasses }}=1-\exp (-0.75 * L A I)$

The Green Roof Module utilizes a modified version of the grasses equation.

The Green Roof Module eq. 4 :

$\boldsymbol{\sigma}_{\mathbf{f}, \mathrm{GRM}}=0.9-0.7 \exp (-0.75 * L A I)$ 
The GRIPV sedum canopy has a measured LAI of 3.67. The equation for $\boldsymbol{\sigma}_{\mathbf{f}, \text { grasses }}$, was evaluated at LAI 3.67 and compared to $\boldsymbol{\sigma}_{\boldsymbol{f}, \boldsymbol{G R M}}$ at LAI 3.67.

Calculating and comparing $\boldsymbol{\sigma}_{f}$ for both methods results in a fractional vegetative cover difference of 0.081 , table 3 .

$\boldsymbol{\sigma}_{\mathbf{f}, \mathbf{G R M}}=0.9-0.7 \exp *(-0.75 * 8.72)=0.855$ fractional vegetative cover.

$\boldsymbol{\sigma}_{\mathbf{f}, \text { grasses }}=1-\exp *(-0.75 * 3.67)=0.936$ fractional vegetative cover.

Table 3: Sigma F (fractional vegetative cover) for minimum to maximum measured LAI values.

\begin{tabular}{ccc}
\hline & \multicolumn{2}{c}{ Sigma F } \\
& $\begin{array}{c}\text { Green } \\
\text { Roof } \\
\text { Module }\end{array}$ & $\begin{array}{c}\text { Grasses, } \\
\text { FASST } \\
\text { Model }\end{array}$ \\
\hline 0 & 0.200 & 0.000 \\
2 & 0.743 & 0.776 \\
3.67 & 0.855 & 0.936 \\
5 & 0.884 & 0.976 \\
7 & 0.896 & 0.995 \\
8.72 & 0.899 & 0.998 \\
\hline
\end{tabular}

Observation of the GRIPV sedum canopy shows no soil exposure through the foliage cover, counter to the $86 \%$ coverage suggested by the $\sigma_{f, G R M}$ calculations, photos $5 \& 6$. Based on the closer representation of foliage cover given by the $\sigma_{f, g r a s s e s}$ equation the eco-roof model LAI was adjusted upward from the measured 3.67 (Appendix “Tables, Figures \&

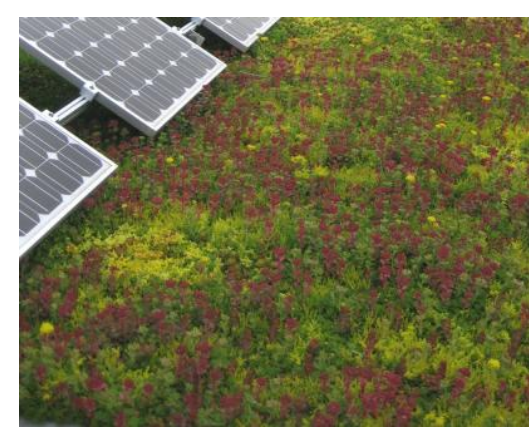

Photo 5: Study area sedum foliage coverage. 
Graphs": figures $34,35,36$ and table 11) to 8.72 , the maximum value found in forestry. By increasing LAI from 3.67 to 8.72 , fractional vegetative cover increased by $4.5 \%$ and the total measured - modeled soil temperature RMSE was reduced in all seasonal validation models: winter

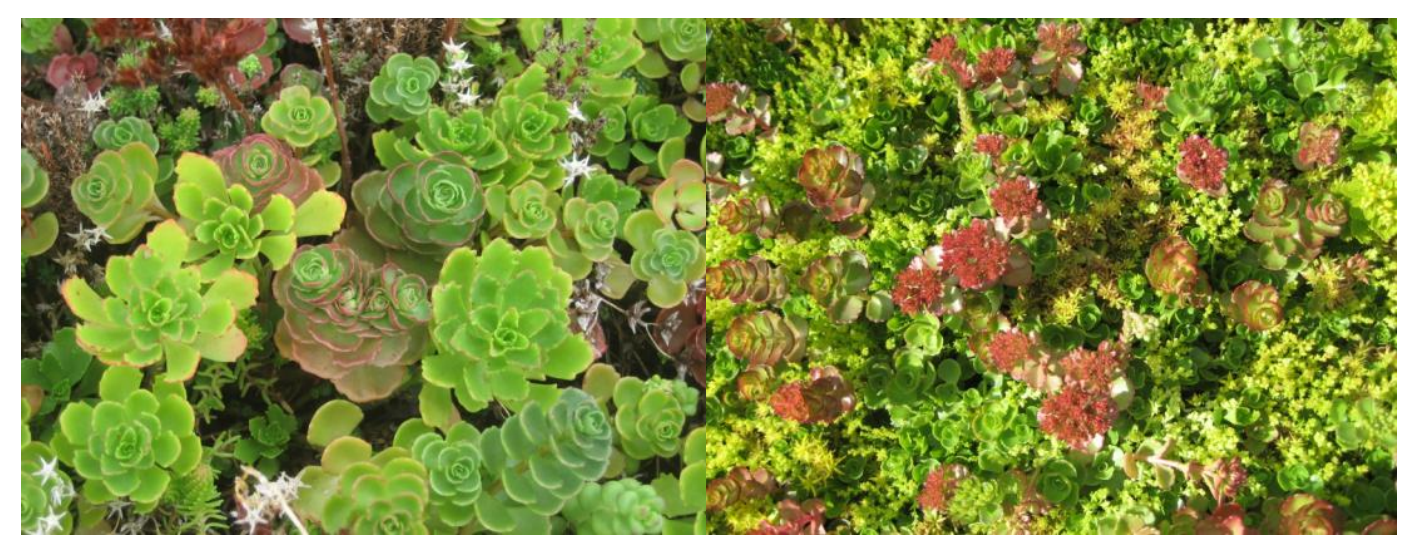

Photo 6: Close up of sedum foliage coverage with no visible soil exposure.

by $0.43^{\circ} \mathrm{C}$, spring by $0.68^{\circ} \mathrm{C}$ and summer by $0.94^{\circ} \mathrm{C}$. Model LAI increase had a proportionally higher impact on daytime measured - modeled soil temperature RMSE for every season but was most significant in summer with a RMSE of $1.64^{\circ} \mathrm{C}$, table $4 \&$ table 11 (Appendix "Tables, Figures \& Graphs").

\subsubsection{Validation}

Model validation was performed for winter, spring and summer. Fall data was not available at the time that validation IDF and weather files were being constructed therefore spring and fall seasons were assumed to be of similar but opposite effect for the purposes of eco-roof model validation. Eco-roof model validation was performed by comparing seasonal hourly averaged GRIPV soil surface temperatures to the tuned seasonal eco-roof model soil surface 
temperature output. The spring model $\left(\mathrm{RMSE}=1.76^{\circ} \mathrm{C}\right)$ has the best agreement with measured data, table 4 and figure 16 . The winter $\left(\mathrm{RMSE}=2.10^{\circ} \mathrm{C}\right)$ and summer $\left(\mathrm{RMSE}=3.49^{\circ} \mathrm{C}\right)$ models have good agreement with measured data, table 4 and figures $15 \& 17$.

Table 4: (Measured - Modeled) seasonal and diurnal validation temperature statistics

\begin{tabular}{|c|c|c|c|c|c|}
\hline & \multicolumn{4}{|c|}{ Temperature Validation Statistics } & \multirow{2}{*}{$\frac{\text { (LAI 8.72) }}{\text { STDEV }}$} \\
\hline & $\begin{array}{c}\text { Day } \\
\text { RMSE }\end{array}$ & $\begin{array}{l}\text { Night } \\
\text { RMSE }\end{array}$ & $\begin{array}{c}\text { Total } \\
\text { RMSE }\end{array}$ & $\begin{array}{c}\text { Ave } \\
\text { Temp }\end{array}$ & \\
\hline Winter & 2.40 & 1.81 & 2.10 & 0.98 & 1.19 \\
\hline Spring & 1.65 & 1.87 & 1.76 & 0.28 & 1.48 \\
\hline Summer & 3.93 & 2.88 & 3.49 & 0.69 & 3.34 \\
\hline
\end{tabular}

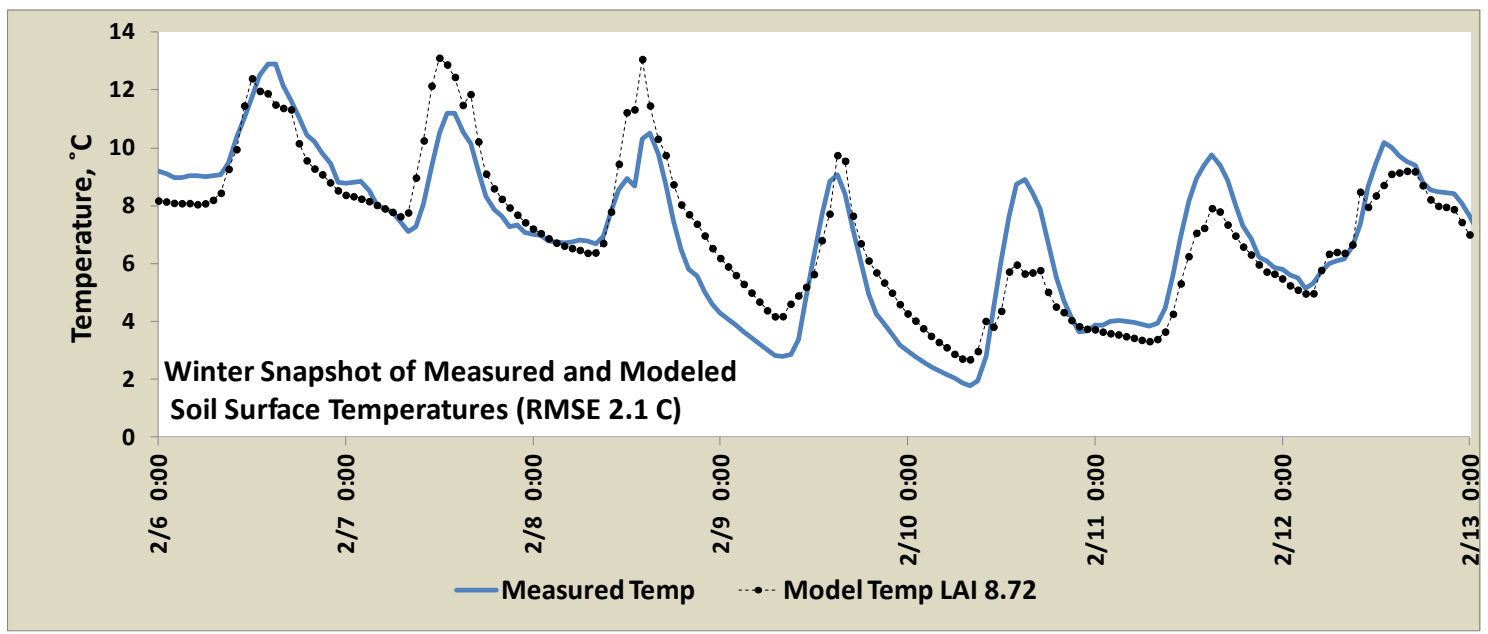

Figure 15: Winter snapshot of measured and modeled validation temperature data. 


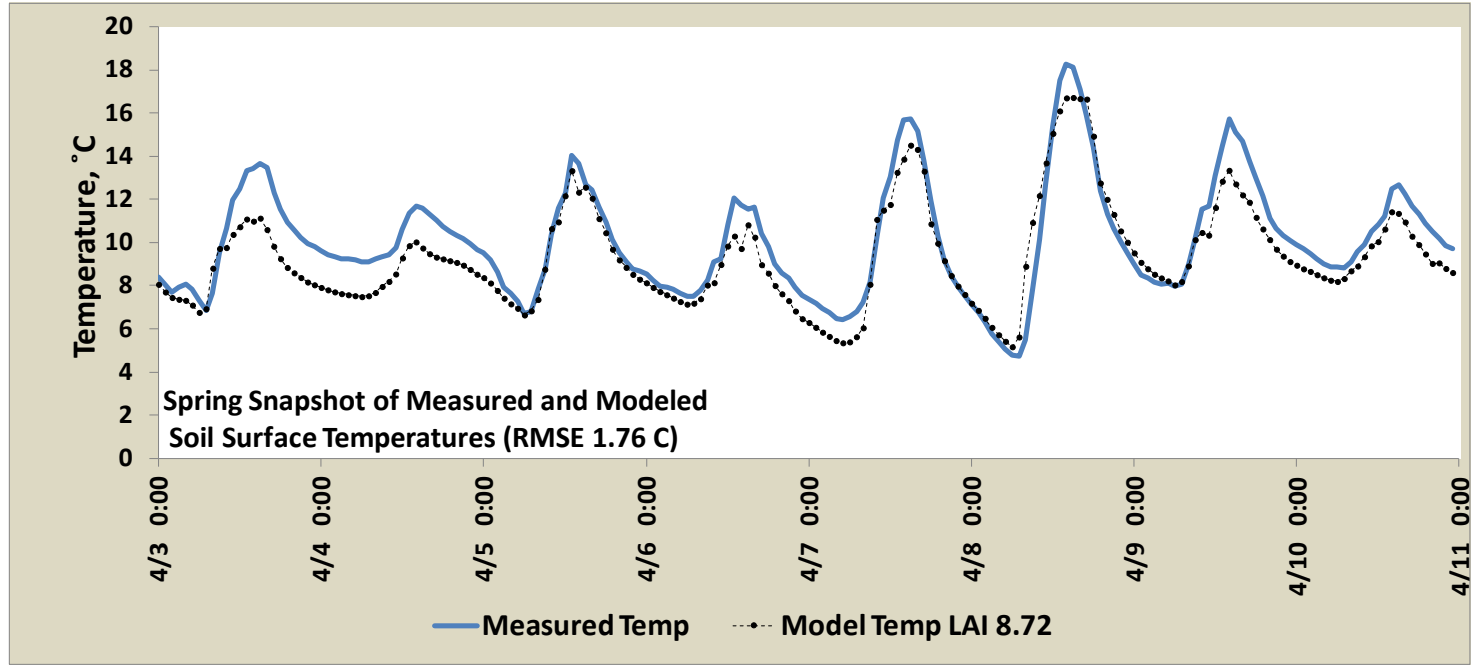

Figure 16: Spring snapshot of measured and modeled validation temperature data.

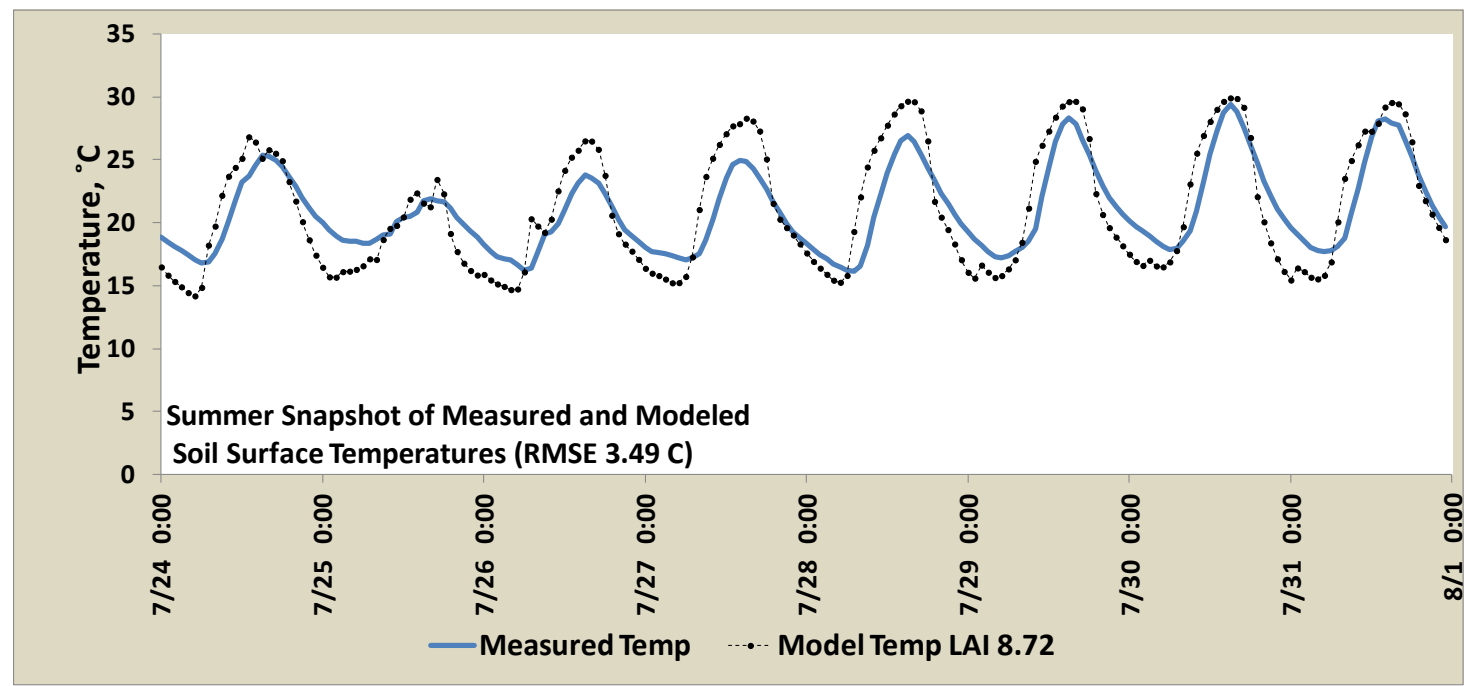

Figure 17: Summer snapshot of measured and modeled validation temperature data.

Two identifiable sources of error are: seasonal averaging of soil moisture (thermal properties), and how LAI is integrated into the Green Roof Module for calculation of fractional vegetation coverage. Section 4.4 discussion of LAI and the implementation of the fractional vegetation coverage equation in the Green Roof Module. Day time error dominates both winter and summer models though 
night time error is still large, which points to LAI in the calculation of fractional vegetation coverage. 


\section{DBMS Calculation in 4 Climates}

\subsection{DBMS with Evaporative Cooling}

A large portion of an eco-roof thermal performance is due to its evaporative cooling effect. The ORNL relationship for DBMS, DBMS $=\frac{R_{T, \text { mass }}}{R_{S S}}$, when $E_{H C, S S}=$ $E_{H C, T m a s s}$ will not always result in $E_{H C, S S}=E_{H C, T m a s s}$ for a thermal mass with evaporative cooling, see section 6.2 At the core of a DBMS calculation is relating the performance of a dynamic system to that of a standard, non-dynamic, steady state equivalent.

The value for $E_{H C, s S}$ is the sum of heating, cooling and fan energy for the building with a standard roof assembly (steady state with R-value, $R_{S S}$ ). $E_{H C, T m a s s}$ is the sum of heating, cooling and fan energy consumption for the eco-roof assembly (dynamic thermal mass with steady state $R_{T, \text { mass }}$ ), equation 11 . See section 6.2 for further discussion of equation 1 modification and application in DBMS calculations. Lastly DBMS is first calculated on a seasonal basis, in order to work around the EnergyPlus Green Roof Module mass transport (moisture) issues addressed in section 4.2. An annual DBMS is calculated by first summing the seasonal energy consumption values, $E_{H C, S S} \& E_{H C, T m a s s}$, then applying equation 11.

DBMS $=\frac{E_{H C, S S}}{E_{H C, T \text { mass }}}$, when $R_{S S, S t d}=R_{S S, T \text { Tmass }}$

\subsection{Standard and Eco-roof Models In 4 Climates}

The climate-locations and buildings modeled, except Portland Oregon, were weather files and CBECS benchmark buildings available from the DOE database (29). The process for the Portland simulations was similar to the validation process 
outlined in section 4. Specifically, a Portland benchmark building was created by modifying a Seattle Washington benchmark building (same region and climate zone) and associated international airport weather file, table 5 \& figure 7.

Table 5: Modeled Cities with corresponding CBECS benchmark buildings, TMY2 weather files and ASHRAE Climate Zone.

\begin{tabular}{|l|l|l|c|}
\hline \multicolumn{1}{|c|}{ Location } & \multicolumn{1}{|c|}{ CBECS Benchmark IDF } & TMY2 Weather File & $\begin{array}{c}\text { ASHRAE } \\
\text { Climate Zone }\end{array}$ \\
\hline Portland, Oregon & mediumoffice_new2004_Seattle & OR_Portland_PDX & 4C \\
\hline Chicago, Illinois & mediumoffice_new2004_Chicago & Il_Chicago_Ohare & 5A \\
\hline Atlanta, Georgia & mediumoffice_new2004_Atlanta & GA_Atlanta & 3A \\
\hline Houston, Texas & mediumoffice_new2004_Houston & TX_Houston & 2A \\
\hline
\end{tabular}

For each location and season the standard CBECS was run to determine the seasonal

$E_{H C, S S}$

$E_{H C, S S}=$ heating, cooling and fan energy consumption of standard model with steady state insulation R-value of 2.54 .

$E_{H C, T m a s s}=$ heating cooling and fan energy consumption of eco-roof (thermal mass) model with steady state R-value of 2.54 .

. $E_{H C, T m a s s}$ was determined from the same climate-location seasonal CBECS model but modified with an eco-roof such that the entire eco-roof assembly had a seasonal steady state R-value ( $\left.R_{S s, T m a s s}\right)$ equal to 2.54 . The seasonal $R_{S s, T m a s s}$ for each climate-location was determined based on two parameters: the climate-location estimated GRIPV30 seasonal soil moisture and the insulation thickness necessary so that the eco-roof assembly $R_{\text {SeasGRIPV30 }}+R_{\text {Insl }}=R_{\text {SS,Tmass }}=2.54$. In this way the heating, cooling and fan energy consumption of equivalent standard and thermally 
dynamic assemblies can be compared in order to determine the DBMS, equations 11 $\& 12$.

$R_{\text {SeasGRIPV30 }}+R_{\text {Insl }}=R_{S s, T \text { mass }}=R_{S S, s t d}=2.54$

The challenge becomes determining seasonal moisture content and related thermal properties of GRIPV30 soil $\left(R_{\text {SeasGRIPV30 }}\right)$ in climate-locations other than Portland in order to run the eco-roof models and implement equations $11 \& 12$.

\subsubsection{Climate-Location Eco-roof Soil Moisture Estimation}

For the 3 alternate climate-locations the seasonal eco-roof model inputs were the same as those used in model validation with the exception of inputs that vary with moisture, each eco-roof model seasonal input detail.

GRIPV30 seasonal soil thermal properties were related to the 3 alternate climates through the NOAA soil moisture monitoring and prediction database (33). NOAA has developed a 1D hydrologic model of the United States that is divided into 344 climate divisions (34). The NOAA soil moisture model uses precipitation and temperature data for, each climate division, from 1931-present (Appendix "Tables, Figures \& Graphs", figure 30) that calculates soil moisture, evaporation and drainage runoff. For this study the monthly soil moisture content for each NOAA climate division was found by averaging the1931-2011 modeled values. The table of average NOAA climate division soil moisture values is found in Appendix "Tables, Figures \& Graphs"., table 14. GRIPV30 average seasonal soil moisture (VM) values were related to Portland NOAA 2011 seasonal soil moisture $(\mathrm{mm})$ values. An average of 7.01e- $4 \frac{V M}{m m}$ was used as correlation for GRIPV30 to NOAA climate division soil 
moisture. The correlation was then applied across climate-locations in order to calculate seasonal GRIPV30 VM. The climate-location and seasonal VM values were used to find GRIPV soil properties, from table 9 Appendix “Tables, Figures \& Graphs", which were used to calculate eco-roof model input parameters.

\subsubsection{Eco-roof Model Insulation Layer}

For each climate-location-seasonal eco-roof model the insulation layer was adjusted so that $R_{\text {SeasGRIPV30 }}+R_{\text {Insl }}=\boldsymbol{R}_{\text {ss,Tmass }}=2.54$. 


\section{Results \& Discussion}

\subsection{GRIPV30 Soil Thermal Properties}

GRIPV30 soil has an average SOM of 30\%, field capacity of 0.51 and bulk density of $345 \frac{\mathrm{kg}}{\mathrm{m}^{3}}$, figure 18 . Compared to the previous 12 GBRL studied eco-roof soils GRIPV30 SOM and field capacity are very high while bulk density is very low.

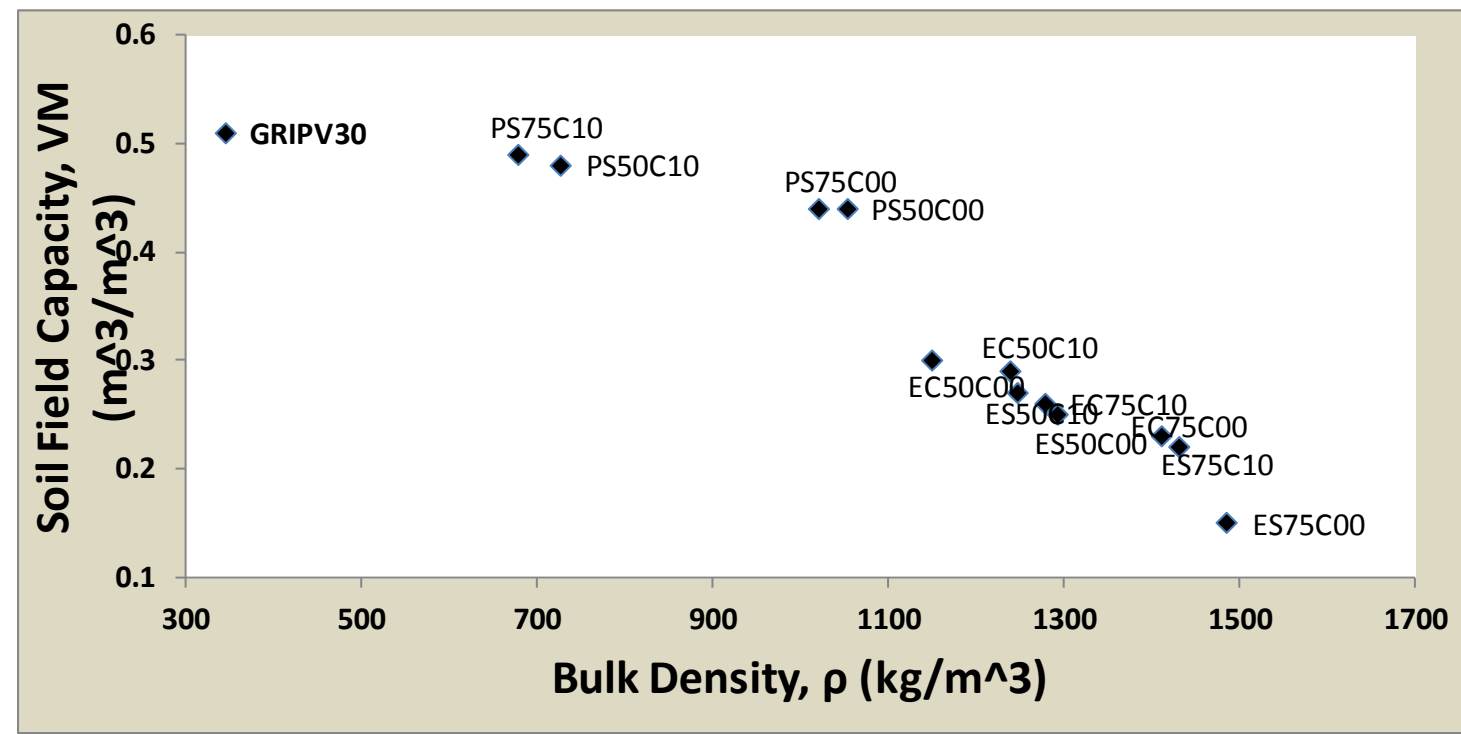

Figure 18: 13 GBRL studied eco-roof soils comparing soil field capacity to bulk density. Numerical value in soil name represents percent SOM.

The conductivity and heat capacity linear relationship to VM is described by (14). The linear relationship between thermal properties and soil VM is confirmed in the GRIPV30 soil testing, figures $19 \& 20$.

The $K$ vs $V M$ slope for GRIPV30 soil is 0.95 and low when compared to the 12 studied soils, figure 19. Conductivity of GRIPV30 soil is low $\left(0.100 \frac{\mathrm{W}}{m *^{\circ} \mathrm{K}}\right)$ at $0 \%$ VM and remains low $\left(0.380 \frac{W}{m *^{\circ} K}\right)$ as VM is increased to $31 \%$. GRIPV30 $C_{p} v s V M$ slope is 4.5 and the largest of all studied soils, figure 20. GRIPV30 soil volumetric 
heat capacity starts low but increases rapidly as a function of VM $\left(0.755 \frac{\mathrm{MJ}}{\mathrm{m}^{3} *^{\circ} \mathrm{K}}\right.$ at $0 \%$ VM increasing to $2.108 \frac{M J}{m^{3} *^{\circ} K}$ at $\left.31 \% \mathrm{VM}\right)$.

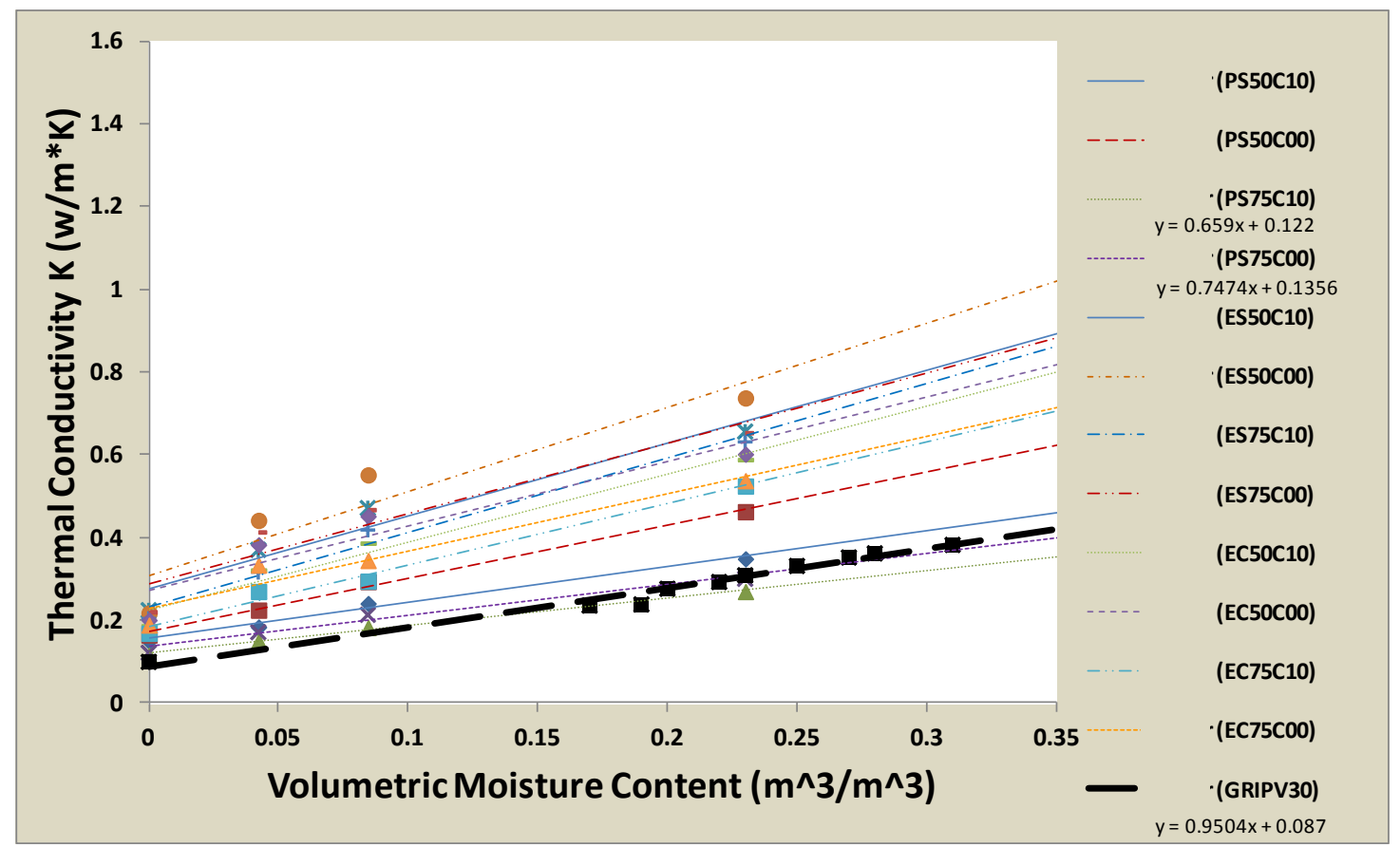

Figure 19: Eco-roof soil conductivity (K) linear fit to volumetric soil moisture content (VM) for each soil. 


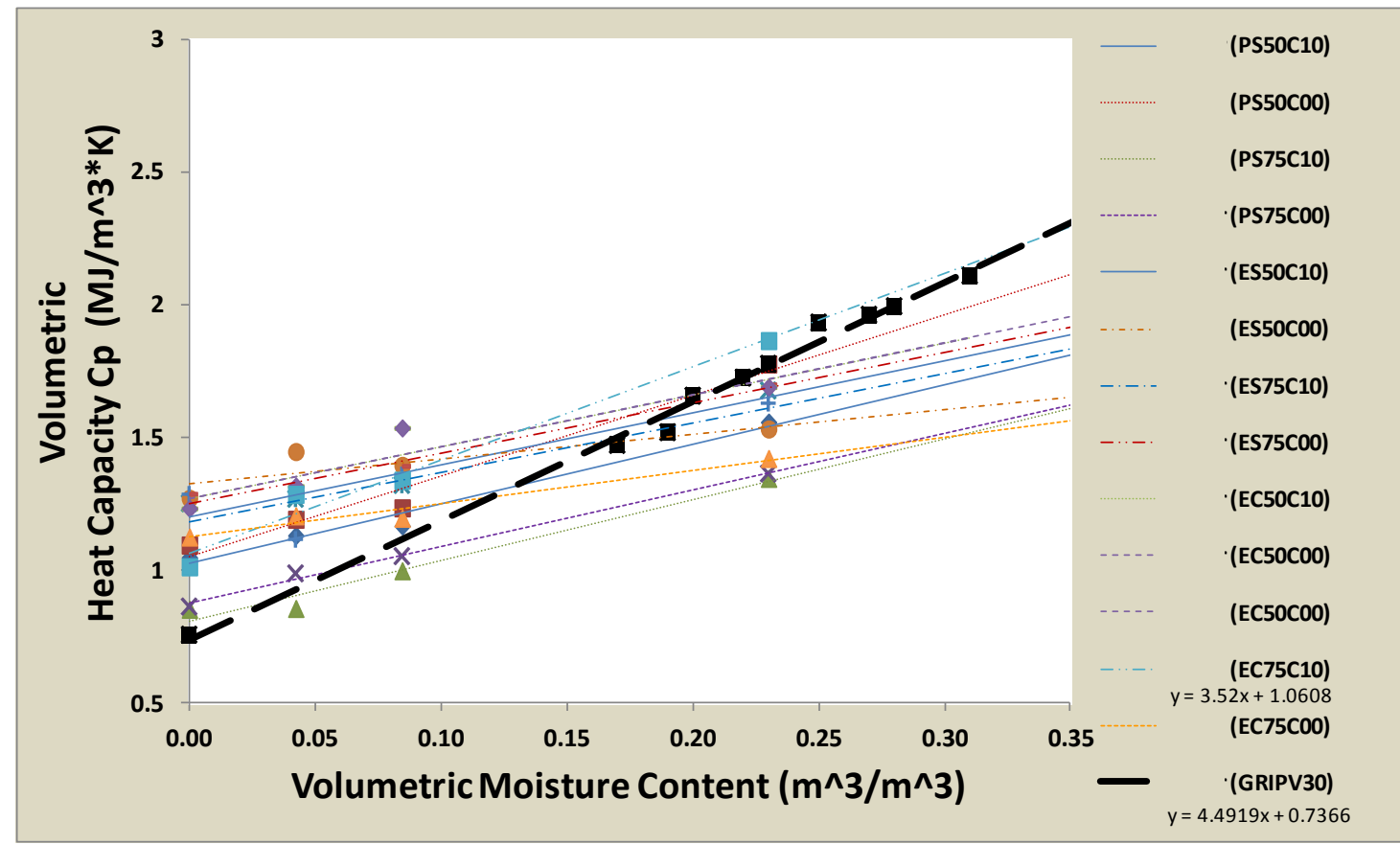

Figure 20: Eco-roof soil volumetric heat capacity $\left(\boldsymbol{C}_{\boldsymbol{p}}\right)$ linear fit to volumetric soil moisture content (VM) for each soil.

\subsection{DBMS \& Evaporative Cooling}

An eco-roof system acts as a thermal mass and an evaporative cooler when in thermal contact with the building. For the CBECS new2004_medium_office model situated in Portland during summer iterating the "Standard Roof" $\mathrm{R}_{\mathrm{ss}}$ roof contribution to heating, cooling and fan energy consumption will approach an asymptote with $\mathrm{R}_{\mathrm{T} \text {,mass }}$ and does not satisfying $\mathrm{E}_{\mathrm{HC}, \mathrm{SS}}=\mathrm{E}_{\mathrm{HC}, \mathrm{Tmass}}$ as outlined in equation 1, see figure 19. 


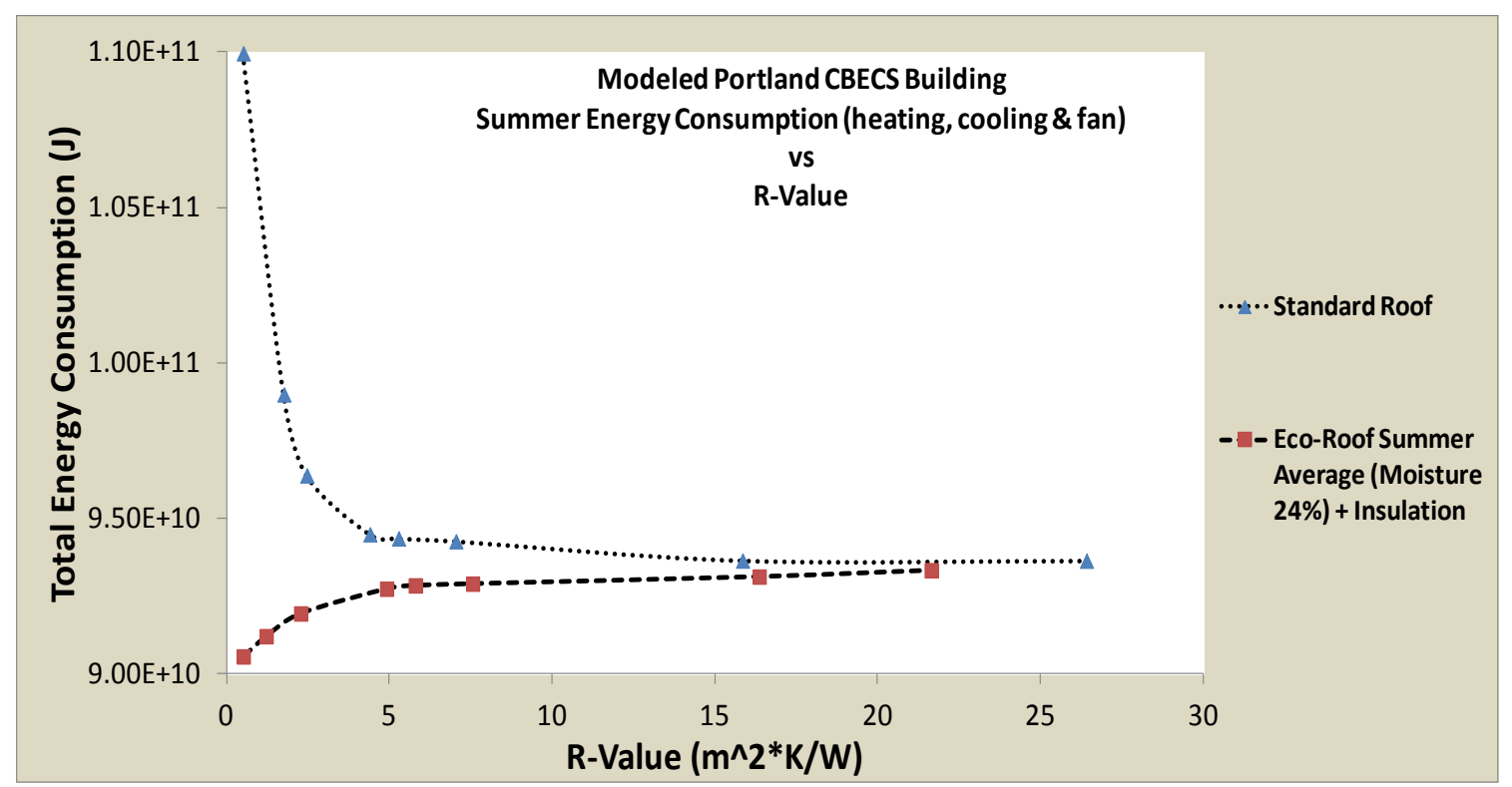

Figure 21: Asymptotic behavior of energy consumption as insulation is added to a standard roof and ecoroof. Eco-roof increase in energy consumption with increasing R-value illustrates evaporative cooling effect.

The $\mathrm{R}_{\mathrm{ss}}$ iterations reach an asymptote due to heat energy being redirected toward the less resistant boundaries, the walls, as the roof R-value increases. Evaporative cooling affect on energy consumption and thermal isolation by addition of insulation is illustrated in the asymptotic behavior of "Eco-Roof Summer Average" data points in figure 19. In the "Eco-Roof" model energy consumption increases as insulation is added and reduces the evaporative cooling affect on the building. Eventually the ecoroof is thermally isolated and has nearly the same energy performance and R-value as the Standard roof. The modification of equation 1 into equation 11 for DBMS calculations encompasses eco-roof evaporative cooling thermally connected to the building and eco-roof insulation optimization while still allowing comparison to a standard roof. 


\subsection{Eco-roof (GRIPV30) DBMS in 4 Climates}

The seasonal and annual energy (heating, cooling \& fan) consumption for the Portland validated eco-roof and standard roof along with the seasonal and annual DBMS are shown in figure 22. The semi-intensive eco-roof configuration has a winter and summer building energy performance benefit (DBMS) of $1.02(2 \%$ improvement) as compared to the CBECS 2004 new medium office benchmark building. Spring and fall shoulder seasons have below standard DBMS performance of 0.95 (5\% decrease) and 0.92 ( $8 \%$ decrease), respectively. The annual eco-roof DBMS for Portland is 0.97 (3\% decrease). This implies that the Portland eco-roof performs 3\% below the standard insulated model.

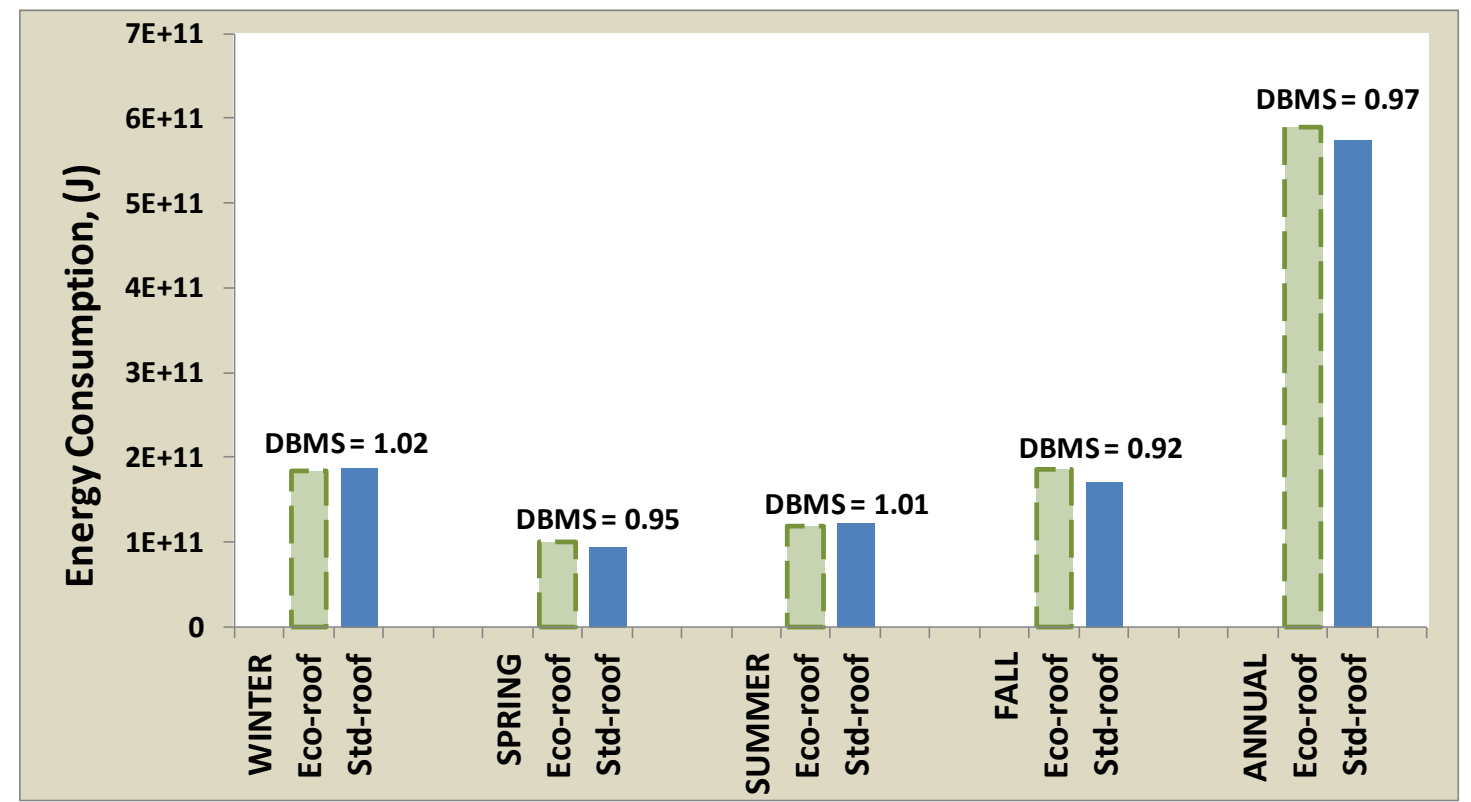

Figure 22: Seasonal and annual energy consumption and DBMS for Portland Oregon.

The Portland winter DBMS of 1.02 was unexpectedly high because winter season for this location is heating dominated with average day time temperature of $6^{\circ} \mathrm{C}$ with 
a maximum of $21^{\circ} \mathrm{C}$ and minimum of $-7^{\circ} \mathrm{C}$. Some winter cooling energy is used but most energy consumption is from fans and heating, figure 23 .

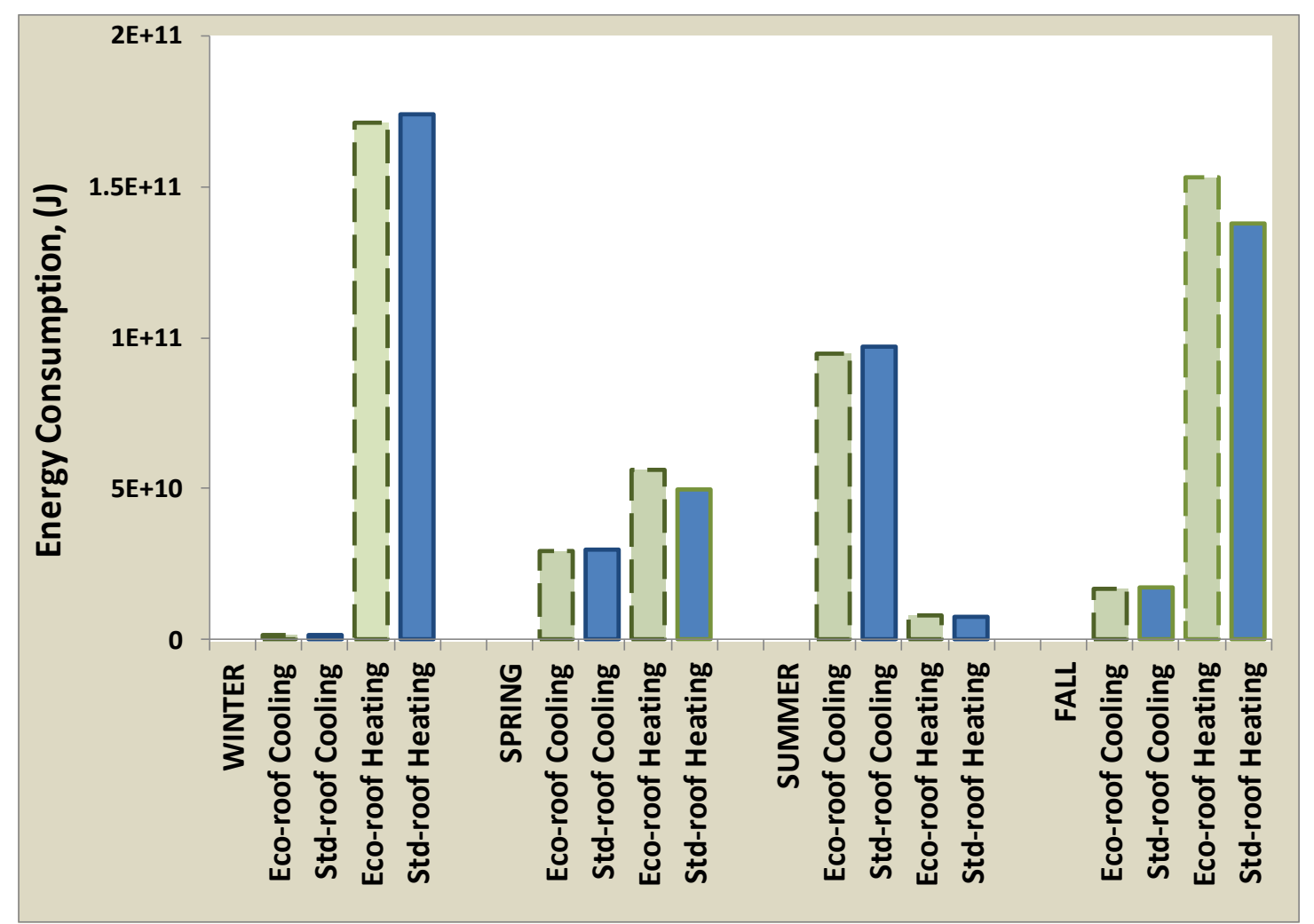

Figure 23: Eco-roof and standard roof comparison of seasonal energy consumption, by type, for Portland Oregon.

The greater than 1 winter DBMS is explained by low temperature peak reduction for outside and inside roof surfaces illustrated in figures $24 . \& 25.89 \%$ of DBMS winter performance is fan and heating energy savings through nighttime low temperature peak reductions, figure $23 \& 25$. Average roof inside surface temperatures are $17^{\circ} \mathrm{C}$ for standard and eco-roof systems. Maximum temperatures for the insides surface of the eco-roof are $3^{\circ} \mathrm{C}$ lower than standard and minimum temperatures are $1{ }^{\circ} \mathrm{C}$ higher than the standard roof, table 6. 


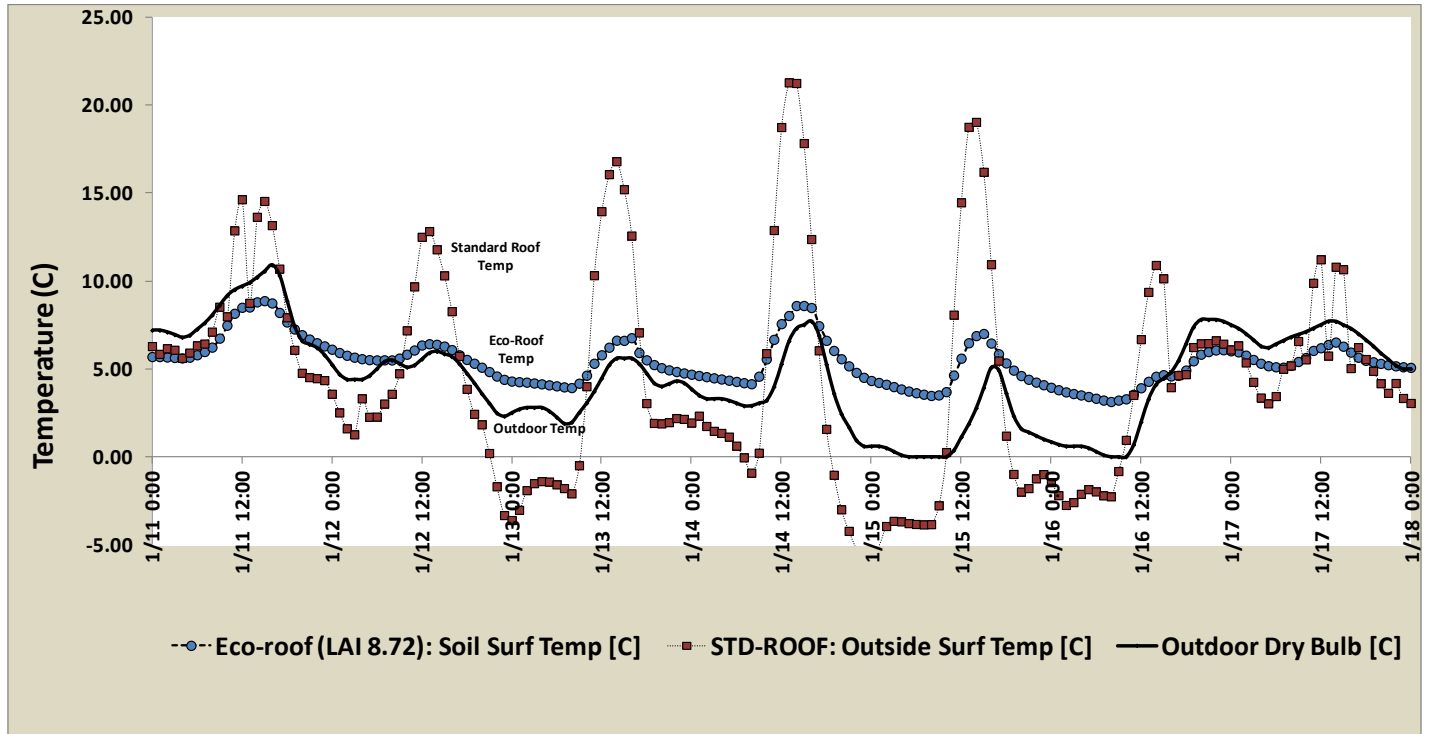

Figure 24: Winter outer surface temperatures demonstrating peak high and low temperature range reduction by eco-roof compared to standard roof and outdoor temperature.

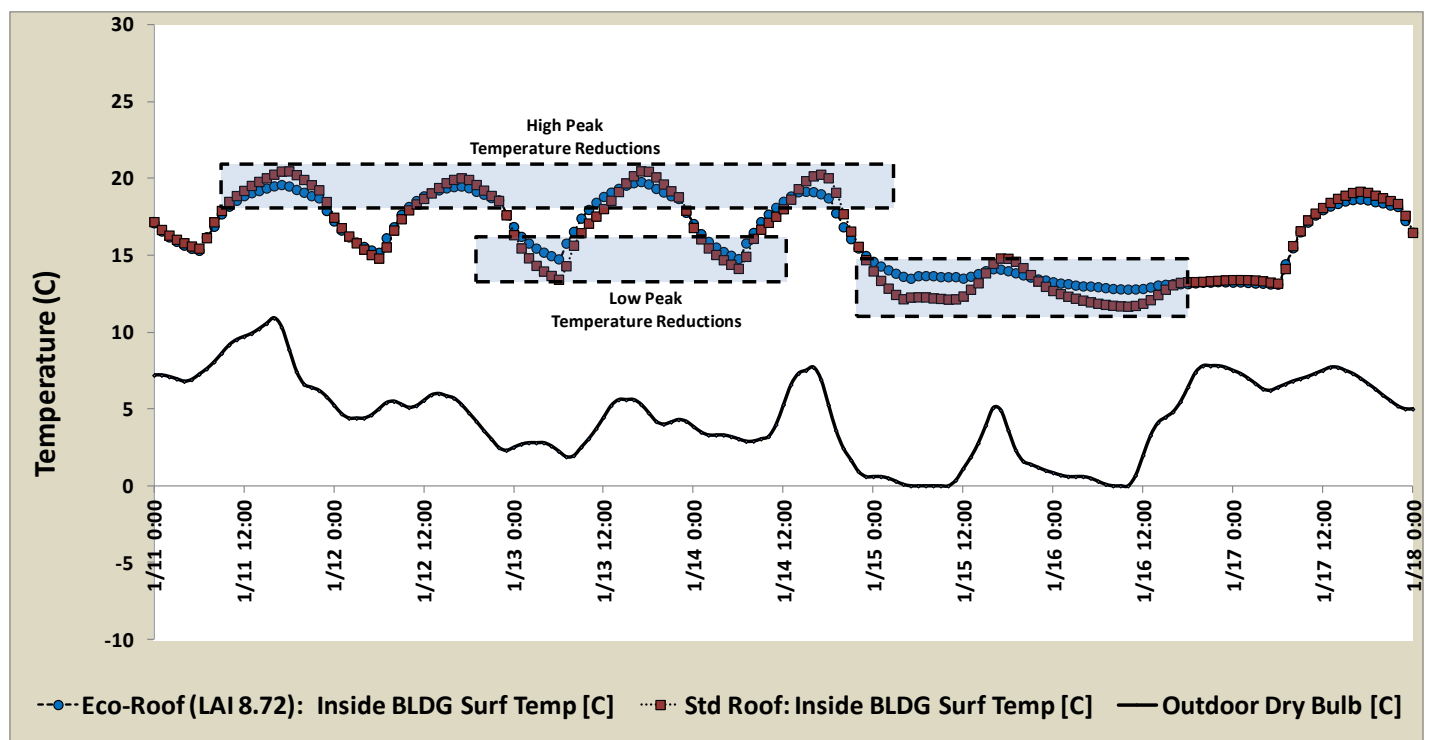

Figure 25: Winter Inside surface temperatures demonstrating relative inside surface temperature stability as well as peak high and low temperature range reduction by eco-roof compared to standard roof and outdoor temperature. 
Table 6: Portland winter outer and inner roof surface and outdoor temperatures.

\begin{tabular}{lcccccc}
\hline \multicolumn{5}{c}{ Portland Winter Surface Temperature Comparison } \\
\hline & $\begin{array}{c}\text { STD-ROOF: } \\
\text { Outside Surface } \\
\text { Ave Temp [C] }\end{array}$ & $\begin{array}{c}\text { Eco-roof (LAI } \\
\text { 8.72): Outside } \\
\text { Surface Temp [C] }\end{array}$ & $\begin{array}{c}\text { Outdoor Dry Bulb } \\
\text { Temp [C] }\end{array}$ & $\begin{array}{c}\text { STD-ROOF: Inside } \\
\text { Bldg Surface Ave } \\
\text { Temp [C] }\end{array}$ & $\begin{array}{c}\text { Eco-roof (LAI } \\
\text { 8.72): Inside Bldg } \\
\text { Surface Temp [C] }\end{array}$ \\
\hline Average & 7 & 6 & 6 & 17 & 17 \\
Maximum & 48 & 16 & 21 & 26 & 23 \\
Minimum & -13 & -3 & -7 & 10 & 11 \\
\hline
\end{tabular}

An additional explanation for winter eco-roof performance could be Portland's cloudy cool winter days dampening winter eco-roof heat losses, suppression of evaporative cooling, similar to effects in the La Rochelle eco-roof study (8).

Spring and Fall DBMS values were lower than 1 due to eco-roof evaporative cooling. Portland spring is heating dominated but warm enough, due to increasing solar radiation and rising average outdoor dry bulb temperature $\left(12^{\circ} \mathrm{C}\right.$ average $)$, to induce eco-roof evaporative cooling which amplifies daytime heat losses through the roof, again similar to that described by (8), figures 23,26 and table 7. Eco-roof inside surface temperatures are an average $21^{\circ} \mathrm{C}$, equal to the temperature at which the thermostat will demand heat $\left(21^{\circ} \mathrm{C}\right.$ space heating set point), and $1{ }^{\circ} \mathrm{C}$ cooler than the standard roof inside surface temperatures, figure 26 and table 7 . The cooler eco-roof inside temperature creates a heating demand that results in greater energy use and less than 1 DBMS, figure 23. 


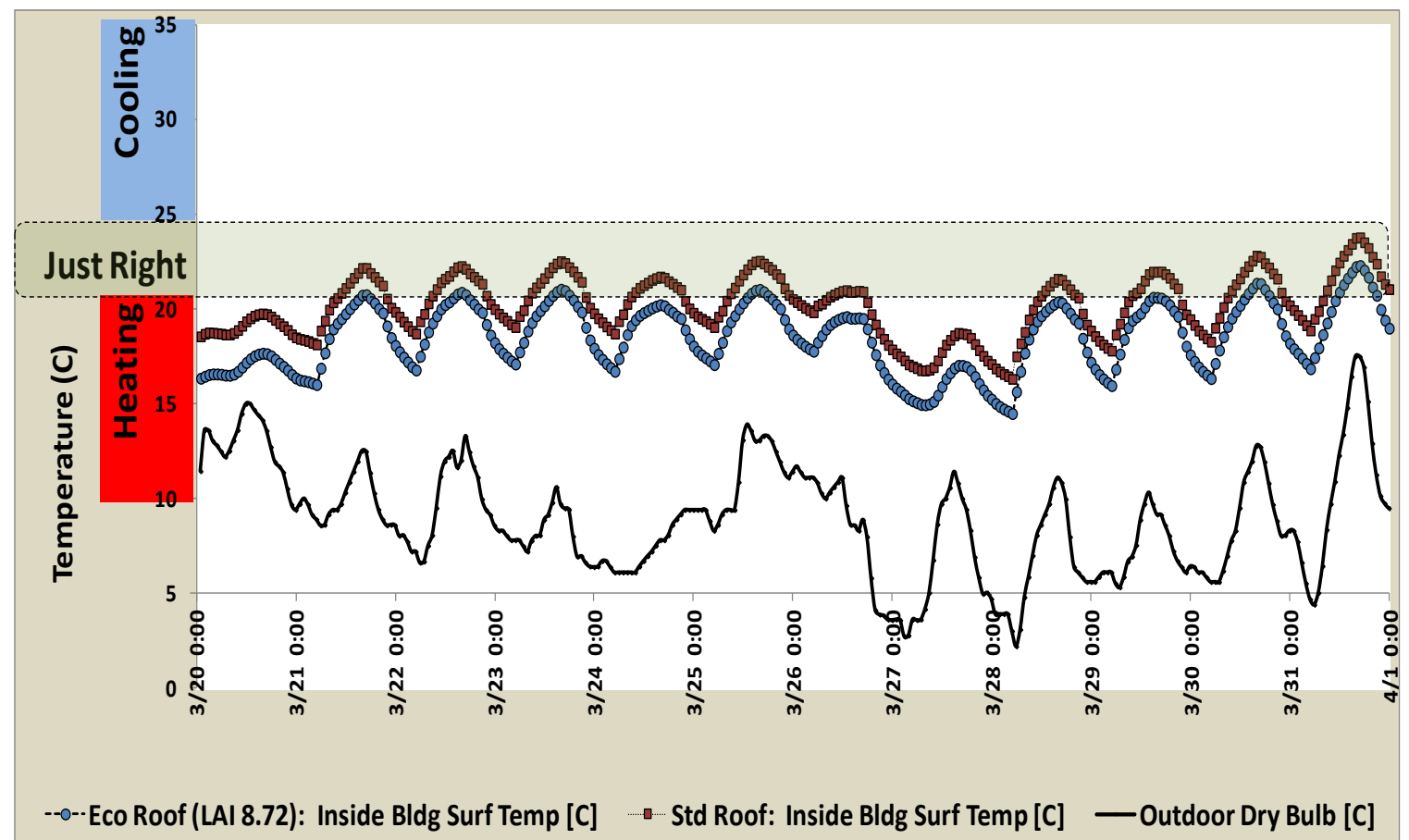

Figure 26: Spring standard and eco-roof inside surface temperature comparison reveals eco-roof consistently lower temperatures due to evaporative cooling.

Table 7: Spring outer and inner roof surface and outdoor temperatures.

\begin{tabular}{lccccc}
\hline \multicolumn{5}{c}{ Portland Spring Surface Temperature Comparison } \\
\hline & $\begin{array}{c}\text { STD-ROOF: } \\
\text { Outside Surface } \\
\text { Ave Temp [C] }\end{array}$ & $\begin{array}{c}\text { Eco-roof (LAI } \\
\text { 8.72): Outside } \\
\text { Surface Temp [C] }\end{array}$ & $\begin{array}{c}\text { Outdoor Dry Bulb } \\
\text { Temp [C] }\end{array}$ & $\begin{array}{c}\text { STD-ROOF: Inside } \\
\text { Bldg Surface Ave } \\
\text { Temp [C] }\end{array}$ & $\begin{array}{c}\text { Eco-roof (LAI } \\
\text { 8.72): Inside BIdg } \\
\text { Surface Temp [C] }\end{array}$ \\
\hline Average & 19 & 14 & 12 & 22 & 21 \\
Maximum & 68 & 24 & 30 & 26 & 25 \\
Minimum & -4 & 7 & 1 & 16 & 14 \\
\hline
\end{tabular}

Portland summer DBMS greater than 1 was due to warm sunny days that induce eco-

roof evaporative cooling, increase roof top heat loss and provide peak temperature

shaving which reduced inside surface temperatures by an average of $1^{\circ} \mathrm{C}$, table 8 .

An important observation is that average summer season eco-roof inside surface temperatures were below the $24^{\circ} \mathrm{C}$ cooling set point, table $8 \&$ figure 27 , which generated large cooling energy savings and the summer DBMS of 1.02 . 
Table 8: Summer outer and inner roof surface and outdoor temperatures.

\begin{tabular}{lccccc}
\hline \multicolumn{5}{c}{ Portland Summer Surface Temperature Comparison } \\
\hline & $\begin{array}{c}\text { STD-ROOF: } \\
\text { Outside Surface } \\
\text { Ave Temp [C] }\end{array}$ & $\begin{array}{c}\text { Eco-roof (LAl } \\
\mathbf{8 . 7 2 ) : ~ O u t s i d e ~} \\
\text { Surface Temp [C] }\end{array}$ & $\begin{array}{c}\text { Outdoor Dry Bulb } \\
\text { Temp [C] }\end{array}$ & $\begin{array}{c}\text { STD-ROOF: Inside } \\
\text { Bldg Surface Ave } \\
\text { Temp [C] }\end{array}$ & $\begin{array}{c}\text { Eco-roof (LAI } \\
\text { 8.72): Inside Bldg } \\
\text { Surface Temp [C] }\end{array}$ \\
\hline Average & 27 & 19 & 19 & 24 & 23 \\
Maximum & 68 & 29 & 33 & 26 & 26 \\
Minimum & 3 & 12 & 8 & 21 & 19 \\
\hline
\end{tabular}

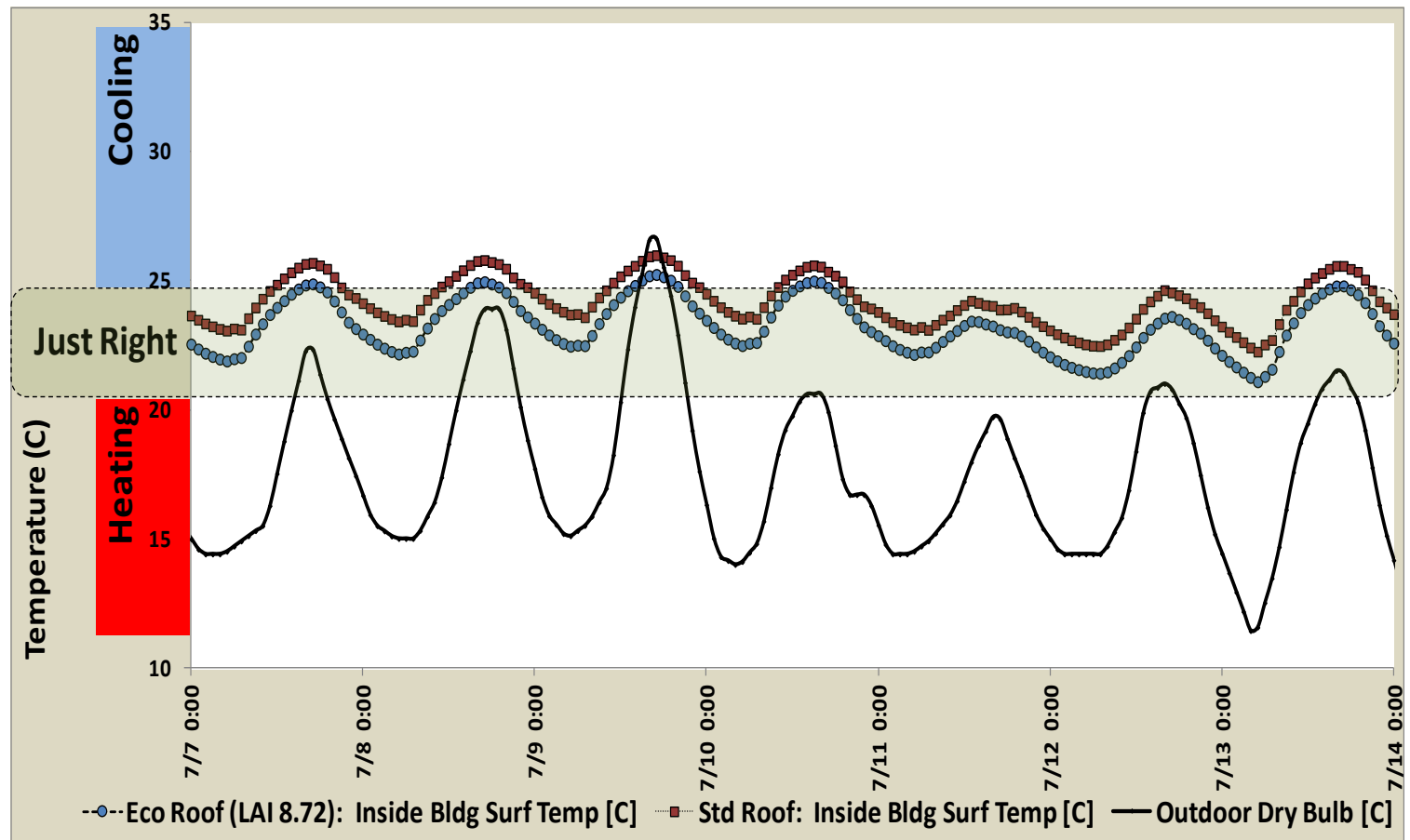

Figure 27: Summer standard and eco-roof inside surface temperature comparison reveals consistently reduced eco-roof inside surface temperatures due to energy storage (peak reductions) and evaporative cooling.

Modeling results for Chicago seasonal, annual energy and DBMS are shown in figure 28. The eco-roof model has a winter building energy performance below the standard model, DBMS $=0.99(-1 \%)$, figure 27. Chicago Spring DBMS $=1.02(+$ $2 \%)$, summer DBMS $=1.04(+4 \%)$ and fall DBMS $=1.00$. The annual eco-roof DBMS for Chicago is 1.01 (+ 1\% improvement) above standard roof building model. 


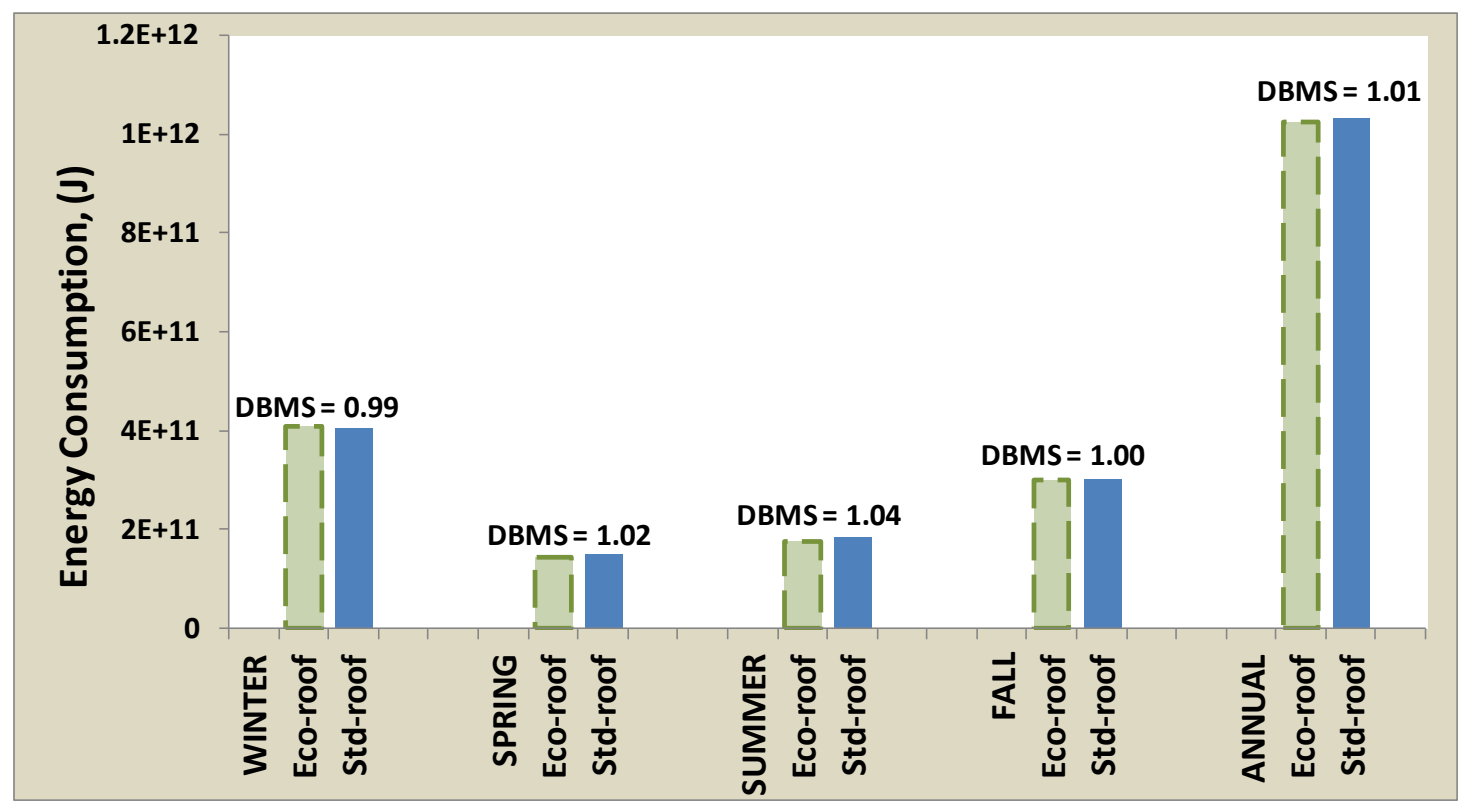

Figure 28: Seasonal and annual energy consumption and DBMS for Chicago Illinois.

Chicago winter DBMS of 0.99 , though less than 1 , was unexpectedly high as winter for this location is a heating dominated season in the extreme, figure 29. Similar to Portland Oregon, reduced eco-roof evaporative cooling and conduction by cloudy winter days and or freeze-thaw conditions could be suppressing winter heat losses. Chicago spring has nearly equal heating and cooling energy consumption. Spring peak high and low temperature reductions along with evaporative cooling heat losses through the eco-roof roof resulted in better than standard performance for spring. Summer greater than 1 DBMS was due to warm sunny days (evaporative cooling) that increased roof top heat loss, peak temperature reductions and reduced eco-roof cooling energy demand. The fall season in Chicago is, similar to winter, a heating dominated season, figure 29 , with daytime average temperatures of $6^{\circ} \mathrm{C}$, maximum of $24^{\circ} \mathrm{C}$ and a minimum of $-20^{\circ} \mathrm{C}$. 


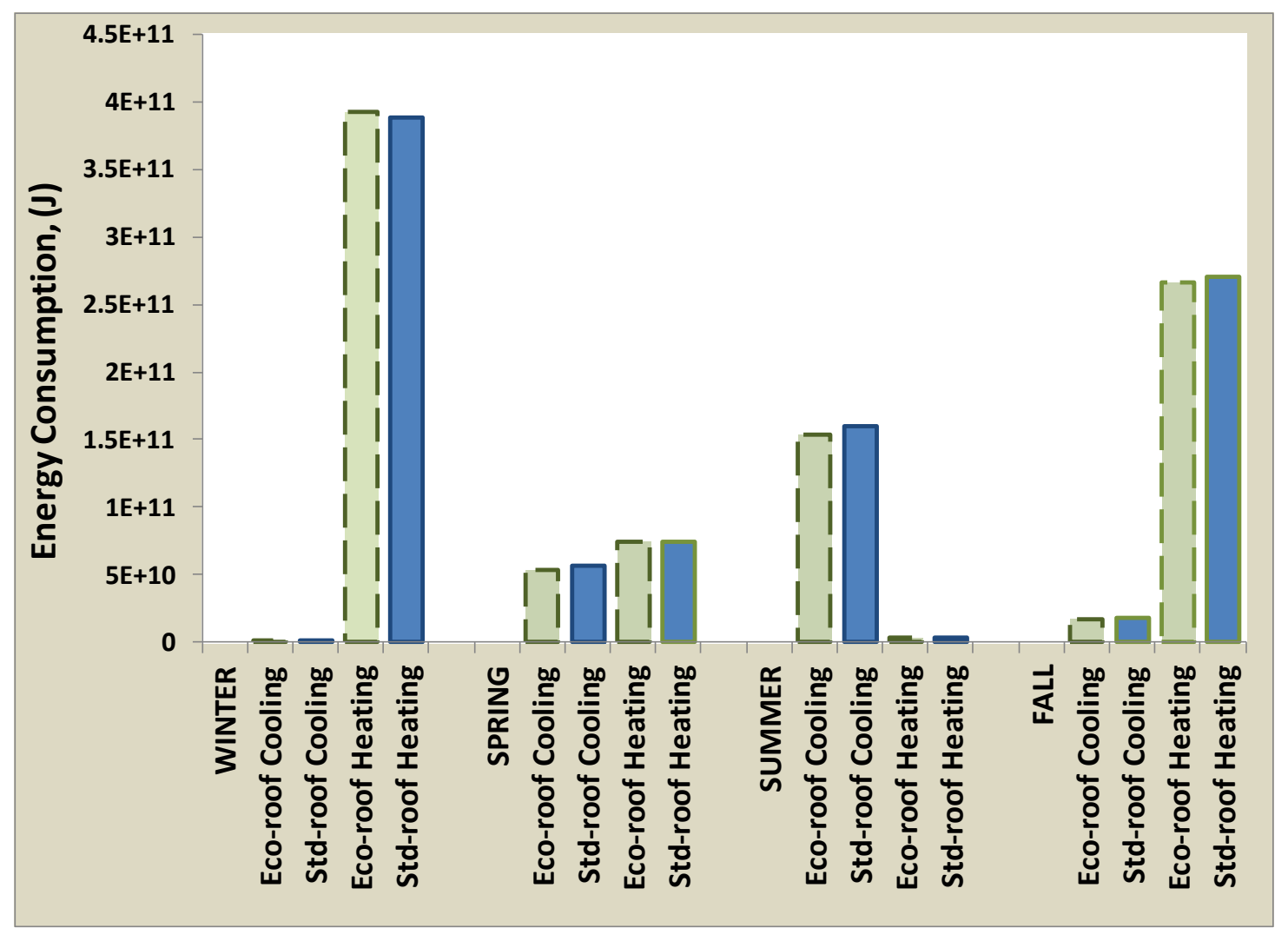

Figure 29: Eco-roof and standard roof comparison of seasonal energy consumption, by type, for Chicago Illinois.

Atlanta modeling results for seasonal/annual energy consumption along with the seasonal/annual DBMS is shown in figure 30. The eco-roof configuration for Atlanta has building energy performance above standard for all seasons: winter DBMS = $1.02(+2 \%)$, spring DBMS $=1.03(+3 \%)$, summer DBMS $=1.03(+3 \%)$ and fall DBMS $=1.03(+3 \%)$. Annual DBMS for Atlanta is 1.03 or $3 \%$ above standard 


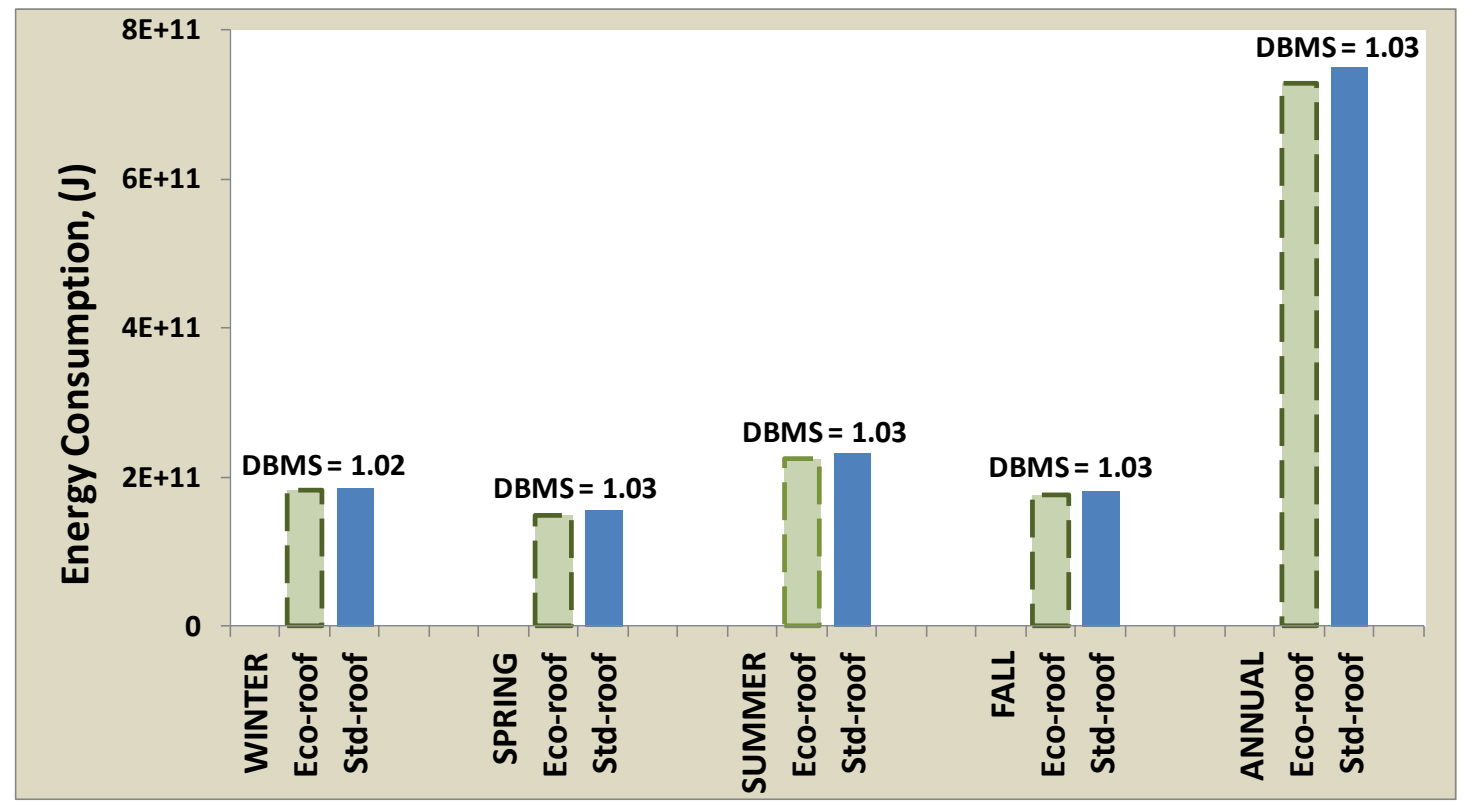

Figure 30: Seasonal and annual energy consumption and DBMS for Atlanta Georgia.

Winter Atlanta DBMS greater than 1 is due to mitigation of winter night time heating energy with a small energy savings from cooling energy, figure 31. Spring and summer are dominated by cooling energy dominate; figure 31, and eco-roof building model performance comes from evaporative cooling and peak temperature reductions. Fall has both cooling and heating energy savings from peak high and low temperature reductions. 


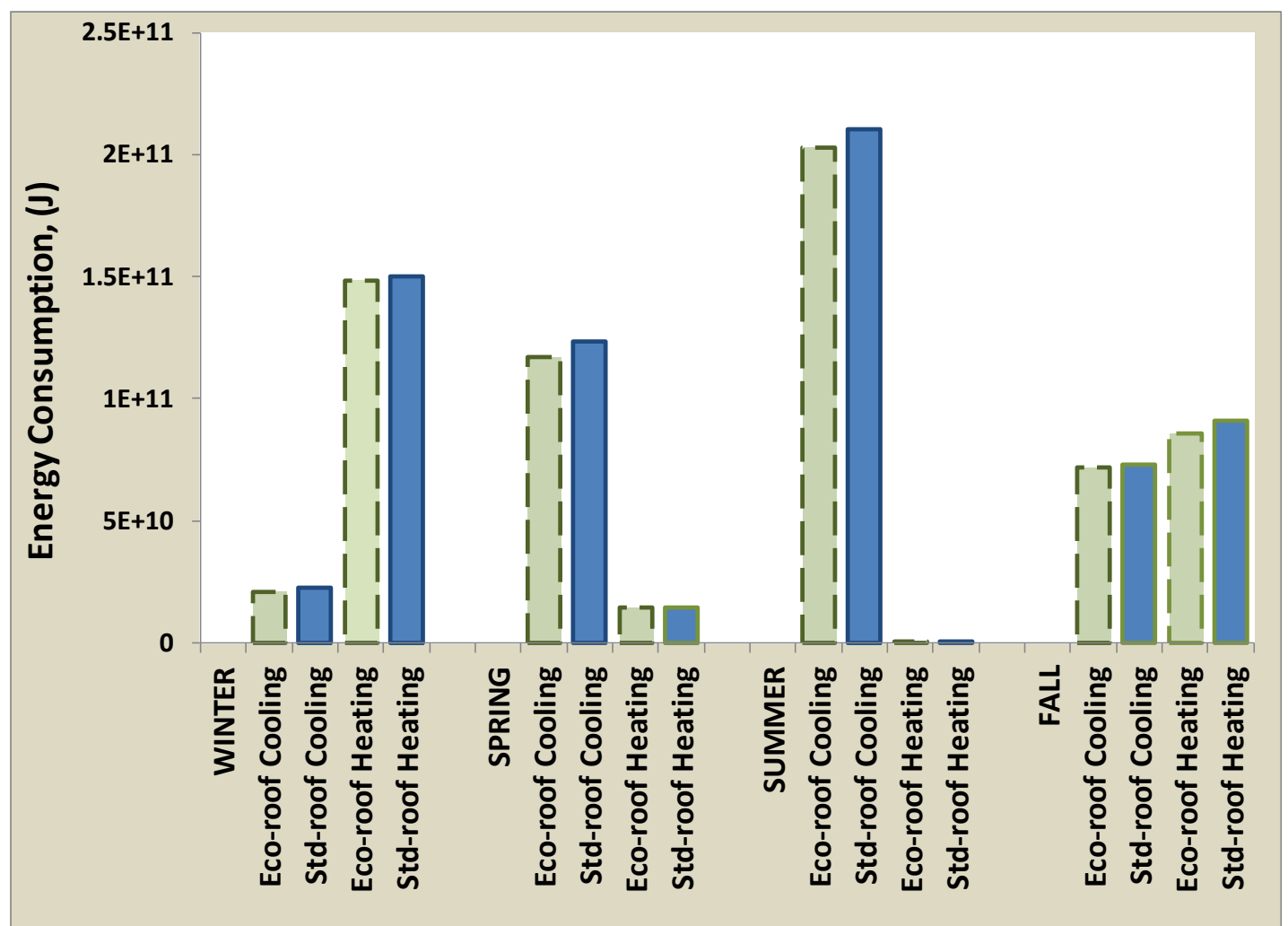

Figure 31: Eco-roof and standard roof comparison of seasonal energy consumption, by type for Atlanta Georgia

Results for Houston seasonal/annual energy consumption and seasonal/annual DBMS modeling are shown in figure 32. All 4 Houston seasons are above standard performance: winter DBMS is $1.02(+2 \%)$, spring DBMS $=1.03(+3 \%)$, summer DBMS $=1.03(+3 \%)$ and fall DBMS $=1.02(+2 \%)$. Annual DBMS for Houston is 1.03 or $3 \%$ better than standard roof performance. Winter is the only season with dominant heating energy consumption with eco-roof energy savings from peak high and low temperature reductions, figure 33, 


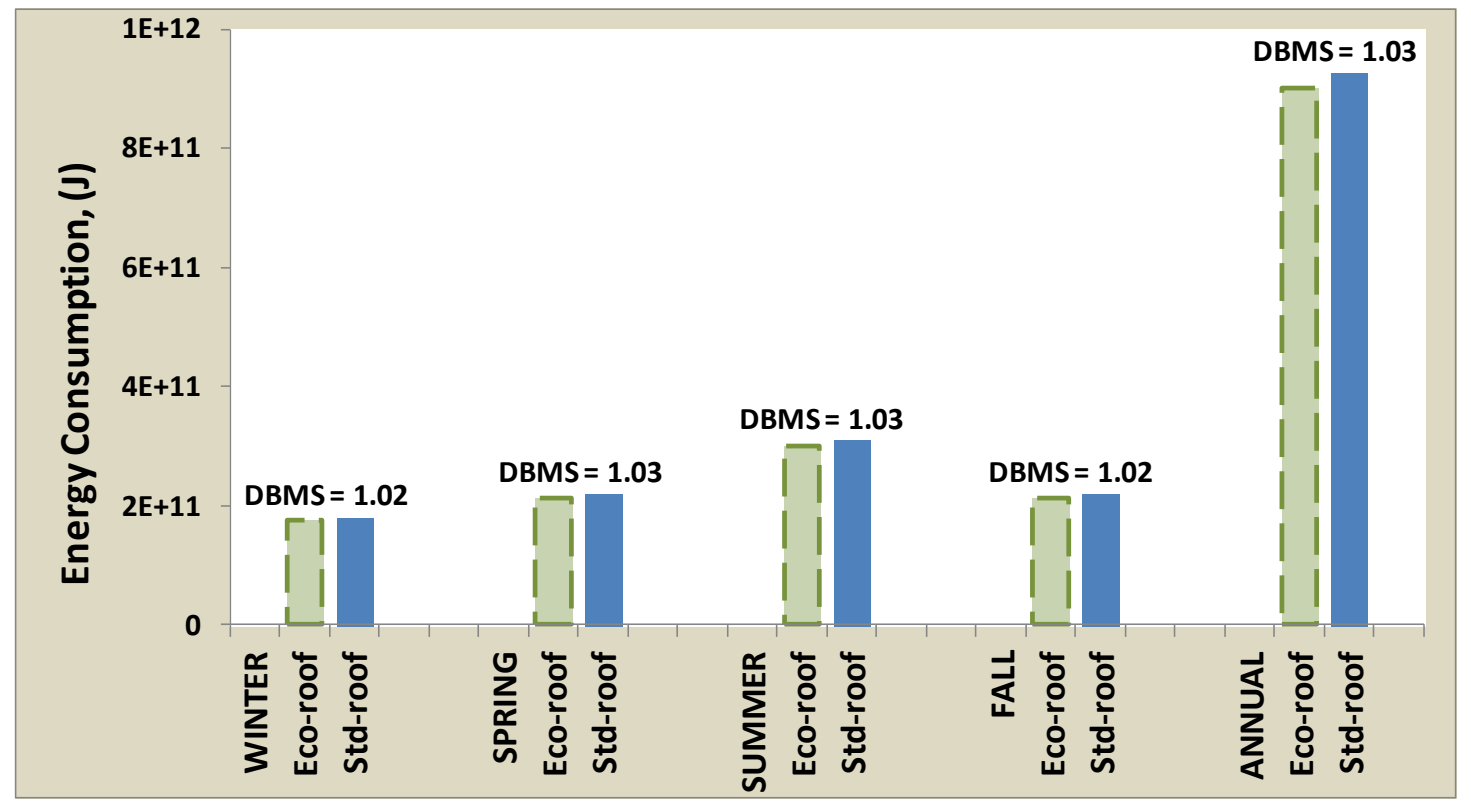

Figure 32: Seasonal and annual energy consumption and DBMS for Houston Texas.

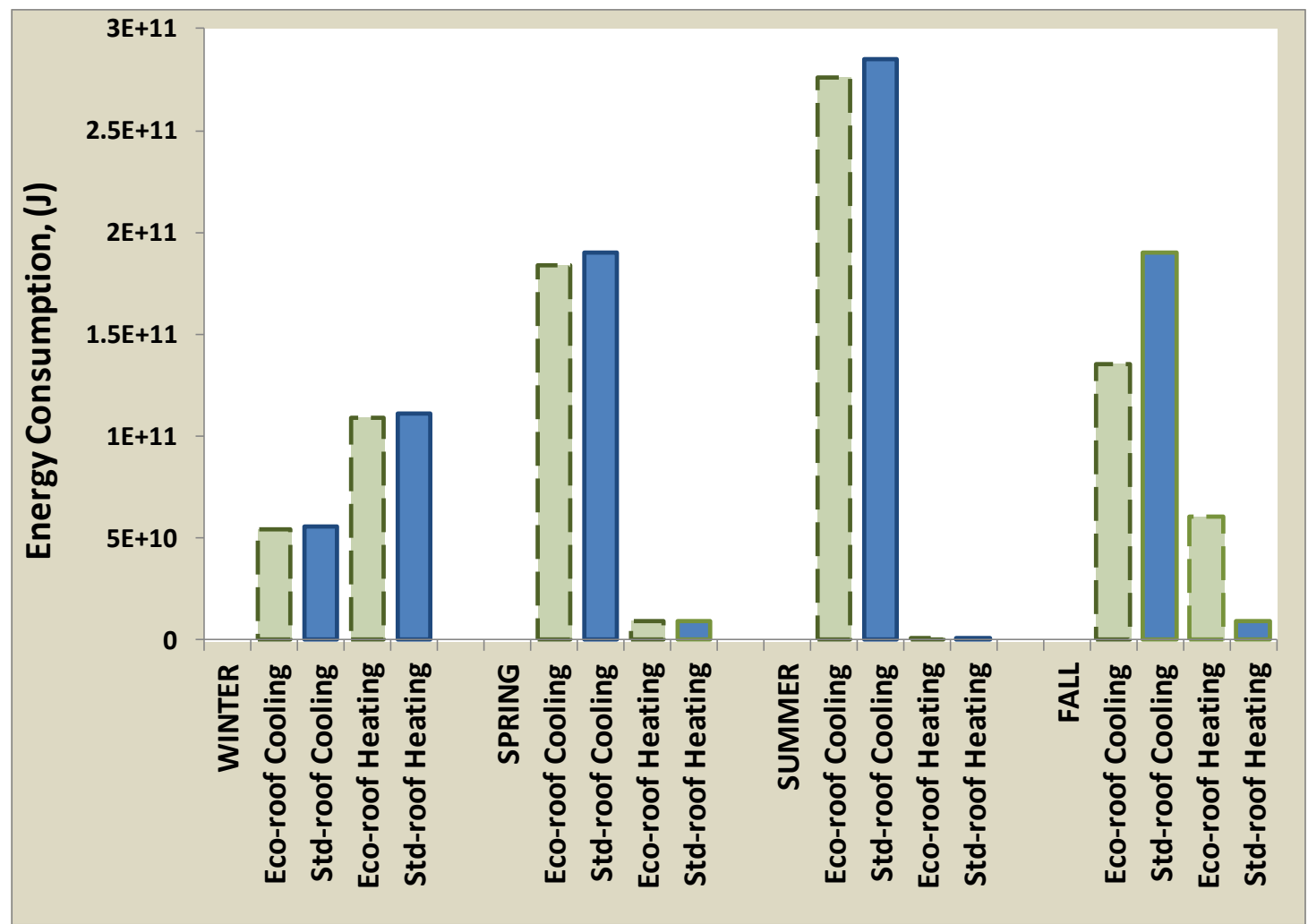

Figure 33: Eco-roof and standard roof comparison of seasonal energy consumption, by type for Houston Texas 


\section{Conclusions}

A variation on the ORNL concept of Dynamic Benefit for Massive Systems (DBMS) was used to evaluate thermal performance of eco-roofs, a thermal mass with evaporative cooling. Data from a research eco-roof on the Portland State University campus and laboratory testing of soil properties was used to validate the performance of an EnergyPlus eco-roof energy model. The validated model was then used to estimate DBMS across four climates. The following discussion highlights results related to the evaluation of GRIPV soil properties, the Green Roof Module and validation of the ecoroof model, the application of DBMS for buildings in 4 climates and the necessary next steps for building integrated eco-roof design decisions.

\section{Soil}

An industry standard eco-roof soil (GRIPV30) was evaluated for moisture retention and thermal properties, and compared to 12 previously studied soils. GRIPV soil with $30 \%$ volumetric proportion of soil organic matter, compared to EC75C10, reduces dry soil conductivity by $50 \%$, increases field capacity by $21 \%$ and reduces dry soil mass per unit volume by $60 \%$. At field capacity (saturated with moisture) the $30 \%$ SOM soil has a density that is $41 \%$ less than EC750C10 soil. The 30\% SOM soil has equal moisture saturated density to porous silicate based soil (PS75C10) when it is oven dry. The $30 \%$ SOM soil had low conductivity at all moisture contents which improves insulative qualities of the eco-roof. Heat capacity for $30 \% \mathrm{SOM}$ is low at low moisture values but increases more rapidly than the other studied soils, as volumetric moisture is increased. The high heat capacity at moderate and high VM improves high and low peak 
temperature range reduction at the roof membrane thereby reducing and or delaying heating and cooling loads in the building space below. The characteristics of high SOM soil $(\sim 30 \%)$ make it a good choice for storm event mitigation and thermally integrating an eco-roof and building.

\section{Green Roof Module}

The EnergyPlus Green Roof Module was validated with foliage LAI of 8.72 and 8 months of GRIPV weather, soil temperature and moisture data. The GRIPV sedums had a measured LAI of 3.67 which place it within the LAI range and standard deviation that classifies it as a grass canopy (22). The eco-roof validation model (LAI 3.67) overestimates temperatures in the day and under estimates temperatures at night. This indicates that the soil is over exposed to solar radiation during the day and the black body sky at night. LAI has a large impact (leaf wetness = evaporative cooling and fractional vegetation coverage) on how the Green Roof Module responds.

The Green Roof Module is not capable of updating soil thermal properties based on changing soil moisture but holding constant seasonal moisture driven eco-roof properties allowed for good measured to modeled eco-roof temperature validation. Dividing validation analysis into seasons was a good time scale for pinpointing parameters of interest and times of better or worse model performance.

\section{DBMS}

Evaluation of dynamic benefit for a massive system was implemented in 4 cities (climate zones). Dividing DBMS analysis into seasons helped to pinpoint times of better or worse eco-roof thermal performance. The seasonal winter temperature reductions for 
low and high peaks were effective in moderate to mild climate zones of Portland, Atlanta and Houston. Low peak temperature reduction by the eco-roof was effective in reducing heating and fan energy consumption by $2 \%$ (DBMS 1.02) in the moderate Portland winter climate and up to 2\% (DBMS 1.02) in the mild Houston winter. Spring eco-roof performance was best in mild-warm climates where average temperatures were elevated and eco-roof evaporative cooling could offset cooling energy resulting in DBMS values for Chicago, Atlanta and Houston that ranged from 1.02 to 1.03. The mild Portland climate had a spring DBMS penalty due to temperatures warm enough to induce eco-roof evaporative cooling but still cool enough to require heating energy. Best seasonal DBMS varied between climates but all summer eco-roof models had a DBMS of between 1.01 and 1.04 ( 1 to $4 \%$ better) as compared to the equivalent standard roof model with steady state R-value. Overall annual eco-roof performance was above standard in climates $5 \mathrm{~A}, 3 \mathrm{~A} \& 2 \mathrm{~A}$ and below standard in climate $4 \mathrm{C}$.

The seasonal process of evaluating DBMS described in section 5 with result evaluation in section 6 , is the first and largest step in understanding plant, soil and insulation decisions regarding thermally connecting an eco-roof to a building. Evaluation of eco-roof optimization applied to all seasons is the next step in eco-roof design for each building. Further evaluation for the studied climate-locations would examine:

- The fall season in Portland, with large heating energy consumption and poor ecoroof performance, is of particular interest for optimizing eco-roof performance and would be the next step in choosing an annual insulation thickness. 
- Winter season in Chicago needs to be examined for improving poor eco-roof performance through adjustment of the insulation layer.

- Atlanta saw benefits in all seasons but winter (1.02 DMS) could be the focus of further eco-roof optimization, if deemed necessary by the designer.

- Houston has good overall eco-roof DBMS performance. Further insulation layer iterations don't appear to be necessary and an insulation thickness of $100 \mathrm{~mm}$ is likely the best choice for Houston. Houston might see better summer performance if the eco-roof soil moisture values were elevated to above $0.25 \mathrm{VM}$. An evaluation of the cost benefit of the amount of water vs cooling energy savings is necessary to keep the eco-roof at $0.25 \mathrm{VM}$.

- Alternatively Atlanta and Houston present opportunities for using building grey water as summer irrigation in order to elevate soil VM in order to improve evaporative cooling and thermal mass benefits of the eco-roof.

DBMS provides a relatively easy to develop and understand metric for thermal mass performance of building envelope assemblies. By comparing dynamic and standard energy consumption at equal steady state R-values rather than comparing dynamic and standard R-values at equal energy consumption the DBMS analysis can be utilized for evaluation of building integrated eco-roof systems (thermal mass assemblies with evaporative cooling). Semi-intensive eco-roof DBMS performance in the mild climates, dominated by cooling energy consumption, of Chicago, Atlanta and Houston show improved thermal performance when compared to the standard CBECS 2004 new medium office building. An eco-roof in a moderate climate with low cooling energy 
consumption will have a performance penalty when evaluation is based on a CBECS 2004 new medium office building. An eco-roof or any thermal mass system is a moderate addition to EEM analysis, among many others, that are necessary for code compliance using a performance based path. 


\section{Further Work}

\subsection{Winter and Spring Eco-roof Performance}

What are the conditions for winter heating energy (flux) reduction by an eco-roof in the moderate Portland climate and what is the mechanism for poor spring and fall performance? A better understanding of the parameters that drive eco-roof seasonal evapotranspiration is needed in order to more accurately account for foliage and soil VM contributions to the building and micro climate energy balance.

\subsection{Green Roof Module}

LAI is the sole direct eco-roof input for the EnergyPlus IDF file that manages: radiative (shading) and latent (evaporative) energy components for the foliage energy balance and radiative energy components for the soil energy balance. Within the Green Roof Module the value of LAI has the largest number of parameter impacts and the greatest impact on the foliage/soil energy budget. LAI is used in every Green Roof Module energy component, other than soil conduction, of the foliage and soil energy balance equations, including $\sigma_{f}$. The parameter that couples the foliage and soil energy balances is $\boldsymbol{\sigma}_{\boldsymbol{f}}$. In the current version of the Green Roof Module this coupling parameter is defined in direct relation to LAI (eqn. 4). In actuality these two parameters can be independent of each other. It is proposed that an additional input, $\boldsymbol{\sigma}_{\boldsymbol{f}}$, fractional vegetative cover, be added to the eco-roof material class within the EnergyPlus IDF file. If $\boldsymbol{\sigma}_{\boldsymbol{f}}$ is not known a method for calculating $\boldsymbol{\sigma}_{\boldsymbol{f}}$, such as that suggested by the FASST model for "other" vegetation, be added to the $\sigma_{f}$ input field. 


\section{Other vegetation:}

$\boldsymbol{\sigma}_{f, \text { other vegetation }}=\sigma_{f \max }-\left[1-F\left(T_{g)}\right]\left[\sigma_{f \max }-\sigma_{f \min }\right]\right.$

It is suggested that if LAI is the only known parameter then a choice of equations for calculating $\boldsymbol{\sigma}_{\boldsymbol{f}}$ based on LAI, such as $\boldsymbol{\sigma}_{\boldsymbol{f}, \boldsymbol{G R M}} \& \boldsymbol{\sigma}_{\boldsymbol{f} \text {,grasses }}$, be added to the $\boldsymbol{\sigma}_{\boldsymbol{f}}$ input field. Direct input of $\boldsymbol{\sigma}_{\boldsymbol{f}}$, without coupling to LAI, or additional methods for calculating $\boldsymbol{\sigma}_{\boldsymbol{f}}$ based on LAI would provide an improvement in eco-roof model validation and evaluating eco-roof energy impact on a building and the urban heat island. 


\section{References}

1. Miller, C and D, Narejo. State of the green roof industry in the United States. s.l. : Geosynthetics Research and Development in Progress, 2005.

2. Kosareo, L and Ries, R. Comparative environmental life cycle assessment of green roofs. Building and Environment. 2007, Vol. 42, pp. 2606 - 2613.

3. DeNardo, J, et al. Stormwater Detention and Retention Abilities of Green Roofs. World Water \& Environmental Resources Congress. 2003.

4. Sailor, D.J. Simulated urban climate response to modification in surface albedo and vegetative cover. Journal of Applied Meteorology. July 1995, Vol. 34, 7.

5. Scherba, A, et al. Modeling impacts of roof reflectivity, integrated photovoltaic panels and green roof systems on sensible heat flux in the urban environment. Building and Environment. 2011, 46, pp. 2542 - 2551.

6. Santamouris, M. et al. Investigating and Analysing the Energy and Environmental Performance of an Experimental Green Roof System Installed in a Nursery School Building in Athens, Greece. Energy. 32, 2007, Vol. 9, pp. 1781-1788.

7. Tabares-Velasco, P.C and Srebric, J. The role of plants in the reduction of heat flux through green roofs: laboratory experiments. ASHRAE Transactions. 2009, Vol. 115, 2, pp. $793-802$.

8. Jaffal, I., Ouldboukhitine, S. and Belarbi, R. A Comprehensive Study of the Impact of Green Roofs on Building Energy Performance. Renewable Energy. 2012, Vol. 43. 
9. Lazzarin, R.M., Castellottie, F. and Busato, F. Experimental measurements and numerical modeling of a green roof. Energy and Buildings. 2005, Vol. 37, 12, pp. 12601267.

10. Spolek, G. Performance monitoring of three ecoroofs in Portland, Oregon. Urban Ecosystems. 2008, Vol. 11, 4, pp. 349-359.

11. Tabares-Velasco, P.C. and Srebric, J. A heat transfer model for assessment of plant based roofing systems in summer conditions. Building and Environment. 2012, 49.

12. ASHRAE. Advanced Energy Design Guides. ASHRAE. [Online]

http://www.ashrae.org/standards-research--technology/advanced-energy-design-guides.

13. U.S. Department of Energy. Stretch Codes \& Beyond Code Programs. Energy Efficiency \& Renewable Energy. [Online] http://www.energycodes.gov/why_codes/stretch_beyond.stm.

14. Sailor, D.J. and Hagos, M. An updated and expanded set of thermal property data for green roof growing media. Energy and Buildings. 2011, 43, pp. 2298 - 2303.

15. ASHRAE. NonResidential Heating and Cooling Load Calculations. ASHRAE Hanbook - Fundementals. 2009, pp. 18.1-18.62.

16. Sailor, D.J. A Green Roof Model for Building Energy Simulation Programs. Energy and Buildings. 2008, Vol. 40, pp. 1246-51.

17. Ouldboukhitine, S., et al. Assessment of Green Roof Thermal Behaviour: A coupled heat and mass transfer model. Building and Environment. 2011, Vol. 46. 
18. Sailor, D.J., Elley, T. and Gibson, M. Exploring the Building Energy Impacts of Green Roof Design Decisions - a modeling study of buildings in four disticnt climates. Journal of Building Physics. 2012, Vol. 35, p. 372.

19. Peck, SW. Greenbacks from green roofs: forging a new industry in Canada. s.l. : Adaption Research Group, Environment Canada, 1999.

20. Abdel-Ghany, A.M. and Al-Helal, I.M. Solar Energy Utilization by A Greenhouse: General Relations. Renewable Energy. 2011, Vol. 36.

21. Frankenstein, S. and Koenig, G. FASST Vegetation Models, US Army Corp of Engineers. ERDC/CRREL TR-04-25. 2004.

22. Scurlock, J.M.O, Asner, G.P. and Gower, S.T. World Historical Estimates of Leaf Area Index, 1932-2000. Oak Ridge, TN : Oak Ridge National Laboratory, 2001.

23. Sailor, D.J., Hutchison, D. and Bokovoy, L. Thermal property measurements for ecoroof soils common in the western U.S. Energy and Buildings. 2008, Vol. 40, pp. --

24. Abu-Hamdeh, N. H. Thermal Properties of Soils as Affected by Density and Water Content. Biosystems Engineering. 86, 2003, Vol. 1, pp. 97-102.

25. The Engineering ToolBox. Bulk Density of Food Materials. [Online] [Cited: May 11, 2012.] http://www.engineeringtoolbox.com/foods-materials-bulk-densityd_1819.html.

26. Kosny, J., et al. Dynamic Thermal Performance and Energy Benefits of Using Massive Walls in Residential Buildings. [Online] Oak Ridge National Laboratories, Aug 
30, 2001. [Cited: 4 20, 2012.]

http://www.ornl.gov/sci/roofs+walls/research/detailed_papers/dyn_perf/index.html.

27. U.S. Department of Energy. EnergyPlus: Getting Started. 2010, pp. 1-5.

28. —. EnergyPlus: Engineering Reference. 2010, pp. 110-120.

29. DOE. Commercial Building Initiative. Energy Efficiency \& Renewable Energy .

[Online] U.S. Department of Energy. [Cited: August 20, 2011.]

http://www1.eere.energy.gov/buildings/commercial_initiative/reference_buildings.html.

30. - EnergyPlus Engineering Reference - The Reference to EnergyPlus Calculations. 2007.

31. Decagon Devices. KD2 Pro Operators Manual. Pullman, Wa : Decagon Devices, 2008. pp. $49-52$.

32. LaserComp. LaserComp 200/300 Series Instruments Manual. Saugus, MA : LaserComp, 2010. pp. 8 - 9.

33. NOAA. Soil Moisture Monitoring and Prediction over U.S.A. [Online] http://www.cpc.ncep.noaa.gov/soilmst/index_jh.html.

34. Huang, J., Van den Dool, H. and Georgakakos, K. Analysis of Model-Calculated Soil Moisture over the United Staes (1931-1993) and Application to Long-Range Temperature Forecasts. Journal of Climate. 1996, Vol. 9, 6. 
35. Saiz, S, et al. Comparative life cycle assessment of standard and green roofs. 2006, Vol. 40, 13, pp. 4312 - 4316.

36. Mentens, J., Raes, D. and Hermy, M. Green roofs as a tool for solving the rainwater runoff problem in the urbanized 21st century? Landscape and Urban Planning. 2006, Vol. 77, 3, pp. 217-226.

37. O'Connor, J. Survey on Actual Service Lives for North American Buildings. Athena Sustainable Materials Insitute. Vancouver, BC., Canada : Athena Sustainable Materials Insitute, 2004. 


\section{Appendix}

Table 9: GRIPV30 moisture dependent thermal properties.

\begin{tabular}{|c|c|c|c|c|}
\hline $\begin{array}{c}\text { Soil } \\
\text { Volumetric } \\
\text { Moisture }\end{array}$ & $\begin{array}{l}\text { GRiPV30 Density } \\
\text { as function of Soil } \\
\text { VM }\left(\mathrm{kg} / \mathrm{m}^{\wedge} 3\right)\end{array}$ & $\begin{array}{l}\text { GRiPV } 30 \text { Conductivity } \\
\text { as function of VM } \\
\left(\mathrm{W} / \mathrm{m}^{\star} \mathrm{K}\right)\end{array}$ & $\begin{array}{l}\text { GRiPV30 Volumetric } \\
\text { Heat Capacity as } \\
\text { function of VM } \\
\left(\mathrm{MJ} / \mathrm{m}^{\wedge} 3^{\star} \mathrm{K}\right)\end{array}$ & $\begin{array}{c}\text { GRiPV30 Specific } \\
\text { Heat as function of } \\
\text { VM }\left(\mathrm{J} / \mathrm{kg}^{\star} \mathrm{K}\right)\end{array}$ \\
\hline 0 & 345 & 0.100 & 0.755 & 2187 \\
\hline 0.01 & 355 & 0.111 & 0.803 & 2259 \\
\hline 0.02 & 365 & 0.123 & 0.850 & 2327 \\
\hline 0.03 & 375 & 0.134 & 0.898 & 2392 \\
\hline 0.04 & 385 & 0.145 & 0.945 & 2453 \\
\hline 0.05 & 395 & 0.157 & 0.993 & 2511 \\
\hline 0.06 & 405 & 0.168 & 1.040 & 2566 \\
\hline 0.07 & 415 & 0.179 & 1.088 & 2619 \\
\hline 0.08 & 425 & 0.191 & 1.135 & 2669 \\
\hline 0.09 & 435 & 0.202 & 1.183 & 2717 \\
\hline 0.1 & 445 & 0.213 & 1.230 & 2762 \\
\hline 0.11 & 455 & 0.225 & 1.278 & 2806 \\
\hline 0.12 & 465 & 0.236 & 1.325 & 2848 \\
\hline 0.13 & 475 & 0.247 & 1.373 & 2888 \\
\hline 0.14 & 485 & 0.259 & 1.420 & 2926 \\
\hline 0.15 & 495 & 0.270 & 1.468 & 2963 \\
\hline 0.16 & 505 & 0.281 & 1.515 & 2998 \\
\hline 0.17 & 515 & 0.292 & 1.563 & 3032 \\
\hline 0.18 & 525 & 0.304 & 1.610 & 3065 \\
\hline 0.19 & 535 & 0.315 & 1.658 & 3097 \\
\hline 0.2 & 545 & 0.326 & 1.705 & 3127 \\
\hline 0.21 & 555 & 0.338 & 1.753 & 3156 \\
\hline 0.22 & 565 & 0.349 & 1.800 & 3184 \\
\hline 0.23 & 575 & 0.360 & 1.848 & 3212 \\
\hline 0.24 & 585 & 0.372 & 1.895 & 3238 \\
\hline 0.25 & 595 & 0.383 & 1.943 & 3263 \\
\hline 0.26 & 605 & 0.394 & 1.990 & 3288 \\
\hline 0.27 & 615 & 0.406 & 2.038 & 3312 \\
\hline 0.28 & 625 & 0.417 & 2.085 & 3335 \\
\hline 0.29 & 635 & 0.428 & 2.133 & 3357 \\
\hline 0.3 & 645 & 0.440 & 2.180 & 3378 \\
\hline 0.31 & 655 & 0.451 & 2.228 & 3399 \\
\hline 0.32 & 665 & 0.462 & 2.275 & 3420 \\
\hline 0.33 & 675 & 0.474 & 2.323 & 3439 \\
\hline 0.34 & 685 & 0.485 & 2.370 & 3458 \\
\hline
\end{tabular}




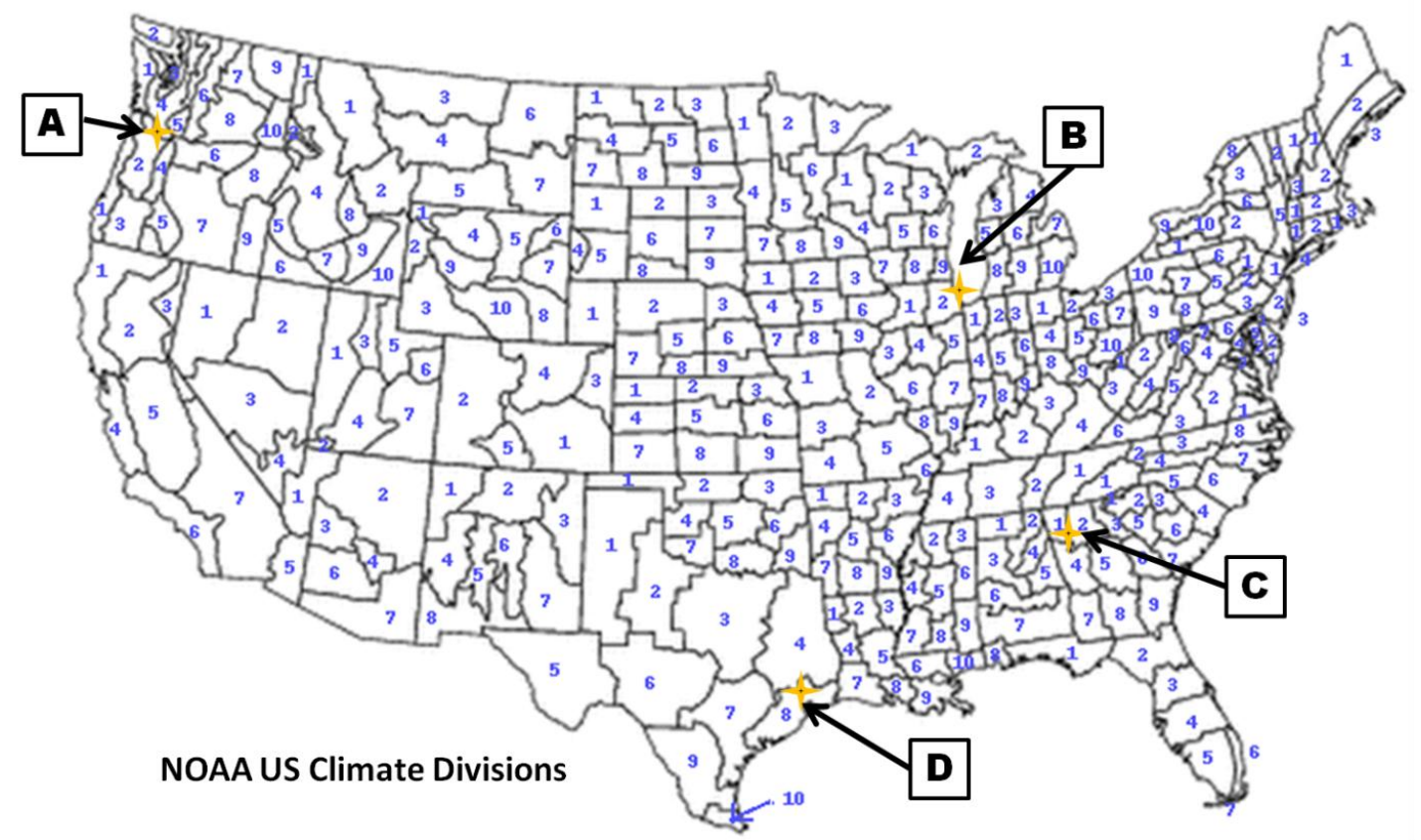

Figure 34: NOAA climate divisions and 4 selected cities evaluated for DBMS in the U.S. Portland Oregon (A), Chicago Illinois (B), Atlanta Georgia (C) and Houston Texas (D).

Table10: Monthly average NOAA soil moisture.

\begin{tabular}{|lcccccccccccc|}
\hline \multicolumn{10}{c|}{ NOAA Climate Division Average Soil Moisture (mm, 1931-2011) } \\
& Jan & Feb & Mar & Apr & May & June & July & Aug & Sep & Oct & Nov & Dec \\
Portland (\#244) & 693 & 686 & 679 & 644 & 591 & 521 & 435 & 375 & 361 & 438 & 585 & 671 \\
Chicago (\#68) & 423 & 417 & 432 & 449 & 451 & 438 & 413 & 403 & 405 & 408 & 420 & 425 \\
Atlanta (\#49) & 555 & 583 & 603 & 580 & 536 & 485 & 457 & 428 & 422 & 425 & 460 & 510 \\
Houston (\#290) & 372 & 379 & 371 & 363 & 365 & 349 & 312 & 288 & 311 & 333 & 346 & 360 \\
\hline
\end{tabular}




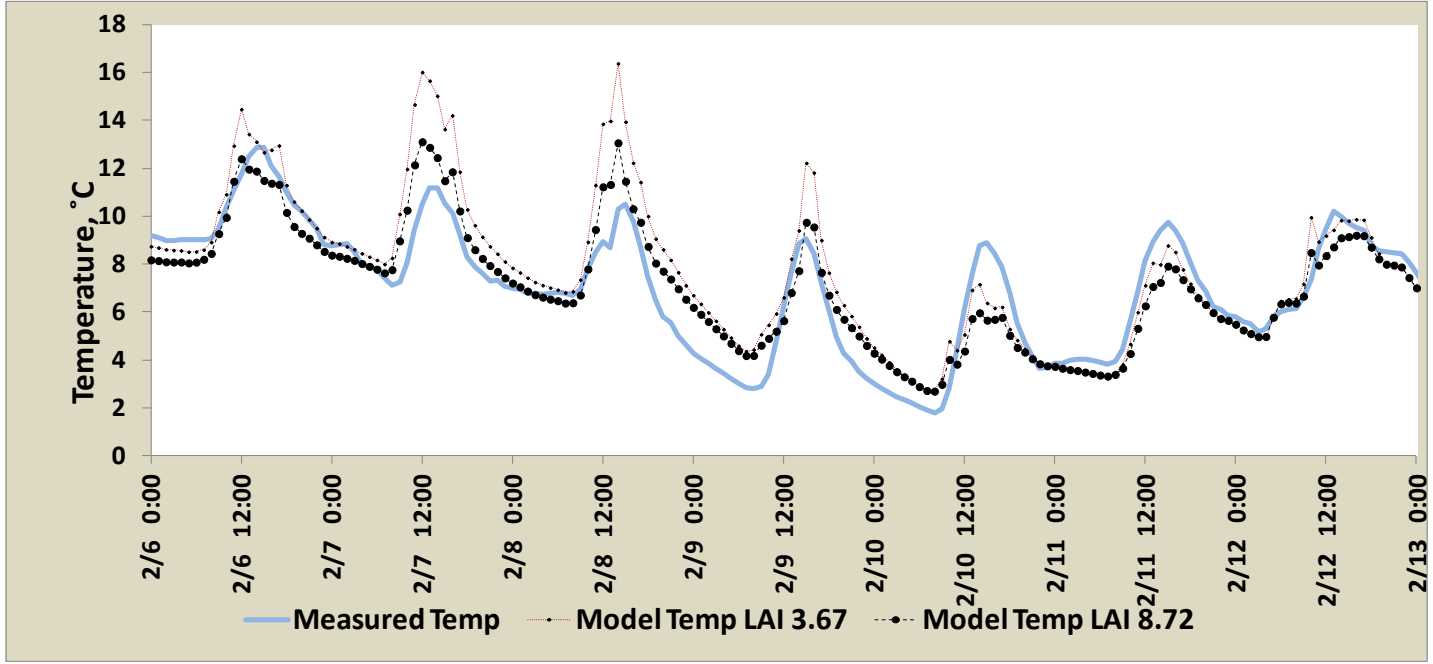

Figure 35: Winter model results for LAI tuning to GRIPV temperature data.

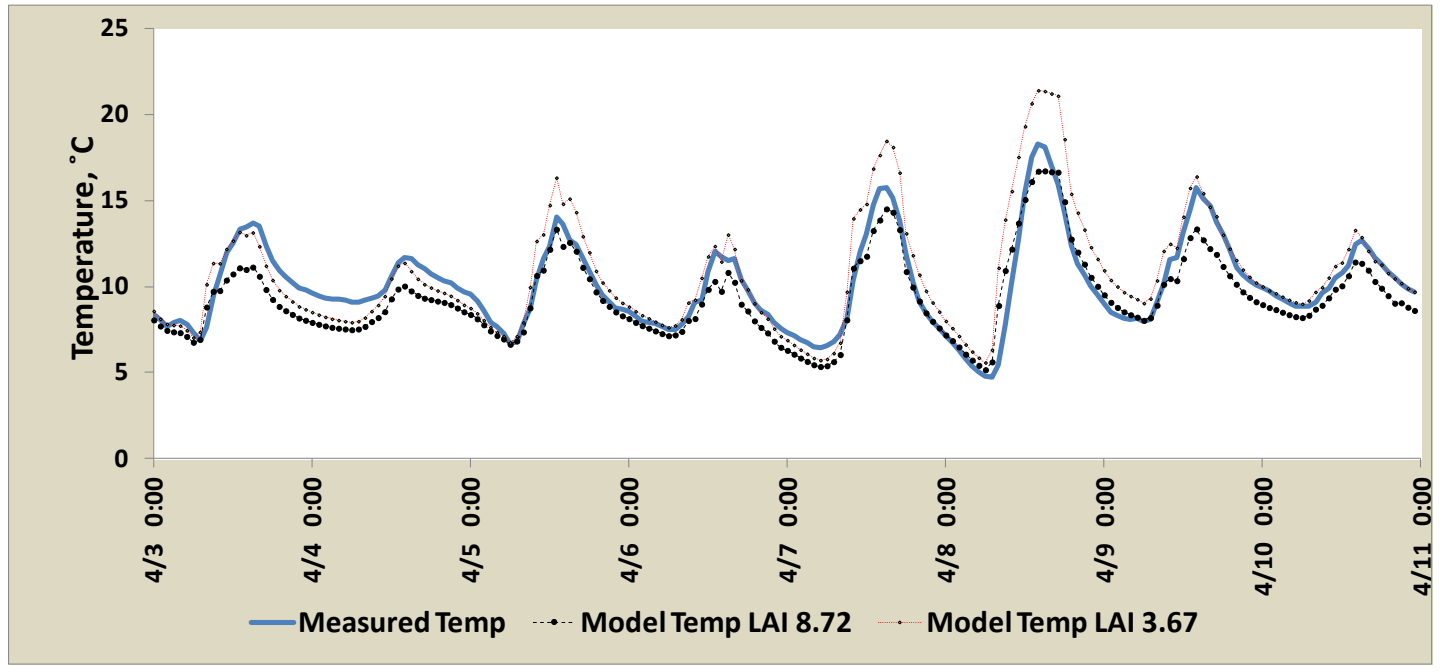

Figure 36: Spring model results for LAI tuning to GRIPV temperature data. 
Table 11: (Measured - Modeled) seasonal and diurnal temperature statistics from LAI of 3.76 (GRIPV actual LAI) eco-roof model.

\begin{tabular}{|c|c|c|c|c|c|}
\hline & \multicolumn{4}{|c|}{ Temperature Validation Statistics } & \multirow{2}{*}{$\begin{array}{r}\text { (LAI } \\
\text { STDEV }\end{array}$} \\
\hline & $\begin{array}{c}\text { Day } \\
\text { RMSE }\end{array}$ & $\begin{array}{l}\text { Night } \\
\text { RMSE }\end{array}$ & $\begin{array}{c}\text { Total } \\
\text { RMSE }\end{array}$ & $\begin{array}{c}\text { Ave } \\
\text { Temp }\end{array}$ & \\
\hline Winter & 3.09 & 1.93 & 2.53 & 1.16 & 1.62 \\
\hline Spring & 3.05 & 1.40 & 2.44 & 0.29 & 2.24 \\
\hline Summer & 5.57 & 1.89 & 4.43 & 1.00 & 4.06 \\
\hline
\end{tabular}

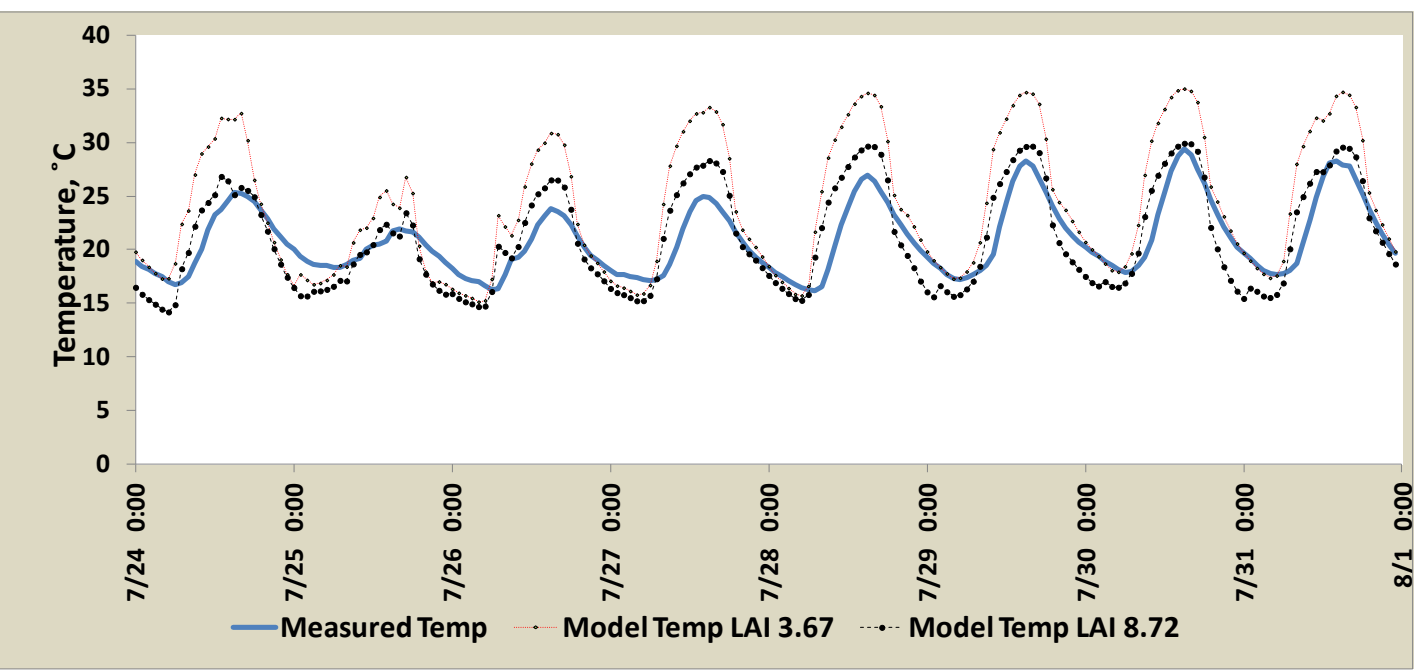

Figure 37: Summer model results for LAI tuning to GRIPV temperature data. 